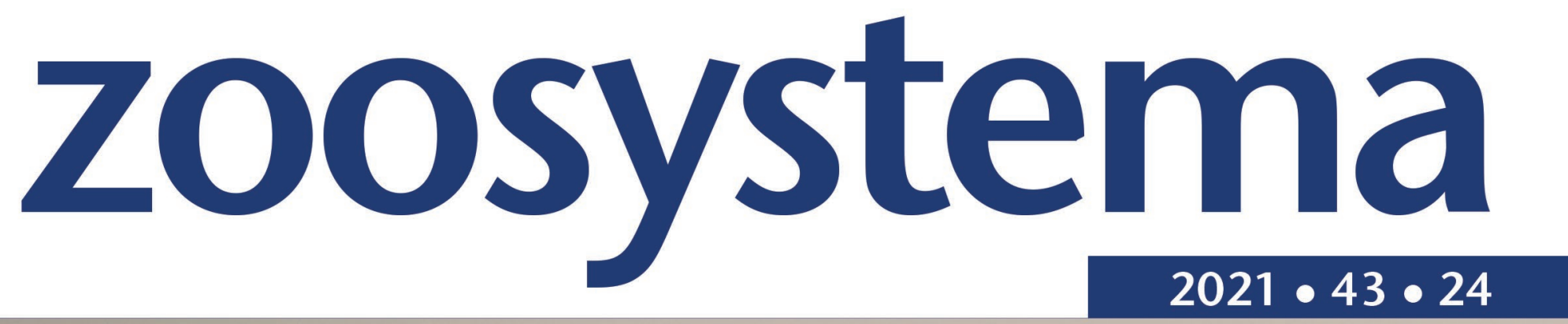

New data on the distribution of the two mole species Talpa aquitania Nicolas, Martínez-Vargas \& Hugot, 2017 and T. europaea Linnaeus, 1758 in France based on museum and newly collected specimens

Violaine NICOLAS, Jean-Pierre HUGOT \& Raphaël CORNETTE 
Directeur de LA publication / Publication diRECTOR: Bruno David

Président du Muséum national d'Histoire naturelle

RÉDACTRICE EN CHEF / EDITOR-IN-CHIEF: Laure Desutter-Grandcolas

AsSISTANTE DE RÉDACTION / AsSISTANT EDITOR: Anne Mabille (zoosyst@mnhn.fr)

Mise en PAge / Page Layout: Anne Mabille

COMITÉ SCIENTIFIQUE / SCIENTIFIC BOARD:

Nesrine Akkari (Naturhistorisches Museum, Vienne, Autriche)

Maria Marta Cigliano (Museo de La Plata, La Plata, Argentine)

Serge Gofas (Universidad de Málaga, Málaga, Espagne)

Sylvain Hugel (CNRS, Université de Strasbourg, France)

Marco Isaia (Università degli Studi di Torino, Turin, Italie)

Rafael Marquez (CSIC, Madrid, Espagne)

Jose Christopher E. Mendoza (Lee Kong Chian Natural History Museum, Singapour)

Annemarie Ohler (MNHN, Paris, France)

Jean-Yves Rasplus (INRA, Montferrier-sur-Lez, France)

Wanda M. Weiner (Polish Academy of Sciences, Cracovie, Pologne)

COUVERTURE / COVER:

Toulouse Museum specimen of Talpa europaea Linnaeus, 1758 from 1758, discovered at Maourine pond, Toulouse, France. Photo: Didier Descouens. Creative Commons Attribution.

Zoosystema est indexé dans / Zoosystema is indexed in:

- Science Citation Index Expanded (SciSearch ${ }^{\circledR}$ )

- ISI Alerting Services ${ }^{\circledR}$

- Current Contents ${ }^{\circledR}$ / Agriculture, Biology, and Environmental Sciences ${ }^{\circledR}$

- Scopus ${ }^{\circledR}$

Zoosystema est distribué en version électronique par / Zoosystema is distributed electronically by:

- BioOne ${ }^{\circledR}$ (http://www.bioone.org)

Les articles ainsi que les nouveautés nomenclaturales publiés dans Zoosystema sont référencés par /

Articles and nomenclatural novelties published in Zoosystema are referenced by:

- ZooBank ${ }^{\circledR}$ (http://zoobank.org)

Zoosystema est une revue en flux continu publiée par les Publications scientifiques du Muséum, Paris / Zoosystema is a fast track journal published by the Museum Science Press, Paris

Les Publications scientifiques du Muséum publient aussi / The Museum Science Press also publish:

Adansonia, Geodiversitas, Anthropozoologica, European Journal of Taxonomy, Naturae, Cryptogamie sous-sections Algologie, Bryologie, Mycologie.

Diffusion - Publications scientifiques Muséum national d'Histoire naturelle

CP $41-57$ rue Cuvier F-75231 Paris cedex 05 (France)

Tél.: 33 (0)1 40794805 / Fax: 33 (0)1 40793840

diff.pub@mnhn.fr / https://sciencepress.mnhn.fr

(C) Publications scientifiques du Muséum national d'Histoire naturelle, Paris, 2021

ISSN (imprimé / print): 1280-9551/ ISSN (électronique / electronic): 1638-9387 


\section{New data on the distribution of the two mole species Talpa aquitania Nicolas, Matinez-Vargas \& Hugot, 2017 and T. europaea Linnaeus, 1758 in France based on museum and newly collected specimens}

Institut de Systématique, Évolution, Biodiversité (ISYEB), Muséum national d'Histoire naturelle, CNRS, Sorbonne Université, EPHE, Université des Antilles case postale 51, 57 rue Cuvier, F-75231 Paris cedex 05 (France) violaine.colin@mnhn.fr (corresponding author) jean-pierre.hugot@mnhn.fr raphael.cornette@mnhn.fr

Nicolas V. Hugot J.-P. \& Cornette R. 2021. - New data on the distribution of the two mole species Talpa aquitania Nicolas, Martínez-Vargas \& Hugot, 2017 and T. europaea Linnaeus, 1758 in France based on museum and newly collected specimens. Zoosystema 43 (24): 585-617. https://doi.org/10.5252/zoosystema2021v43a24. http://zoosystema. $\mathrm{com} / 43 / 24$

KEY WORDS

Talpa aquitania Talpa europaea France,

distribution, mammals.

\section{ABSTRACT}

A new species of mole, Talpa aquitania Nicolas, Martínez-Vargas \& Hugot, 2017, was recently described from France. Based on the genetic identification of 270 individuals it was hypothesized that T. aquitania and T. europaea Linnaeus, 1758 are allopatric, being distributed on opposite sides of the Loire River, with the exception of a small area of sympatry in eastern Pyrénées mountains. The aim of the present study is to get a better understanding of the distribution of these two species in France based on the re-identification of museum specimens and extensive field sampling through a citizen science study. 1099 specimens were identified at the specific level (574 T. europaea and 525 T. aquitania) based on external characteristics, molar tooth morphology and/or genetic data. Our results confirm that T. aquitania is mainly distributed south and west of the Loire River, while the reverse is true for T. europaea. However, the Loire River is not a strict biogeographic barrier between these two species: several specimens of T. aquitania were recorded north and east of the Loire River in the Loire-Atlantique, Loiret and Nièvre departments. Moreover, two specimens were captured in the Var department. Several specimens of T. europaea were captured south and west of the Loire River in the Indre-et-Loire, Loir-et-Cher, Loiret and Loire departments. Furthermore, both species were found in sympatry or in close proximity in the Pyrénées Mountains. The role of climate, soil type, food resources abundance (earthworms) and historical factors in explaining the actual distribution of these species is discussed. 


MOTS CLÉS
Talpa aquitania,
Talpa europaea,
France,
distribution,
mammiferes.

\begin{abstract}
RÉSUMÉ
Nouvelles données sur la distribution des deux espèces de taupe Talpa aquitania Nicolas, Martínez-Vargas \& Hugot, 2017 et T. europaea Linnaeus, 1758 en France à partir de spécimens de musée et de spécimens nouvellement collectés.

Une nouvelle espèce de taupe, Talpa aquitania Nicolas, Martínez-Vargas \& Hugot, 2017, a récemment été décrite de France. Le génotypage de 270 individus a permis de proposer pour les espèces T. aquitania et T. europaea Linnaeus, 1758 une distribution allopatrique, de part et d'autre du cours de la Loire, à l'exception toutefois d'une petite zone de contact à l'est de Pyrénées. Le but de la présente étude est de préciser les distributions géographiques respectives de ces deux espèces en France. Ce travail repose sur un important effort de collecte via les sciences participatives et sur la ré-identification des spécimens de musées. 1099 spécimens ( 574 T. europaea et 525 T. aquitania) ont ainsi pu être identifiés à partir de leur morphologie externe ou dentaire, et/ou de données génétiques. Si nos résultats confirment que T. aquitania est majoritairement présente au sud et à l'ouest de la Loire, ils montrent aussi que cette barrière biogéographique n'est pas stricte : plusieurs spécimens de T. aquitania ont été capturés au nord et à l'est de la Loire dans les départements de la Loire-Atlantique, du Loiret et de la Nièvre, et deux spécimens l'ont été dans le département du Var. Réciproquement, plusieurs spécimens de T. europaea ont été capturés au sud et à l'ouest de la Loire, dans les départements de l'Indre-et-Loire, du Loir-etCher, du Loiret et de la Loire. Enfin, les deux espèces sont en sympatrie ou proche géographiquement dans les Pyrénées. Le rôle du climat, du type de sol, de l'abondance des ressources alimentaires (vers de terre) et des processus historiques sur la distribution de ces deux espèces sont discutés.
\end{abstract}

\section{INTRODUCTION}

Mammalian systematics is dynamic, with a long-term global rate of 25 new species recognized per year (Burgin et al. 2018). In the last 10 years numerous progress were made regarding our knowledge of the species diversity, systematic relationships and geographical distribution of mole species of the genus Talpa Linnaeus, 1758. This genus is endemic to the western Palaearctic region and is well known to the public through its characteristic heaps of soil, i.e., the molehills. The number of species within this genus was heavily underestimated for a long time because of their cryptic morphology linked to their semi-fossorial lifestyle. However between 2005 and 2020 , the number of recognized species increased of $56 \%$, from nine (Hutterer 2005) to 14 (Kryštufek et al. 2017; Kryštufek \& Motokawa 2018; Demırtaş et al. 2020). This spectacular increase was possible due to the development of molecular tools in alpha systematics combined with a wide taxonomic sampling.

In 2017, Nicolas et al. (2017a) described a new species from France, Talpa aquitania Nicolas, Martínez-Vargas \& Hugot, 2017, based on molecular (mitochondrial gene sequencing) and morphological data (eyelids fused together or not, and form of the mesostyle of the first, second and third upper molar). Nuclear data based on the HDAC2 gene confirmed the distinctiveness of this species (Nicolas et al. 2017b). Based on genetic identification of 270 individuals from France it was hypothesized that T. aquitania and T. europaea Linnaeus, 1758 may be allopatric, the first one being distributed south and west, and the second one north and east of the Loire River. However, two specimens of T. europaea were captured in the locality of Mosset in the Pyrenees mountains, inside the expected geographical range of T. aquitania (Nicolas et al. 2017b). More recently Rosoux \& Lemarchand (2020) mentioned the capture of three specimens of T. aquitania north of the Loire River in the locality of Bray-Saint-Aignan (Loiret department), and Poitevin \& Quéré (2021) mentioned it east of the Loire River in the Ardèche and Loire departments.

Species distribution data are useful not only for population monitoring, biodiversity mapping and conservation management (Reese et al. 2005), but also in evolutionary studies aiming to understand the processes that lead to species distribution. Ultimately, spatial distributions of species are limited by three broad groups of constraints (Stewart et al. 2015): 1) tolerance of physical environmental conditions (temperature, $\mathrm{pH}$, humidity, etc.), including both insurmountable physical barriers, such as rivers, oceans or mountains, but also spatial gradients in, for example, climatic variables (temperature, precipitation), or soil and water chemistry; 2) the availability and spatial distribution of resources (food, nest sites, shelter, etc.); and 3) interactions with other species, including predation, competition, mutualism, and parasitism/disease. History may also have an influence (e.g. where the location of an introduction or of refugia during previous range shifts determines the pattern of subsequent geographical spread). Although cases may exist where a single factor limits the distribution of a species, it is undoubtedly more likely that combinations of factors act synergistically, antagonistically, or independently of one another in limiting the expansion of species beyond their current range limits (Mott 2010).

Based on the re-identification of museum specimens and an extensive field sampling through a citizen science study, the aim of the present work is to get a better understanding of the distribution of the two mole species in France and the factors explaining it. 


\section{MATERIAL AND METHODS}

This study includes only specimens whose species identification has been confirmed by the authors and does not includes bibliographical data only.

Specimens from the following museums were included in this study: MNHN (France), MHNL (France), MHNN (France), MHNA (France), MZS (France), Muséum d'Histoire naturelle d'Aix-en-Provence (France), Muséum d'Histoire naturelle de Bourges (France), Muséum-Aquarium de Nancy (France), MHNGr (France), MHNT (MHNT), Muséum d'Histoire naturelle de Bayonne (France), BMNH (United Kingdom), MHNG (Switzerland), MVZ (USA) and NMNH (USA).

In order to include as many specimens as possible a citizen science study was developed. Numerous professional mole trappers and French naturalists sent us new records (either mole bodies in alcohol, skulls, tissues in ethanol or pictures of the eyes or the molars). Species records validated by genetic data and present in the Genbank database were also included.

1099 specimens from France were identified at the specific level (574 T. europaea and 525 T. aquitania; Appendices 1 and 2) based on external characteristics (open eyes in T. europaea; eyelids fused together in T. aquitania); molar tooth morphology (in T. europaea the mesostyles of the upper second molar (M2) and the third upper molar (M3) are divided into two cusps of subequal size, and they are aligned on a plane that extends parallel to the parastyle and the metastyle; T. aquitania specimens have either a simple mesostyle in M2 or an additional minute cusp, but unlike T. europaea this cusp is much smaller than the main cusp of the mesostyle and is located in the crest that connects the mesostyle to the metacone of M2 that is in a more lingual position than the mesostyle itself; in some T. aquitania specimens the mesostyle of M3 is composed on a main anterior cusp and a slightly smaller posterior cusp, while in other specimens this posterior cusp is not clearly discernible because its posterior border is fused to the crest that runs from the mesostyle to the metacone of M3) and/or genetic data following Nicolas et al. (Nicolas et al. 2017a, b). For specimens identified based on molar tooth morphology only adult specimens with unworn molars were considered (the pattern on the mesostyle cannot be determined on worn molars).

The locality of collect was known for 1058 specimens. Species records were mapped using DIVA-GIS 7.5.0.0 software. When available, exact GPS coordinates of the capture site were used. For museum specimens, when precise GPS coordinates were not available, they were estimated based on locality names and the use of public database such as mapawi. com or google earth.

\section{ABBREVIATIONS}

Institutions

MNHN Muséum national d'Histoire naturelle, Paris;

MHNL Muséum d'Histoire naturelle de Lyon;

MHNN Muséum d'Histoire naturelle de Nantes;

MHNA Muséum des Sciences naturelles d'Angers;

MZS Musée Zoologique de Strasbourg, Strasbourg;

MHNGr Muséum d'Histoire naturelle de Grenoble, Grenoble;
MHNT Muséum d'Histoire naturelle de Toulouse;

BMNH Natural History Museum, London;

MHNG Muséum d'Histoire naturelle de Genève;

MVZ Museum of Vertebrate Zoology at the University of California, Berkeley;

NMNH Smithsonian National Museum of Natural History, Washington.

\section{RESULTS}

Our results confirm that T. aquitania is mainly distributed south and west of the Loire River, while T. europaea is mainly distributed north and east of it (Fig. 1). However, the Loire River is not a strict biogeographic barrier between these two species: several specimens of T. aquitania were recorded north and east of the Loire River in the Loire-Atlantique (locality of Pontchâteau), Loiret (Bray-Saint-Aignan) and Nièvre (Gouloux and Montsauche-les-Settons) departments. Moreover two specimens, identified based on molars morphology, were captured in southern France in the Var department (Saint-Raphaël). Several specimens of T. europaea were captured south and west of the Loire River in the Indre-et-Loire (Tours, la Ville-aux-Dames), Loir-et-Cher (Saint-Aignan, Sassay, Neuvy, Sologne region), Loiret (Isde) and Loire (SaintHaon-le-Châtel) departments. Furthermore, in the Pyrénées Mountains both species are found in sympatry or close proximity in the Pyrénées-Orientales (Mosset) and in south of the Haute-Garonne (Juzet-de-Luchon and Luchon). The two specimens of T. europaea found in Mosset were identified based on molecular analyses (both mitochondrial and nuclear data), and the specimen from Juzet-de-Luchon was identified based on molar morphology.

All records were double checked to be sure that there is no mislabelling or taxonomic misidentification. One could argue that morphological traits are not always clear-cuts and that taxonomic misidentification is possible when it is based on only one morphological character. Even if it can never be completely ruled out, we are confident in our species identification because we had a perfect match (100\% identity) between our identifications based on molecular data and morphological characters for the 351 specimens identified based on the two structures (121 specimens identified based on both molecular data and eyes morphology, and 230 specimens identified based on both molecular data and molars morphology).

\section{DISCUSSION}

This study shows that while T. aquitania is mainly distributed south and west of the Loire River, and T. europaea north and east of it, the Loire River is not a strict biogeographic barrier between the two species. This is not surprising given that moles are able to swim for 30-50 minutes, during which they can cover distances of over $1 \mathrm{~km}$ (Gorman \& Stone 1990). Other big rivers like the Seine, the Garonne or the Rhine do not constitute effective barriers to geographical dispersal of French moles. 


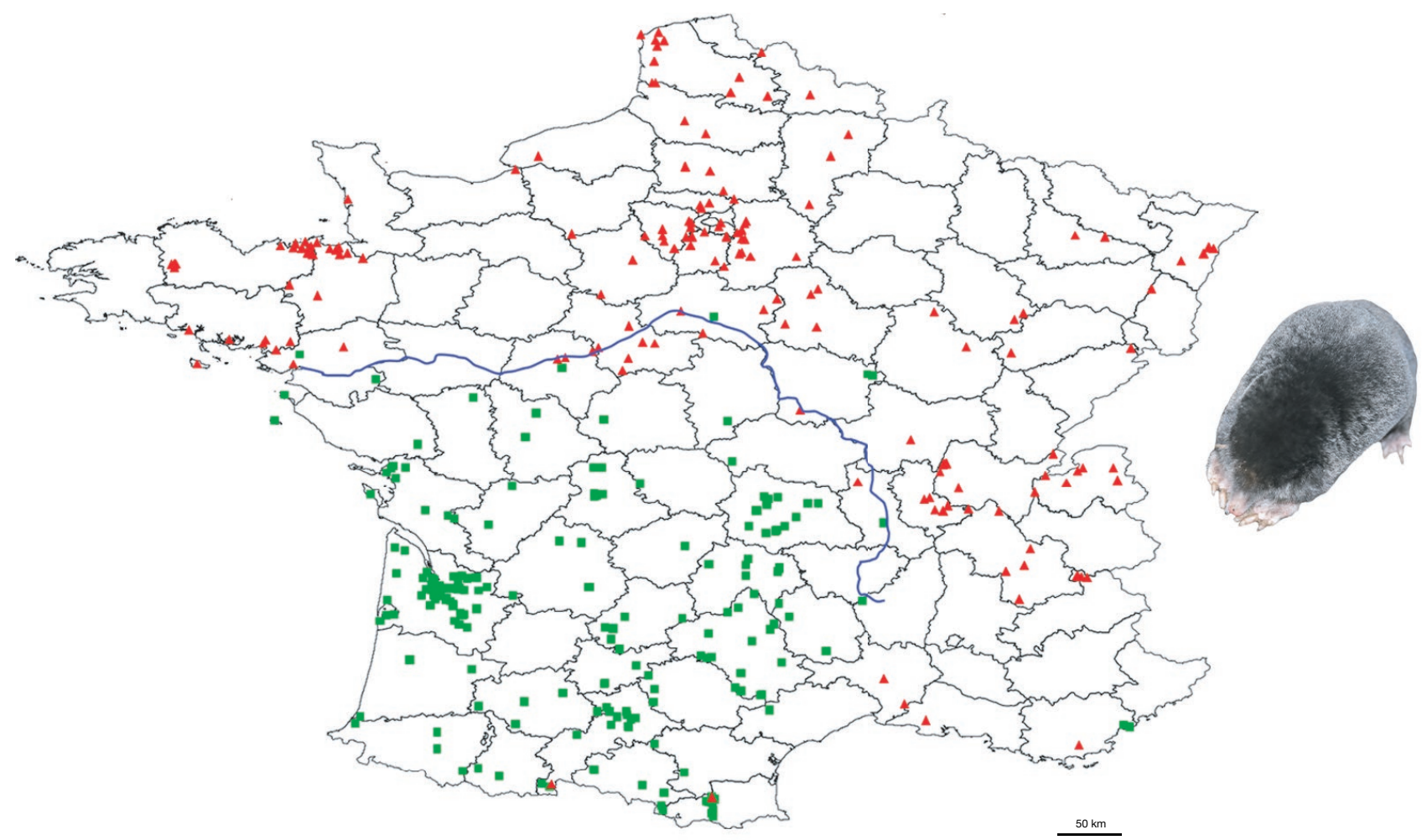

FIG. 1. - Map of the distribution of Talpa aquitania Nicolas, Martínez-Vargas \& Hugot, 2017 ( $₫)$ and T. europaea Linnaeus, 1758 ( $\Delta$ ) in France based on 1058 verified species records. The Loire River is indicated in blue, and department boundaries are in black.

According to Nicolas et al. (2017b), who modelled the climatically favourable areas for the two mole species on the basis of environmental niche models, climatic factors only partly explain the actual distribution of these species. In fact, the actual distribution of both species, and particularly those of T. aquitania, is much more reduced that expected based on climatic variables alone. Thus, the factors explaining the current distribution of these two species are probably not only climatic.

Species interactions (e.g. mutual competitive exclusion, predation, parasitism, mutualism) are also important in determining species distribution (Pearman et al. 2008; Sinclair et al. 2010; Giannini et al. 2013). Mutual competitive exclusion between the two French mole species may explain their geographical distribution. Sympatric tandems of congeneric moles occur in North America (genus Scapanus Pomel, 1848), the Mediterranean area (genus Talpa) and eastern Asia (genus Mogera Pomel, 1848) (Kryštufek \& Motokawa 2018). Species in such tandems differ in size, and the larger mole is normally more abundant and widespread and occupies a broadest niche. It was shown that despite their widely corresponding distributions and their non-overlapping sizes, the co-occurring moles are only exceptionally syntopic, and can co-occur only if they occupy different habitat patches in a habitat mosaic (Kryštufek \& Motokawa 2018). For example, in the Japanese moles, the dominant mole species, Mogera wogura (Temminck, 1842), is progressively expanding its range northwards, dis- placing the small inferior species M. imaizumii (Kuroda, 1957) (Abe 2001). Soil hardness is an important factor affecting the geographical distribution of these species and it allows their coexistence only under very specific circumstances. In other subterranean mammals, like pocket gophers, interspecific differences in body size and digging strategy have been shown to confer competitive dominance of one species over another depending on soil characteristics (Marcy et al. 2013). In regions where divergent soil types co-occur, the ranges of different pocket gopher species can overlap (Thaeler 1968). Significant body size differences between T. aquitania and T. europaea were found (Nicolas et al. 2017b). Studies are underway to test how these differences in body size, and potentially other morphological differences in anterior limb and hand morphology, affect the digging behaviour of these moles and their competitive dominance. It is interesting to note that areas of contact between the two French mole species correspond to highly heterogeneous lithological areas: areas of sympatry in the Pyrénées-Orientales, Haute-Garonne, Loire-Atlantique, Nièvre and Var departments correspond mostly to a mixture of Acid Plutonic Rocks and Metamorphic Rocks, and areas of sympatry in the Indre-et-Loire and Loiret departments correspond mostly to a mixture of Siliciclastic Sedimentary Rocks and Unconsolidated Sediments (Hartmann \& Moosdorf 2012). More data on the ability of moles to dig in different soil types are harshly needed to test whether interspecific differences in body size and digging strategy explain the mostly 
allopatric distribution of these two species and their possible coexistence in few highly heterogeneous lithological areas.

Due to its small stomach capacity, fast digestion and low fat storage in tissues moles can endure only short periods of fasting, and are constantly in search of food during most of their active time (Kryštufek \& Motokawa 2018). Several studies suggested that food is an important limiting factor affecting the spatial distribution and abundance of moles (Beolchini et al. 1996; Loy \& Capanna 1998). Moles are mainly earthworm feeders, even if there may be seasonal and regional differences in the importance of earthworms in their diet (Gorman \& Stone 1990; Kryštufek \& Motokawa 2018). Earthworm abundance is not evenly distributed in France, being strongly affected by land use, climate-related parameters (e.g. soil moisture), vegetation, soil texture, soil organic matter and soil pH (Rutgers et al. 2016; Phillips et al. 2019). It is much lower is the south-western part of France (less than 50 individuals $/ \mathrm{m}^{2}$ ) than in the rest of the country (mostly 100-500 individuals $/ \mathrm{m}^{2}$ ), and this area of low earthworm abundance matches pretty well the distribution of T. aquitania. Additional data are needed on the diet of the two mole species in France and their ability to catch and consume different kind of prey, and on the competitive behavior. Unpublished geometric morphometric analyses showed significant differences in both size and shape of the skulls and mandibles of the two species suggesting different bite force and olfactory capacities (Martínez-Vargas et al. comm pers.)

Finally, historical processes are also important in explaining species present-day distribution. The time of divergence between the two mole species is dated back to the Pliocene-Pleistocene boundary (Feuda et al. 2015; Nicolas et al. 2017b). Climatic oscillations leading to extreme drought or freezing, which dramatically increase hardness of soils and lower the availability of feeding resources represented by the foil fauna, have a significant impact on moles (Gorman \& Stone 1990). During the Quaternary Period, which was dominated by Ice Ages and involved repeated global cooling, moles were frequently isolated in several glacial refuges, their populations expanding again during interglacial periods (Feuda et al. 2015; Nicolas et al. 2017b). Their current distribution would thus depend on their capacity to disperse from these refuges. The populations of T. aquitania in the Var department and of T. europaea in the Pyrénées Mountains may correspond to relict populations dating form glacial periods: climatic niche modelling analyses based on the Model for Interdisciplinary Research on Climate highlighted a high probability of presence of these species during the Last Glacial Maximum in these areas (Nicolas et al. 2017b).

To conclude, historical processes, contemporary environmental variables and species interactions are probably important in explaining the distribution of the two mole species in France. Our study represents an important step toward a better understanding of the geographical distribution of these moles. However, more occurrence data are still needed in south-eastern France, Pyrénées Mountains and along the Loire River to complete the maps. Moreover, precise data on the habitat of collect (including both abiotic and biotic data) of each specimen are required. This kind of data could maybe help us to explain the presence of T. aquitania in the Var department and of T. europaea in the Pyrénées Mountains. A multidisciplinary project including geometric morphometry, functional morphology, diet and behaviour analyses is underway to better understand species digging ability, their ability to catch and consume different kinds of prey and their competitive behaviour.

\section{Acknowledgments}

Funding support was provided by the department "Origines et Evolution" of the MNHN. We would like to thank the following curators for access to collections: Audibert Cédric (MHNL), Guerin Marie-Laurence (MHNN), Mellier Benoît (MHNA), Wandhammer Marie-Dominique (MZS), Vialle Nicolas (Muséum d'Histoire naturelle d'Aix-en-Provence), Besson Ludovic (Muséum d'Histoire naturelle de Bourges), Braxenthaler Aurélie (Muséum-Aquarium de Nancy), Candegabe Philippe and Chiche Joëlle (MHNGr), Cap Henri (MHNT), Guiho Eric (Muséum d'Histoire naturelle de Bayonne), Jenkins Paula (BMNH), Ruedi Manuel (MHNG), Conroy Chris (MVZ), Lunde Darrin, Rochon Ingrid and Krol Megan (NMNH). This work would not have been possible without the help of all mole trappers and naturalists who actively participated to collect new field data: Alriq Michel, Amouretti Paul, Bachelard Louis, Barthes Laurent, Benumes Jérémy, Bergues Emilie, Bernadet M., Boisguérin Jean-Christophe, Boussès Patrick, Burgot François, Cairey-Remonnay Frédéric, Cambournac Yves, Carr Charlotte, Catil Jean-Michel, Champagnat Alain, Chassang Pascal, Coulon Florine, Cristol Marie-Laure, Cugnasse Jean-Marc, de Jong Justine, de Massary Jean-Christophe, Delapré Arnaud, Deputte Bertrand, Derosier Michel, Desandre Bernard, Dormion Jérôme, Dréno Pauline, Duplantier Jean-Marc, Dupont Yves, Feliu Carlos, Fabre Pierre-Henri, Fournier-Chambrillon Christine, Frémont Yannick, Geigl Eva-Maria, Georgeon Jean-Michel, Gervais Michel, Giroud Michèle, Grèzes Jean-Philippe, Grisvard Pierre, Guisset Claude, Haffner Patrick, Houssin Céline, Laclamette Jean-Luc, Ladagnous Alain, Laffon Eric, Laffont Eric, Lagrue Denis, Lemarchand Charles, Long Benjamain, Martinez Quentin, Molinier Cécile, Molinier Thierry, Molinier Florence, Moncel Gwendoline, Morichon David, Nadal Renaud, Nicolas Daniel, Pagès Gabriel, Petit Daniel, Pons Jean-Marc, Pradier Bernard, Quemener Léon, Ribas Alexis, Riols Christian, Robert Alain, Rosoux René, Talhoet Samuel, Tesseydre Gilbert, Trille Magali, Vabre Annie, and Veron Géraldine. We are grateful to the referees for their helpful comments on the manuscript.

\section{REFERENCES}

AвE H. 2001. - Soil hardness, a factor affecting the range expansion of Mogera wogura in Japan. Mammal Study 26: 45-52. https:// doi.org/10.3106/mammalstudy.26.45

Beolchini F., Dupré E. \& Loy A. 1996. - Territorial behaviour of Talpa romana in two different habitats: food resources and reproduc- 
tive needs as potential causes of variation. Zeitschrift für Säugetierkunde 61: 193-201. https://doi.org/10.1080/11250009409355887

Burgin C., Colella J. P., Kahn P. \& Upham N. S. 2018. - How many species of mammals are there? Journal of Mammalogy 99: 1-14. https://doi.org/10.1093/jmammal/gyx147

Demirtaș S., Silsüpür M., Searle J. B., Bilton D. \& GÜNdÜz İ. 2020. - What should we call the Levant mole? Unravelling the systematics and demography of Talpa levantis Thomas, 1906 sensu lato (Mammalia: Talpidae). Mammalian Biology 100: 1-18. https://doi.org/10.1007/s42991-020-00010-4

Feuda R., Bannikova A. A., Zemlemerova E. D., Febbraro M., Loy A., Hutterer R., Aloise G., Zykov A. E., Annesi F. \& COLANGELO P. 2015. - Tracing the evolutionary history of the mole, Talpa europaea, through mitochondrial DNA phylogeography and species distribution modelling. Biological Journal of the Linnean Society 114: 495-512. https://doi.org/10.1111/bij.12459

Giannini T. C., Chapman D. S., Saraiva A. M., Alves-Dos-Santos I. \& BIESMEIJER J. C. 2013. — Improving species distribution models using biotic interactions: a case study of parasites, pollinators and plants. Ecography 36: 649-656. https://doi. org/10.1111/j.1600-0587.2012.07191.x

Gorman M. L. \& STONE R. D. 1990. — The natural history of moles. Christopher Helm Publications, London, 138

Hartmann J. \& Moosdorf N. 2012. - The new global lithological map database GLiM: A representation of rock properties at the Earth surface. Geochemistry, Geophysics, Geosystems 113 Q12004. https://doi.org/10.1029/2012GC004370

HutTerer R. 2005. - Order Soricomorpha, in Wilson D. E. \& ReEder D. M. (eds), Mammal Species of the World: A Taxonomic and Geographic Reference, third ed. Johns Hopkins University Press, Baltimore: 220-311.

KryštufeK B. \& MotoKaWA M. 2018. — Family Talpidae (Moles, desmans, star-nosed moles and shrew moles), in WILSON D. E., Lacher T. A. \& MitTermeier R. A. (eds), Handbook of the Mammals of the World. Vol. 8. Insectivores, sloths and colugos. Lynx Edicions, Barcelona, 552-619.

Kryštufek B., NedyalkOV N., Astrin J. J. \& Hutterer R. 2017. News from the Balkan refugium: Thrace has an endemic mole species (Mammalia: Talpidae). Bonn zoological Bulletin 67: 41-57.

LOY A. \& CAPANNA E. 1998. - A parapatric contact area between two species of moles (genus Talpa): character displacement investigated through the geometric morphometric of skull. Acta Zoologica Academiae Scientiarum Hungaricae 44: 151-164.

Marcy A. E., Fendorf S., Patton J. L. \& Hadly E. A. 2013. Morphological adaptations for digging and climate-impacted soil properties define Pocket Gopher (Thomomys spp.) Distributions. Plos One 8: e64935. https://doi.org/10.1371/journal.pone.0064935

Mотт L. 2010. - Environmental Constraints to the Geographic Expansion of Plant and Animal Species. Nature Education Knowledge 3: 72.

Nicolas V., MartíneZ-Vargas J. \& HugOt J.-P. 2017a. - Talpa aquitania sp. nov. (Talpidae, Soricomorpha), a new mole species from SW France and N Spain Mammalia 81: 641-642. https:// doi.org/10.1515/mammalia-2017-0057

Nicolas V., Martínez-Vargas J. \& Hugot J.-P. 2017b. — Molecular data and ecological niche modelling reveal the evolutionary history of the common and Iberian moles (Talpidae) in Europe. Zoologica Scripta 46: 12-26. https://doi.org/10.1111/zsc. 12189

Pearman P. B., Guisan A., Broennimann O. \& Randin C. F. 2008. - Niche dynamics in space and time. Trends in Ecology \& Evolution 23: 149-158. https://doi.org/10.1016/j.tree.2007.11.005

Phillips H. R. P., Guerra C. A., Bartz M. L. C., Briones M. J. I., Brown G., Crowther T. W., Ferlian O., Gongalsky K. B., van den Hoogen J., Krebs J., Orgiazzi A., Routh D., Schwarz B., Bach E. M., Bennett J., Brose U., Decaens T., KonigRies B., Loreau M., Mathieu J., Mulder C., van der Putten W. H., Ramirez K. S., Rillig M. C., Russell D., Rutgers M., Thakur M. P., de Vries F. T., Wall D. H., Wardle D. A., Ara M., Ayuke F. O., Baker G. H., Beausejour R., Bedano J. C., BirkHofer K., Blanchart E., Blossey B., Bolger T., Bradley R. L., Callaham M. A., Capowiez Y., Caulfield M. E., Choi A., Crotty F. V., Davalos A., Cosin D. J. D., Dominguez A., Duhour A. E., van Eekeren N., Emmerling C., Falco L. B., Fernandez R., Fonte S. J., Fragoso C., Franco A. L. C., Fugere M., Fusilero A. T., Gholami S., Gundale M. J., Lopez M. G., Hackenberger D. K., Hernandez L. M., Hishi T., Holdsworth A. R., Holmstrup M., Hopfensperger K. N., Lwanga E. H., Huhta V., Hurisso T. T., Iannone B. V., 3rd, IORDaChe M., JoschKo M., KaneKo N., Kanianska R., Keith A. M., Kelly C. A., Kernecker M. L., Klaminder J., Kone A. W., KoOch Y., KukKonen S. T., LalthanZara H., Lammel D. R., LebedeV I. M., Li Y., LidON J. B. J., LinCOLN N. K., LOSS S. R., Marichal R., Matula R., Moos J. H., Moreno G., Moron-Rios A., Muys B., Neirynck J., Norgrove L., Novo M., Nuutinen V., Nuzzo V., Rahman P. M., Pansu J., Paudel S., Peres G., Perez-Camacho L., Pineiro R., Ponge J. F. Rashid M. I., Rebollo S., Rodeiro-Iglesias J., Rodriguez M. A., Roth A. M., Rousseau G. X., Rozen A., SAYAD E., vaN SCHAiK L., SCHARENBroch B. C., SCHIRrmanN M., SCHMidt O., Schroder B., SeEber J., ShashKov M. P., Singh J., SMith S. M., Steinwandter M., Talavera J. A., Trigo D., Tsukamoto J., DE VALENCA A. W., VANEK S. J., VirTo I., WACKETT A. A., WARREN M. W., Wehr N. H., Whalen J. K., Wironen M. B., Wolters V., Zenkova I. V., Zhang W., Cameron E. K. \& Eisenhauer N. 2019. - Global distribution of earthworm diversity. Science 366: 480-485. https://doi.org/10.1126/science.aax4851

POITEVIN F. \& QUÉRÉ J.-P. 2021. — Insectivores et rongeurs du Sud de la France. Editions Ecologistes de l'Euzière, Montpellier, 408 p.

Reese G. C., Wilson K. R., Hoeting J. A. \& Flather C. H. 2005. - Factors affecting species distribution predictions: A simulation modeling experiment. Ecological Applications 15: 554-564. https://doi.org/10.1890/03-5374

Rosoux R. \& Lemarchand C. 2020. — Une nouvelle espèce de mammifère pour la région Centre-Val de Loire. Recherches naturalistes 10: 7-9.

Rutgers M., Orgiazzi A., Gardi C., Rombke J., Jansch S., Keith A. M., Neilson R., BoAg B., Schmidt O., Murchie A. K., Blackshaw R. P., Peres G., Cluzeau D., Guernion M., Briones M. J. I., Rodeiro J., Pineiro R., Cosin D. J. D., Sousa J. P., Suhadolc M., Kos I., Krogh P. H., Faber J. H., Mulder C., Bogte J. J., van Wijnen H. J., SChouten A. J. \& DE ZWART D. 2016. - Mapping earthworm communities in Europe. Applied Soil Ecology 97: 98-111. https://doi.org/10.1016/j. apsoil.2015.08.015

Sinclair S. J., White M. D. \& Newell G. R. 2010. — How useful are species distribution models for managing biodiversity under future climates? Ecology and Society 15: 8.

STEWART A. J. A., BANTOCK T. M., BECKMANN B. C., BOTHAM M. S., Hubble D. \& Roy D. B. 2015. - The role of ecological interactions in determining species ranges and range changes. Biological Journal of the Linnean Society 115: 647-663. https:// doi.org/10.1111/bij.12543

Thaeler C. S. 1968. - An Analysis of the Distribution of Pocket Gopher Species in Northeastern California (Genus Thomomys). University of California Press, Berkeley, 46 
APPENDIX 1. - Details on the specimens of T. aquitania Nicolas, Martínez-Vargas \& Hugot, 2017 included in this study with their geographic origin, collector name and how the species identification was carried out (DNA: genetic analysis based on Cytochrome b sequencing, Eyes: morphology of the eylelids, Molars: morphology of the molars). Abbreviations: Lat., latitude; Long., longitude; Post., Postal code.

\begin{tabular}{|c|c|c|c|c|c|c|c|c|c|c|}
\hline Museum Number & Field Nb & Date & Departement & Post. & Town & Lat. & Long. & Collector & Identification & Genbank \\
\hline- & LPO Aveyron $\mathrm{S}$ & 92019.03 .29 & Ardèche $(07)$ & 07470 & Coucouron, Montlaur & 44.787 & 3.969 & Grèzes Jean-Philippe & Eyes & - \\
\hline NMNH 152332 & Li & - & Ariège $(09)$ & 09110 & Ax-les-Thermes & 42.716 & 1.833 & Builles V. & Eyes & - \\
\hline NMNH 152333 & - & - & Ariège (09) & 09110 & Ax-les-Thermes & 42.716 & 1.833 & Builles V. & Eyes & - \\
\hline MNHN-ZM-MO-1993-4174 & - & 1969.04 .10 & Ariège (09) & 09200 & Moulis & 42.966 & 1.083 & Saint Girons Marie-Charlotte & Molars & - \\
\hline MNHN-ZM-MO-1993-691 & - & 1969.04 .18 & Ariège (09) & 09200 & Moulis & 42.966 & 1.083 & Saint Girons Marie-Charlotte & Molars & - \\
\hline MNHN-ZM-MO-1993-692 & - & 1969.04 .01 & Ariège (09) & 09200 & Moulis & 42.966 & 1.083 & Saint Girons Marie-Charlotte & Molars & - \\
\hline MNHN-ZM-MO-1993-694 & - & 1969.03 .28 & Ariège (09) & 09200 & Moulis & 42.966 & 1.083 & Saint Girons Marie-Charlotte & Molars & - \\
\hline MNHN-ZM-MO-1993-695 & - & 1969.03.29 & Ariège (09) & 09200 & Moulis & 42.966 & 1.083 & Saint Girons Marie-Charlotte & Molars & - \\
\hline MNHN-ZM-MO-1993-696 & - & 1969.04 .25 & Ariège (09) & 09200 & Moulis & 42.966 & 1.083 & Saint Girons Marie-Charlotte & Molars & - \\
\hline MNHN-ZM-MO-1993-703 & - & 1972.06 .26 & Ariège (09) & 09200 & Moulis & 42.966 & 1.083 & Saint Girons Marie-Charlotte & Molars & - \\
\hline MNHN-ZM-MO-1993-705 & - & 1972.06 .23 & Ariège (09) & 09200 & Moulis & 42.966 & 1.083 & Saint Girons Marie-Charlotte & Molars & - \\
\hline MNHN-ZM-MO-1993-706 & - & 1972.06 .02 & Ariège (09) & 09200 & Moulis & 42.966 & 1.083 & Saint Girons Marie-Charlotte & Molars & - \\
\hline MNHN-ZM-MO-1993-707 & - & 1972.05 .30 & Ariège (09) & 09200 & Moulis & 42.966 & 1.083 & Saint Girons Marie-Charlotte & Molars & - \\
\hline MNHN-ZM-MO-1993-708 & - & 1971.09 .29 & Ariège (09) & 09200 & Moulis & 42.966 & 1.083 & Saint Girons Marie-Charlotte & Molars & - \\
\hline MNHN-ZM-MO-1994-2163 & - & 1905.05 .22 & Ariège (09) & 09200 & Moulis & 42.966 & 1.083 & Saint Girons Marie-Charlotte & Molars & - \\
\hline MNHN-ZM-MO-1993-702 & - & 1972.05 .23 & Ariège (09) & 09200 & Moulis & 42.961 & 1.091 & Saint Girons Marie-Charlotte & Molars, DNA & KU189583 \\
\hline NMNH 152330 & 2591 & 1906.08 .24 & Ariège (09) & 09390 & L'Hospitalet-près-l'Andorre & 42.583 & 1.800 & Robert A. & Molars & - \\
\hline NMNH 152331 & 2592 & 1906.08 .24 & Ariège (09) & 09390 & L'Hospitalet-près-l'Andorre & 42.583 & 1.800 & Robert A. & Molars & - \\
\hline BMNH 51.42 & - & 1905.05 .04 & Ariège (9) & 09400 & Tarascon-sur-Ariège & 42.800 & 1.600 & - & Molars & - \\
\hline - & LPO Aude 2 & 2019.08 .15 & Aude (11) & 11230 & Puivert, Coume Gounde & 42.933 & 2.05 & Riols Christian (LPO Aude) & Eyes & - \\
\hline - & LPO Aude 1 & 2020.01 .25 & Aude (11) & 11420 & Molandier, Paulinois & 43.250 & 1.733 & Riols Christian (LPO Aude) & Molars & - \\
\hline- & $\begin{array}{l}\text { LPO Aveyron } \\
\qquad 13\end{array}$ & 2019.03 .08 & Aveyron (12) & 12100 & Millau, SPA & 44.123 & 3.097 & Dréno Pauline & Eyes & - \\
\hline- & $\begin{array}{c}\text { LPO Aveyron } \\
14\end{array}$ & 2019.03 .17 & Aveyron (12) & 12100 & Millau, SPA & 44.123 & 3.097 & Dréno Pauline & Eyes & - \\
\hline - & LPO Aveyron 3 & 32018.09 .15 & Aveyron (12) & 12130 & $\begin{array}{l}\text { Saint-Geniez-d'Olt, le Moulin } \\
\text { de Salelles }\end{array}$ & 44.478 & 2.982 & Talhoet Samuel & Eyes & - \\
\hline - & LPO Aveyron 2 & 22018.11 .24 & Aveyron (12) & 12130 & Aurelle-Verlac, Rieuzens & 44.538 & 3.016 & Talhoet Samuel & Eyes & - \\
\hline - & LPO Aveyron 2 & 42018.11 .29 & Aveyron (12) & 12140 & Le Fel, le Mas & 44.657 & 2.515 & Talhoet Samuel & Eyes & - \\
\hline - & LPO Aveyron $€$ & 62018.06 .09 & Aveyron (12) & 12310 & Bertholène, la Bouldoire & 44.350 & 2.784 & Talhoet Samuel & Eyes & - \\
\hline- & LPO Aveyron & 12018.12 .05 & Aveyron (12) & 12360 & $\begin{array}{l}\text { Peux-et-Couffouleux, } \\
\text { Couffouleux }\end{array}$ & 43.768 & 2.876 & Talhoet Samuel & Eyes & - \\
\hline - & LPO Aveyron 5 & 52018.04 .23 & Aveyron (12) & 12360 & $\begin{array}{l}\text { Peux-et-Couffouleux, } \\
\text { le Barthas }\end{array}$ & 43.779 & 2.887 & Talhoet Samuel & Eyes & - \\
\hline- & $\begin{array}{l}\text { LPO Aveyron } \\
20\end{array}$ & 2019.06 .22 & Aveyron (12) & 12380 & Pousthomy, les Combettes & 43.851 & 2.598 & Talhoet Samuel & Eyes & - \\
\hline - & $\begin{array}{r}\text { JM Cugnasse } \\
\text { tubes } 1 \text { et } 2\end{array}$ & 2019.08 .31 & Aveyron (12) & 12380 & $\begin{array}{l}\text { Laval-Roquecezière, } \\
\text { La Claparède }\end{array}$ & 43.813 & 2.663 & Cugnasse Jean-Marc & DNA & - \\
\hline- & $\begin{array}{l}\text { LPO Aveyron } \\
\qquad 11\end{array}$ & 2019.03 .10 & Aveyron (12) & 12390 & Rignac, Le Rial & 44.432 & 2.311 & Carr Charlotte & Eyes & - \\
\hline- & $\begin{array}{l}\text { LPO Aveyron } \\
12\end{array}$ & 2019.01.20 & Aveyron (12) & 12390 & Rignac, Le Rial & 44.432 & 2.311 & Carr Charlotte & Eyes & - \\
\hline MNHN-ZM-2018-2246 & QM007 & 2017.05.01 & Aveyron (12) & 12420 & Cantoin, Vines & 44.856 & 2.806 & Martinez Quentin & Eyes, DNA & - \\
\hline MNHN-ZM-2018-2245 & QM008 & 2017.05 .01 & Aveyron (12) & 12420 & Cantoin, Vines & 44.856 & 2.806 & Martinez Quentin & Eyes, DNA & - \\
\hline MNHN-ZM-2018-2240 & QM016 & 2017.05 .01 & Aveyron (12) & 12420 & Cantoin, Vines & 44.856 & 2.806 & Martinez Quentin & Eyes, DNA & - \\
\hline - & QM047 & 2017.05.01 & Aveyron (12) & 12420 & Cantoin, Vines & 44.856 & 2.806 & Martinez Quentin & Eyes & - \\
\hline MNHN-ZM-2018-2248 & QM049 & 2017.05 .01 & Aveyron (12) & 12420 & Cantoin, Vines & 44.856 & 2.806 & Martinez Quentin & Eyes, DNA & - \\
\hline
\end{tabular}




\begin{tabular}{|c|c|c|c|c|c|c|c|c|c|c|}
\hline Museum Number & Field $\mathrm{Nb}$ & Date & Departement & Post. & Town & Lat. & Long. & Collector & Identification & Genbank \\
\hline MNHN-ZM-2018-2243 & QM051 & 2017.05 .01 & Aveyron (12) & 12420 & Cantoin, Vines & 44.856 & 2.806 & Martinez Quentin & Eyes, DNA & - \\
\hline MNHN-ZM-2018-2241 & QM052 & 2017.05 .01 & Aveyron (12) & 12420 & Cantoin, Vines & 44.856 & 2.806 & Martinez Quentin & Eyes, DNA & - \\
\hline MNHN-ZM-2018-2247 & QM053 & 2017.05 .01 & Aveyron (12) & 12420 & Cantoin, Vines & 44.856 & 2.806 & Martinez Quentin & Eyes, DNA & - \\
\hline - & QM056 & 2017.05.01 & Aveyron (12) & 12420 & Cantoin, Vines & 44.856 & 2.806 & Martinez Quentin & Eyes & - \\
\hline MNHN-ZM-2018-2244 & QM057 & 2017.05 .01 & Aveyron (12) & 12420 & Cantoin, Vines & 44.856 & 2.806 & Martinez Quentin & Eyes, DNA & - \\
\hline MNHN-ZM-2018-2239 & QM058 & 2017.05.01 & Aveyron (12) & 12420 & Cantoin, Vines & 44.856 & 2.806 & Martinez Quentin & Eyes, DNA & - \\
\hline MNHN-ZM-2018-2242 & QM059 & 2017.05 .01 & Aveyron (12) & 12420 & Cantoin, Vines & 44.856 & 2.806 & Martinez Quentin & Eyes, DNA & - \\
\hline - & QM060 & 2017.05.01 & Aveyron (12) & 12420 & Cantoin, Vines & 44.856 & 2.806 & Martinez Quentin & Eyes & - \\
\hline MNHN-ZM-2021-1445 & QM061 & 2017.05 .01 & Aveyron (12) & 12420 & Cantoin, Vines & 44.856 & 2.806 & Martinez Quentin & Eyes, DNA & - \\
\hline - & QM062 & 2017.05.01 & Aveyron (12) & 12420 & Cantoin, Vines & 44.856 & 2.806 & Martinez Quentin & Eyes, DNA & - \\
\hline MNHN-ZM-2021-1446 & QM063 & 2017.05 .01 & Aveyron (12) & 12420 & Cantoin, Vines & 44.856 & 2.806 & Martinez Quentin & Eyes, DNA & - \\
\hline MNHN-ZM-2021-1447 & QM064 & 2017.05 .01 & Aveyron (12) & 12420 & Cantoin, Vines & 44.856 & 2.806 & Martinez Quentin & Eyes, DNA & - \\
\hline MNHN-ZM-2021-1448 & QM065 & 2017.05 .01 & Aveyron (12) & 12420 & Cantoin, Vines & 44.856 & 2.806 & Martinez Quentin & Eyes, DNA & - \\
\hline - & QM066 & 2017.05 .01 & Aveyron (12) & 12420 & Cantoin, Vines & 44.856 & 2.806 & Martinez Quentin & Eyes & - \\
\hline MNHN-ZM-2021-1449 & QM067 & 2017.05 .01 & Aveyron (12) & 12420 & Cantoin, Vines & 44.856 & 2.806 & Martinez Quentin & Eyes, DNA & - \\
\hline- & QM068 & 2017.05 .01 & Aveyron (12) & 12420 & Cantoin, Vines & 44.856 & 2.806 & Martinez Quentin & Eyes & - \\
\hline- & QM069 & 2017.05 .01 & Aveyron (12) & 12420 & Cantoin, Vines & 44.856 & 2.806 & Martinez Quentin & Eyes & - \\
\hline MNHN-ZM-2021-1450 & QM070 & 2017.05 .01 & Aveyron (12) & 12420 & Cantoin, Vines & 44.856 & 2.806 & Martinez Quentin & Eyes, DNA & - \\
\hline MNHN-ZM-2021-1451 & QM071 & 2017.05 .01 & Aveyron (12) & 12420 & Cantoin, Vines & 44.856 & 2.806 & Martinez Quentin & Eyes, DNA & - \\
\hline MNHN-ZM-2021-1452 & QM072 & 2017.05 .01 & Aveyron (12) & 12420 & Cantoin, Vines & 44.856 & 2.806 & Martinez Quentin & Eyes, DNA & - \\
\hline- & QM073 & 2017.05 .01 & Aveyron (12) & 12420 & Cantoin, Vines & 44.856 & 2.806 & Martinez Quentin & Eyes & - \\
\hline MNHN-ZM-2021-1453 & QM074 & 2017.05 .01 & Aveyron (12) & 12420 & Cantoin, Vines & 44.856 & 2.806 & Martinez Quentin & Eyes, DNA & - \\
\hline MNHN-ZM-2021-1454 & QM075 & 2017.05 .01 & Aveyron (12) & 12420 & Cantoin, Vines & 44.856 & 2.806 & Martinez Quentin & Eyes, DNA & - \\
\hline MNHN-ZM-2021-1455 & QM076 & 2017.05 .01 & Aveyron (12) & 12420 & Cantoin, Vines & 44.856 & 2.806 & Martinez Quentin & Eyes, DNA & - \\
\hline - & QM077 & 2017.05 .01 & Aveyron (12) & 12420 & Cantoin, Vines & 44.856 & 2.806 & Martinez Quentin & Eyes, DNA & - \\
\hline MNHN-ZM-2021-1456 & QMA & 2017.05 .01 & Aveyron (12) & 12421 & Cantoin, Vines & 44.856 & 2.806 & Martinez Quentin & Eyes, DNA & - \\
\hline - & QMB & 2017.05.01 & Aveyron (12) & 12422 & Cantoin, Vines & 44.856 & 2.806 & Martinez Quentin & Eyes, DNA & - \\
\hline MNHN-ZM-2021-1457 & QMC & 2017.05.01 & Aveyron (12) & 12423 & Cantoin, Vines & 44.856 & 2.806 & Martinez Quentin & Eyes, DNA & - \\
\hline MNHN-ZM-2021-1458 & QMD & 2017.05.01 & Aveyron (12) & 12424 & Cantoin, Vines & 44.856 & 2.806 & Martinez Quentin & Eyes, DNA & - \\
\hline MNHN-ZM-2021-1459 & QME & 2017.05.01 & Aveyron (12) & 12425 & Cantoin, Vines & 44.856 & 2.806 & Martinez Quentin & Eyes, DNA & _- \\
\hline MNHN-ZM-2021-1460 & QMF & 2017.05 .01 & Aveyron (12) & 12426 & Cantoin, Vines & 44.856 & 2.806 & Martinez Quentin & Eyes, DNA & - \\
\hline MNHN-ZM-2021-1461 & QMG & 2017.05.01 & Aveyron (12) & 12427 & Cantoin, Vines & 44.856 & 2.806 & Martinez Quentin & Eyes, DNA & - \\
\hline MNHN-ZM-2021-1462 & $\mathrm{QMH}$ & 2017.05.01 & Aveyron (12) & 12428 & Cantoin, Vines & 44.856 & 2.806 & Martinez Quentin & Eyes, DNA & _- \\
\hline - & $\begin{array}{c}\text { LPO Aveyron } \\
19\end{array}$ & 2019.05 .06 & Aveyron (12) & 12440 & Tayrac, Calmels & 44.196 & 2.233 & Vabre Annie & Eyes & - \\
\hline- & $\begin{array}{c}\text { LPO Aveyron } \\
16\end{array}$ & 2019.04 .30 & Aveyron (12) & 12460 & Montézic, les Clauzades & 44.710 & 2.627 & Talhoet Samuel & Eyes & - \\
\hline- & $\begin{array}{r}\text { JM Cugnasse } \\
\text { tubes } 3 \text { et } 4\end{array}$ & 2019.09 .06 & Aveyron (12) & 12480 & Brousse-le-Château, Prades & 44.006 & 2.658 & Cugnasse Jean-Marc & DNA & - \\
\hline - & $\begin{array}{c}\text { LPO Aveyron } \\
15\end{array}$ & 2019.04 .22 & Aveyron (12) & 12800 & Crespin, Belmont & 44.170 & 2.293 & Trille Magali & Eyes & - \\
\hline- & LPO Aveyron 7 & 72019.01 .05 & Aveyron (12) & 12800 & Naucelle, Bonnefon & 44.183 & 2.345 & Trille Magali & Eyes & - \\
\hline MNHN-ZM-2021-1482 & 1 Rouge & 2019 & Cantal (15) & 15231 & Talizat, Pierrefitte & 45.103 & 3.060 & Alriq Michel & Molars & - \\
\hline MNHN-ZM-2021-1483 & 2 Rouge & 2019 & Cantal (15) & 15231 & Talizat, Pierrefitte & 45.103 & 3.060 & Alriq Michel & Molars & - \\
\hline MNHN-ZM-2021-1484 & 3 Rouge & 2019 & Cantal (15) & 15231 & Talizat, Pierrefitte & 45.103 & 3.060 & Alriq Michel & Molars & - \\
\hline MNHN-ZM-2021-1485 & 5 Rouge & 2019 & Cantal (15) & 15231 & Talizat, Pierrefitte & 45.103 & 3.060 & Alriq Michel & Molars & - \\
\hline MNHN-ZM-2021-1486 & 3 Noir & 2019 & Cantal (15) & 15231 & Talizat, Vernières & 45.109 & 3.066 & Alriq Michel & Molars & - \\
\hline MNHN-ZM-2021-1479 & 1 Noir & 2019 & Cantal (15) & 15231 & Talizat, Bolzat & 45.148 & 3.075 & Alriq Michel & Molars & - \\
\hline MNHN-ZM-2021-1480 & 2 Noir & 2019 & Cantal (15) & 15231 & Talizat, Bolzat & 45.148 & 3.075 & Alriq Michel & Molars & - \\
\hline MNHN-ZM-2021-1481 & 7 Rouge & 2019 & Cantal (15) & 15231 & Talizat, Bolzat & 45.130 & 3.077 & Alriq Michel & Molars & - \\
\hline MNHN-ZM-MO-1938-1221 & - & 1938.05 .09 & Cantal (15) & 15400 & Le Claux & 45.166 & 2.716 & Cantuel Paul & Molars & - \\
\hline
\end{tabular}




\begin{tabular}{|c|c|c|c|c|c|c|c|c|c|c|}
\hline Museum Number & Field Nb & Date & Departement & Post. & Town & Lat. & Long. & Collector & Identification & n Genbank \\
\hline MNHN-ZM-MO-1938-1222 & - & 1938.04 .16 & Cantal (15) & 15400 & Le Claux & 45.166 & 2.716 & Cantuel Paul & Molars & - \\
\hline MNHN-ZM-MO-1938-1223 & - & 1938.04 .25 & Cantal (15) & 15400 & Le Claux & 45.166 & 2.716 & Cantuel Paul & Molars & - \\
\hline MNHN-ZM-MO-1938-1224 & - & 1938.07.17 & Cantal (15) & 15400 & Le Claux & 45.166 & 2.716 & Cantuel Paul & Molars & - \\
\hline MNHN-ZM-MO-1938-1225 & - & 1938.05 .07 & Cantal (15) & 15400 & Le Claux & 45.166 & 2.716 & Cantuel Paul & Molars & - \\
\hline MNHN-ZM-MO-1938-1226 & - & 1938.07 .01 & Cantal (15) & 15400 & Le Claux & 45.166 & 2.716 & Cantuel Paul & Molars & - \\
\hline MNHN-ZM-MO-1938-1277 & - & 1938.07.19 & Cantal (15) & 15400 & Le Claux & 45.166 & 2.716 & Cantuel Paul & Molars & - \\
\hline MNHN-ZM-MO-1938-1278 & - & 1938.07.14 & Cantal (15) & 15400 & Le Claux & 45.166 & 2.716 & Cantuel Paul & Molars & - \\
\hline MNHN-ZM-MO-1942-197 & - & 1941.09 .19 & Cantal (15) & 15400 & Le Claux & 45.166 & 2.716 & Cantuel Paul & Molars & - \\
\hline MNHN-ZM-MO-1942-198 & - & 1939.05 .31 & Cantal (15) & 15400 & Le Claux & 45.166 & 2.716 & Cantuel Paul & Molars & - \\
\hline MNHN-ZM-MO-1942-199 & - & 1941.04 .24 & Cantal (15) & 15400 & Le Claux & 45.166 & 2.716 & Cantuel Paul & Molars & - \\
\hline MNHN-ZM-MO-1942-200 & - & 1941.04 .14 & Cantal (15) & 15400 & Le Claux & 45.166 & 2.716 & Cantuel Paul & Molars & - \\
\hline MNHN-ZM-MO-1942-202 & - & 1939.06 .19 & Cantal (15) & 15400 & Le Claux & 45.166 & 2.716 & Cantuel Paul & Molars & - \\
\hline MNHN-ZM-MO-1942-203 & - & 1939.06 .15 & Cantal (15) & 15400 & Le Claux & 45.166 & 2.716 & Cantuel Paul & Molars & - \\
\hline MNHN-ZM-MO-1942-204 & - & 1939.08 .15 & Cantal (15) & 15400 & Le Claux & 45.166 & 2.716 & Cantuel Paul & Molars & - \\
\hline MNHN-ZM-MO-1942-207 & - & 1941.04 .12 & Cantal (15) & 15400 & Le Claux & 45.166 & 2.716 & Cantuel Paul & Molars & - \\
\hline MNHN-ZM-MO-1942-208 & - & 1939.06.22 & Cantal (15) & 15400 & Le Claux & 45.166 & 2.716 & Cantuel Paul & Molars & - \\
\hline MNHN-ZM-MO-1944-263 & - & 1942.12 .05 & Cantal (15) & 15400 & Le Claux & 45.166 & 2.716 & Cantuel Paul & Molars & - \\
\hline MNHN-ZM-MO-1949-140 & - & 1948.04 .23 & Cantal (15) & 15400 & Le Claux & 45.166 & 2.716 & Cantuel Paul & Molars & - \\
\hline MNHN-ZM-MO-1962-2034 & - & 1939.08 .29 & Cantal (15) & 15400 & Le Claux & 45.166 & 2.716 & Cantuel Paul & Molars & - \\
\hline MNHN-ZM-MO-1962-2035 & - & 1941.04 .04 & Cantal (15) & 15400 & Le Claux & 45.166 & 2.716 & Cantuel Paul & Molars & - \\
\hline MNHN-ZM-MO-1962-2036 & - & 1942.05 .16 & Cantal (15) & 15400 & Le Claux & 45.166 & 2.716 & Cantuel Paul & Molars & - \\
\hline MNHN-ZM-MO-1962-2037 & - & 1941.04 .17 & Cantal (15) & 15400 & Le Claux & 45.166 & 2.716 & Cantuel Paul & Molars & - \\
\hline MNHN-ZM-MO-1942-205 & - & 1941.03 .17 & Cantal (15) & 15400 & Le Claux & 45.166 & 2.716 & Cantuel Paul & Molars, DNA & - \\
\hline $\begin{array}{l}\text { MNHN-ZM-MO-1939- } \\
1139 \mathrm{~A}\end{array}$ & - & 1939.01 .20 & Cantal (15) & 15400 & Cheylade & 45.233 & 2.733 & Cantuel Paul & Molars & - \\
\hline $\begin{array}{l}\text { MNHN-ZM-MO-1939- } \\
\text { 1139B }\end{array}$ & - & 1939.01 .20 & Cantal (15) & 15400 & Cheylade & 45.233 & 2.733 & Cantuel Paul & Molars & - \\
\hline MNHN-ZM-MO-1942-201 & - & 1939.05 .19 & Cantal (15) & 15700 & Ally & 45.174 & 2.315 & Cantuel Paul & Molars & - \\
\hline MHNG 1861-021 & - & 1970.07.11 & Cantal (15) & 15800 & Saint-Jacques-des-Blats & 45.053 & 2.715 & Mevlan A. & Molars & - \\
\hline MNHN-ZM-2017-2728 & YA0388 & 2014.03 .17 & Charente (16) & 16120 & Châteauneuf-sur-Charente & 45.599 & -0.052 & Derosier Michel & Molars, DNA & KU189654 \\
\hline MNHN-ZM-2017-2729 & YA0389 & 2014.03 .17 & Charente (16) & 16120 & Châteauneuf-sur-Charente & 45.599 & -0.052 & Derosier Michel & Molars, DNA & KU189655 \\
\hline MNHN-ZM-2017-2730 & YA0390 & 2014.03 .17 & Charente (16) & 16120 & Châteauneuf-sur-Charente & 45.599 & -0.052 & Derosier Michel & Molars, DNA & KU189656 \\
\hline MNHN-ZM-2017-2731 & YA0391 & 2014.03.17 & Charente (16) & 16120 & Châteauneuf-sur-Charente & 45.599 & -0.052 & Derosier Michel & Molars, DNA & KU189657 \\
\hline MNHN-ZM-2017-2732 & YA0392 & 2014.03 .17 & Charente (16) & 16120 & Châteauneuf-sur-Charente & 45.599 & -0.052 & Derosier Michel & Molars, DNA & KU189658 \\
\hline- & YA0393 & 2014.03.17 & Charente (16) & 16120 & Châteauneuf-sur-Charente & 45.599 & -0.052 & Derosier Michel & DNA & KU189659 \\
\hline MNHN-ZM-2017-2733 & YA0394 & 2014.03 .17 & Charente (16) & 16120 & Châteauneuf-sur-Charente & 45.599 & -0.052 & Derosier Michel & Molars, DNA & KU189660 \\
\hline MNHN-ZM-2017-2734 & YA0395 & 2014.03.17 & Charente (16) & 16120 & Châteauneuf-sur-Charente & 45.599 & -0.052 & Derosier Michel & Molars, DNA & KU189661 \\
\hline BMNH 34.6.22.3 & - & 1930.08 .27 & Charente (16) & 16700 & Near Ruffec & 46.016 & 0.200 & - & Molars & - \\
\hline MHNG 1256-094 & - & 1951.01 & $\begin{array}{l}\text { Charente- } \\
\text { Maritime (17) }\end{array}$ & 17000 & $\begin{array}{l}\text { Canal de Marans à la } \\
\text { Rochelle (=Canal de } \\
\text { Rompsay) }\end{array}$ & 46.234 & -1.074 & Chanudet F. & Molars & - \\
\hline MHNG 1267-09 & - & - & $\begin{array}{l}\text { Charente- } \\
\text { Maritime (17) }\end{array}$ & 17000 & Environ de la Rochelle & 46.166 & -1.15 & Chanudet $\mathrm{F}$. & Eyes & - \\
\hline MHNG 1267-091 & - & - & $\begin{array}{l}\text { Charente- } \\
\text { Maritime (17) }\end{array}$ & 17000 & Environ de la Rochelle & 46.166 & -1.15 & Chanudet $\mathrm{F}$. & Eyes & - \\
\hline MHNG 1256-093 & - & 1953.02 .04 & $\begin{array}{l}\text { Charente- } \\
\text { Maritime (17) }\end{array}$ & 17138 & Saint-Xandre & 46.205 & -1.101 & Chanudet $\mathrm{F}$. & Molars & - \\
\hline MHNG 1256-095 & - & 1951.04 .04 & $\begin{array}{l}\text { Charente- } \\
\text { Maritime (17) }\end{array}$ & 17220 & Salles-sur-Mer & 46.100 & -1.050 & Chanudet F. & Molars & - \\
\hline MNHN-ZM-2017-2284 & - & 2015.06.19 & $\begin{array}{l}\text { Charente- } \\
\text { Maritime (17) }\end{array}$ & 17310 & $\begin{array}{l}\text { Saint-pierre-d'Oléron, Le } \\
\text { Bois d'Anga }\end{array}$ & 45.925 & -1.323 & Cornette Raphael & Eyes, DNA & - \\
\hline
\end{tabular}




\begin{tabular}{|c|c|c|c|c|c|c|c|c|c|c|}
\hline Museum Number & Field $\mathrm{Nb}$ & Date & Departement & Post. & Town & Lat. & Long. & Collector & Identification & Genbank \\
\hline MHNG 1267-083 & - & 1965.12 .12 & $\begin{array}{l}\text { Charente- } \\
\text { Maritime (17) }\end{array}$ & 17540 & Angliers & 46.216 & -0.950 & Chanudet $\mathrm{F}$. & Eyes & - \\
\hline MHNG 1267-084 & - & 1967.11.26 & $\begin{array}{l}\text { Charente- } \\
\text { Maritime (17) }\end{array}$ & 17540 & Angliers & 46.216 & -0.950 & Chanudet $\mathrm{F}$. & Eyes & - \\
\hline MHNG 1267-085 & - & - & $\begin{array}{l}\text { Charente- } \\
\text { Maritime (17) }\end{array}$ & 17540 & Angliers & 46.216 & -0.950 & Chanudet $\mathrm{F}$. & Eyes & - \\
\hline MHNG 1267-086 & - & - & $\begin{array}{l}\text { Charente- } \\
\text { Maritime (17) }\end{array}$ & 17540 & Angliers & 46.216 & -0.950 & Chanudet $\mathrm{F}$. & Eyes & - \\
\hline MHNG 1267-092 & - & 1967.05 .28 & $\begin{array}{l}\text { Charente- } \\
\text { Maritime (17) }\end{array}$ & 17540 & Angliers & 46.216 & -0.950 & Chanudet $\mathrm{F}$. & Molars & - \\
\hline MHNG 1267-093 & - & 1971.07 .05 & $\begin{array}{l}\text { Charente- } \\
\text { Maritime (17) }\end{array}$ & 17540 & Angliers & 46.216 & -0.950 & Chanudet $\mathrm{F}$. & Molars & - \\
\hline MHNG 1267-094 & - & 1969.05 .18 & $\begin{array}{l}\text { Charente- } \\
\text { Maritime (17) }\end{array}$ & 17540 & Angliers & 46.216 & -0.950 & Chanudet $\mathrm{F}$. & Molars & - \\
\hline MNHN-ZM-MO-1992-1407A & - & 1992.01. & $\begin{array}{l}\text { Charente- } \\
\text { Maritime (17) }\end{array}$ & 17610 & Dompierre sur Charente & 45.702 & -0.490 & Denys Christiane & Eyes & - \\
\hline MNHN-ZM-MO-1992-1407B & - & 1992.01. & $\begin{array}{l}\text { Charente- } \\
\text { Maritime (17) }\end{array}$ & 17610 & Dompierre-sur-Charente & 45.702 & -0.490 & Denys Christiane & Eyes & - \\
\hline MNHN-ZM-MO-1992-1407C & - & 1992.01. & $\begin{array}{l}\text { Charente- } \\
\text { Maritime (17) }\end{array}$ & 17610 & Dompierre-sur-Charente & 45.702 & -0.490 & Denys Christiane & Eyes & - \\
\hline MNHN-ZM-MO-2001-487 & - & - & $\begin{array}{l}\text { Charente- } \\
\text { Maritime (17) }\end{array}$ & 17610 & Dompierre-sur-Charente & 45.702 & -0.490 & Denys Christiane & Eyes, DNA & KU189585 \\
\hline MNHN-ZM-MO-2001-488 & - & - & $\begin{array}{l}\text { Charente- } \\
\text { Maritime (17) }\end{array}$ & 17610 & Dompierre-sur-Charente & 45.702 & -0.490 & Denys Christiane & Eyes, DNA & KU189586 \\
\hline MNHN-ZM-MO-1994-1116 & - & 1992.11. & $\begin{array}{l}\text { Charente- } \\
\text { Maritime (17) }\end{array}$ & 17610 & $\begin{array}{l}\text { Dompierre-sur-Charente, } \\
\text { Beauvais }\end{array}$ & 45.702 & -0.490 & Rabache Etienne & Eyes & - \\
\hline MNHN-ZM-MO-1994-1117 & - & 1992.11. & $\begin{array}{l}\text { Charente- } \\
\text { Maritime (17) }\end{array}$ & 17610 & $\begin{array}{l}\text { Dompierre-sur-Charente, } \\
\text { Beauvais }\end{array}$ & 45.702 & -0.490 & Rabache Etienne & Eyes & - \\
\hline MNHN-ZM-MO-1994-1118 & - & 1992.11. & $\begin{array}{l}\text { Charente- } \\
\text { Maritime (17) }\end{array}$ & 17610 & $\begin{array}{l}\text { Dompierre-sur-Charente, } \\
\text { Beauvais }\end{array}$ & 45.702 & -0.490 & Rabache Etienne & Eyes & - \\
\hline MNHN-ZM-2021-1368 & VN1866 & 2018.07.23 & $\begin{array}{l}\text { Charente- } \\
\text { Maritime (17) }\end{array}$ & 17800 & Salignac-sur-Charente & 45.672 & -0.421 & Houssin Céline & Eyes, DNA & - \\
\hline MNHN-ZM-2017-2735 & YA0407 & - & $\begin{array}{l}\text { Charente- } \\
\text { Maritime (17) }\end{array}$ & 17810 & Nieul-les-Saintes & 45.760 & -0.731 & Derosier Michel & Molars, DNA & KU189672 \\
\hline- & YA0408 & - & $\begin{array}{l}\text { Charente- } \\
\text { Maritime (17) }\end{array}$ & 17810 & Nieul-les-Saintes & 45.760 & -0.731 & Derosier Michel & Molars, DNA & KU189673 \\
\hline- & YA0409 & - & $\begin{array}{l}\text { Charente- } \\
\text { Maritime (17) }\end{array}$ & 17810 & Nieul-les-Saintes & 45.760 & -0.731 & Derosier Michel & Molars, DNA & KU189674 \\
\hline MNHN-ZM-2017-2736 & YA0410 & - & $\begin{array}{l}\text { Charente- } \\
\text { Maritime (17) }\end{array}$ & 17810 & Nieul-les-Saintes & 45.760 & -0.731 & Derosier Michel & Molars, DNA & KU189675 \\
\hline MNHN-ZM-2017-2737 & YA0411 & - & $\begin{array}{l}\text { Charente- } \\
\text { Maritime (17) }\end{array}$ & 17810 & Nieul-les-Saintes & 45.760 & -0.731 & Derosier Michel & Molars, DNA & - \\
\hline $\begin{array}{l}\text { Museum Bourges } \\
2018.11 .3\end{array}$ & - & 2000.10 .02 & Cher (18) & 18200 & Saint-Amand-Montrond & 46.716 & 2.516 & - & DNA & - \\
\hline $\begin{array}{l}\text { Museum Bourges } \\
2001.11 .1\end{array}$ & - & 1905.05 .27 & Cher (18) & - & unknown & \multicolumn{2}{|c|}{ unknown unknown } & - & Molars, DNA & - \\
\hline $\begin{array}{l}\text { Museum Bourges } \\
2001.11 .2\end{array}$ & - & 1905.05 .27 & Cher (18) & - & unknown & \multicolumn{2}{|c|}{ unknown unknown } & - & Molars, DNA & - \\
\hline Museum Aix en Provence & VN1856 & 2018.03 .28 & Corrèze (19) & 19300 & Rosiers-d'Égletons & 45.375 & 2.059 & Vialle Nicolas & Eyes, DNA & - \\
\hline
\end{tabular}




\begin{tabular}{|c|c|c|c|c|c|c|c|c|c|c|}
\hline Museum Number & Field Nb & Date & Departement & Post. & Town & Lat. & Long. & Collector & Identification & Genbank \\
\hline- & YA0497 & 2016.03 .15 & Creuse (23) & 23430 & Saint-Goussaud & 46.041 & 1.578 & Morichon David & DNA & - \\
\hline MHNA n.2010.711 & - & - & Deux-Sèvres (79) & 79100 & Thouars & 46.966 & -0.216 & - & Eyes & - \\
\hline MHNA n.2010.712 & - & - & Deux-Sèvres (79) & 79100 & Thouars & 46.966 & -0.216 & - & Eyes & - \\
\hline MNHN-ZM-2017-2741 & YA0479 & 2015.02 .18 & Dordogne (24) & 24530 & Quinsac & 45.430 & 0.706 & Laclamette Jean-Luc & Molars & - \\
\hline MNHN-ZM-AC-1996-537 & - & 1996.03 .10 & Dordogne (24) & 24620 & Eyzies-de-Tayac & 44.933 & 1.033 & - & Molars & - \\
\hline MNHN-ZM-2016-475 & YA0425 & 2014.04.17 & Dordogne (24) & 24800 & Nantheuil & 45.413 & 0.944 & Laclamette Jean-Luc & Molars, DNA & KU189690 \\
\hline MNHN-ZM-2017-2738 & YA0426 & 2014.04.17 & Dordogne (24) & 24800 & Nantheuil & 45.413 & 0.944 & Laclamette Jean-Luc & Molars, DNA & KU189691 \\
\hline MNHN-ZM-2017-2739 & YA0427 & 2014.04 .18 & Dordogne (24) & 24800 & Nantheuil & 45.413 & 0.944 & Laclamette Jean-Luc & Molars, DNA & KU189692 \\
\hline MNHN-ZM-2017-2740 & YA0428 & 2014.04 .18 & Dordogne (24) & 24800 & Nantheuil & 45.413 & 0.944 & Laclamette Jean-Luc & Molars, DNA & KU189693 \\
\hline MNHN-ZM-AC-1996-536 & - & 1996.03.10 & Dordogne (24) & 25240 & Mouthe & 44.933 & 1.017 & - & Molars & - \\
\hline MNHN-ZM-AC-1985-27 & - & - & Dordogne (24) & - & unknown & unknown & lunknown & ר - - - & Molars & - \\
\hline- & $\begin{array}{c}\text { Emilie Bergues } \\
1\end{array}$ & s 2019.08.21 & Gers (32) & 32170 & Monpardiac, lac & 43.460 & 0.236 & Bergues Emilie & Eyes & - \\
\hline- & $\begin{array}{c}\text { Emilie Bergues } \\
\qquad 2\end{array}$ & s 2019.04.07 & Gers (32) & 32190 & $\begin{array}{l}\text { Caillavet, église Saint-Orens } \\
\text { de Laas }\end{array}$ & 43.701 & 0.327 & Bergues Emilie & Eyes & - \\
\hline BMNH 6.4.1.28 & - & 1900.02 .14 & Gers (32) & - & Forêt de Bouconne & 43.597 & 1.120 & - & Molars & - \\
\hline BMNH 6.4.1.29 & - & 1900.02 .26 & Gers (32) & - & Forêt de Bouconne & 43.597 & 1.120 & - & Molars & - \\
\hline BMNH 6.4.1.31 & - & 1900.02 .27 & Gers (32) & - & Forêt de Bouconne & 43.597 & 1.120 & - & Molars & - \\
\hline MNHN-ZM-2017-2265 & - & 2016.05 .01 & Gironde (33) & 33000 & Bordeaux, lac & 44.890 & -0.574 & Laclamette Jean-Luc & Eyes, DNA & - \\
\hline MNHN-ZM-2017-2263 & - & 2016.05 .10 & Gironde (33) & 33000 & Bordeaux & 44.837 & -0.579 & Laclamette Jean-Luc & Eyes, DNA & - \\
\hline Museum Nancy 2013.0.834 & - & - & Gironde (33) & 33000 & Bordeaux & 44.837 & -0.579 & - & DNA & - \\
\hline Museum Nancy 2016.0.834 & - & - & Gironde (33) & 33000 & Bordeaux & 44.837 & -0.579 & - & Eyes & - \\
\hline MNHN-ZM-MO-1962-2050 & - & - & Gironde (33) & 33000 & Bordeaux & 44.837 & -0.579 & Cantuel Paul & Molars & - \\
\hline MNHN-ZM-2017-2744 & YA0125 & 2013.05.22 & Gironde (33) & 33010 & Arcins & 44.798 & -0.514 & Laclamette Jean-Luc & Molars, DNA & KU189600 \\
\hline MNHN-ZM-2017-2752 & YA0126 & 2013.06 .05 & Gironde (33) & 33056 & Blanquefort & 44.900 & -0.643 & Laclamette Jean-Luc & Molars, DNA & KU189601 \\
\hline MNHN-ZM-2017-2753 & YA0127 & 2013.06.05 & Gironde (33) & 33056 & Blanquefort & 44.900 & -0.643 & Laclamette Jean-Luc & Molars, DNA & KU189602 \\
\hline MNHN-ZM-2017-2754 & YA0128 & 2013.06 .05 & Gironde (33) & 33056 & Blanquefort & 44.900 & -0.643 & Laclamette Jean-Luc & Molars, DNA & KU189603 \\
\hline MNHN-ZM-2017-2755 & YA0129 & 2013.06 .05 & Gironde (33) & 33056 & Blanquefort & 44.900 & -0.643 & Laclamette Jean-Luc & Molars, DNA & KU189604 \\
\hline- & YA0477 & 2014.12.03 & Gironde (33) & 33056 & Blanquefort & 44.900 & -0.643 & Laclamette Jean-Luc & Eyes & - \\
\hline - & YA0478 & 2014.12 .03 & Gironde (33) & 33056 & Blanquefort & 44.900 & -0.643 & Laclamette Jean-Luc & Eyes & - \\
\hline - & YA0457 & 2014.11.12 & Gironde (33) & 33115 & Pyla-sur-Mer & 44.572 & -1.222 & Laclamette Jean-Luc & DNA & - \\
\hline - & YA0458 & 2014.11.12 & Gironde (33) & 33115 & Pyla-sur-Mer & 44.572 & -1.222 & Laclamette Jean-Luc & DNA & - \\
\hline- & YA0485 & 2015.03 .10 & Gironde (33) & 33121 & Carcans & 45.079 & -1.043 & Laclamette Jean-Luc & DNA & - \\
\hline MNHN-ZM-2017-2759 & YA0486 & 2015.03 .10 & Gironde (33) & 33121 & Carcans & 45.079 & -1.043 & Laclamette Jean-Luc & Molars, DNA & - \\
\hline- & YA0490 & 2015.02.19 & Gironde (33) & 33121 & Carcans & 45.079 & -1.043 & Laclamette Jean-Luc & DNA & - \\
\hline- & YA0491 & 2015.02.19 & Gironde (33) & 33121 & Carcans & 45.079 & -1.043 & Laclamette Jean-Luc & Eyes & - \\
\hline- & YA0492 & 2015.02.19 & Gironde (33) & 33121 & Carcans & 45.079 & -1.043 & Laclamette Jean-Luc & Eyes & - \\
\hline MNHN-ZM-2017-2760 & YA0493 & 2015.02.19 & Gironde (33) & 33121 & Carcans & 45.079 & -1.043 & Laclamette Jean-Luc & Molars & - \\
\hline- & YA0494 & 2015.02 .19 & Gironde (33) & 33121 & Carcans & 45.079 & -1.043 & Laclamette Jean-Luc & Eyes & - \\
\hline - & YA0495 & 2015.02.19 & Gironde (33) & 33121 & Carcans & 45.079 & -1.043 & Laclamette Jean-Luc & Eyes & - \\
\hline - & YA0449 & 2014.11 .08 & Gironde (33) & 33127 & Martignas-sur-Jalles & 44.841 & -0.774 & Laclamette Jean-Luc & DNA & - \\
\hline - & YA0416 & 2013.09.19 & Gironde (33) & 33127 & Martignas-sur-Jalles & 44.841 & -0.774 & Laclamette Jean-Luc & DNA & KU189681 \\
\hline - & YA0487 & 2014.10 .14 & Gironde (33) & 33160 & Saint-Aubin-de-Médoc & 44.913 & -0.724 & Laclamette Jean-Luc & DNA & - \\
\hline- & YA0132 & 2013.05 .16 & Gironde (33) & 33207 & Izon & 44.914 & -0.427 & Laclamette Jean-Luc & Molars, DNA & KU189607 \\
\hline MNHN-ZM-2017-2768 & YA0133 & 2013.05.16 & Gironde (33) & 33207 & Izon & 44.914 & -0.427 & Laclamette Jean-Luc & Molars, DNA & KU189608 \\
\hline- & YA0134 & 2013.05.16 & Gironde (33) & 33207 & Izon & 44.914 & -0.427 & Laclamette Jean-Luc & Molars, DNA & KU189609 \\
\hline MNHN-ZM-2017-2769 & YA0134.1 & 2013.05.16 & Gironde (33) & 33207 & Izon & 44.914 & -0.427 & Laclamette Jean-Luc & Molars & - \\
\hline MNHN-ZM-2017-2770 & YA0134.2 & 2013.05.16 & Gironde (33) & 33207 & Izon & 44.914 & -0.427 & Laclamette Jean-Luc & DNA & - \\
\hline MNHN-ZM-2017-2771 & YA0135 & 2013.05.16 & Gironde (33) & 33207 & Izon & 44.914 & -0.427 & Laclamette Jean-Luc & Molars, DNA & KU189610 \\
\hline MNHN-ZM-2017-2772 & YA0136 & 2013.05 .16 & Gironde (33) & 33207 & Izon & 44.914 & -0.427 & Laclamette Jean-Luc & Molars, DNA & KU189611 \\
\hline
\end{tabular}




\begin{tabular}{|c|c|c|c|c|c|c|c|c|c|c|}
\hline Museum Number & Field $\mathbf{N b}$ & Date & Departement & Post. & Town & Lat. & Long. & Collector & Identification & Genbank \\
\hline MHNG 1476-05 & - & $1967 .$. & Gironde (33) & 33210 & Roaillan & 44.500 & -0.283 & Chanudet $\mathrm{F}$. & Eyes & - \\
\hline MHNG 1267-077 & - & 1968.. & Gironde (33) & 33210 & Roaillan & 44.500 & -0.283 & Chanudet $\mathrm{F}$. & Molars & - \\
\hline MHNG 1267-079 & - & 1968.. & Gironde (33) & 33210 & Roaillan & 44.500 & -0.283 & Chanudet $\mathrm{F}$. & Molars & - \\
\hline MHNG 1267-096 & - & 1966.. & Gironde (33) & 33210 & Roaillan & 44.500 & -0.283 & Chanudet $\mathrm{F}$. & Molars & - \\
\hline MHNG 1267-097 & - & $1966 .$. & Gironde (33) & 33210 & Roaillan & 44.500 & -0.283 & Chanudet $\mathrm{F}$. & Molars & - \\
\hline MHNG 1256-098 & - & 1953.08 .22 & Gironde (33) & 33210 & Sauternes & 44.533 & -0.366 & Chanudet $\mathrm{F}$. & Molars & - \\
\hline MHNG 1267-08 & - & 1962.09.15 & Gironde (33) & 33210 & Sauternes & 44.533 & -0.366 & Chanudet F. & Molars & - \\
\hline MHNG 1267-081 & - & 1964.04.02 & Gironde (33) & 33210 & Sauternes - Dhnijzan & 44.533 & -0.366 & Chanudet F. & Molars & - \\
\hline- & YA0476 & 2015.03.29 & Gironde (33) & 33220 & $\begin{array}{l}\text { Port-Sainte-Foy-et- } \\
\text { Ponchapt }\end{array}$ & 44.844 & 0.211 & Laclamette Jean-Luc & DNA & - \\
\hline- & YA0467 & 2015.03 .09 & Gironde (33) & 33230 & Guitres & 45.041 & -0.185 & Laclamette Jean-Luc & DNA & - \\
\hline MNHN-ZM-2016-474 & YA0424 & 2013.10 .18 & Gironde (33) & 33240 & La Lande-de-Fronsac & 44.980 & -0.38 & Laclamette Jean-Luc & Molars, DNA & KU189689 \\
\hline MNHN-ZM-2017-2784 & YA0445 & 2014.12 .18 & Gironde (33) & 33240 & Peujard & 45.047 & -0.429 & Laclamette Jean-Luc & Molars, DNA & - \\
\hline MNHN-ZM-2017-2785 & YA0446 & 2014.12 .18 & Gironde (33) & 33240 & Peujard & 45.047 & -0.429 & Laclamette Jean-Luc & Molars, DNA & - \\
\hline MNHN-ZM-2017-2786 & YA0447 & 2014.12 .18 & Gironde (33) & 33240 & Peujard & 45.047 & -0.429 & Laclamette Jean-Luc & Molars & - \\
\hline MNHN-ZM-2017-2787 & YA0462 & 2014.12.12 & Gironde (33) & 33240 & Peujard & 45.047 & -0.429 & Laclamette Jean-Luc & Molars & - \\
\hline MNHN-ZM-2017-2788 & YA0463 & 2014.12.12 & Gironde (33) & 33240 & Peujard & 45.047 & -0.429 & Laclamette Jean-Luc & Molars & - \\
\hline MNHN-ZM-2021-1476 & YA0217 & 2013.08 .28 & Gironde (33) & 33260 & La Teste-de-Buch & 44.631 & -1.148 & Laclamette Jean-Luc & Molars, DNA & KU189618 \\
\hline- & YA0448 & 2015.02 .07 & Gironde (33) & 33270 & Bouliac & 44.815 & -0.500 & Laclamette Jean-Luc & Eyes & - \\
\hline MNHN-ZM-2017-2254 & - & 2016.10 .24 & Gironde (33) & 33290 & Izon, Les chapeaux ronds & 44.916 & -0.366 & Laclamette Jean-Luc & Eyes, DNA & - \\
\hline MNHN-ZM-2017-2773 & YA0417 & 2013.10 .08 & Gironde (33) & 33290 & Le Pian-Médoc & 44.955 & -0.668 & Laclamette Jean-Luc & Molars, DNA & KU189682 \\
\hline MNHN-ZM-2017-2774 & YA0219 & 2013.09 .02 & Gironde (33) & 33320 & Le Taillan & 44.904 & -0.669 & Laclamette Jean-Luc & Molars, DNA & KU189620 \\
\hline MNHN-ZM-2017-2795 & YA0440 & 2014.04 .15 & Gironde (33) & 33330 & Saint-Émilion & 44.893 & -0.154 & Laclamette Jean-Luc & DNA & KU189702 \\
\hline MNHN-ZM-2017-2763 & YA0434 & 2014.03.02 & Gironde (33) & 33340 & Gaillan-en-Médoc & 45.325 & -0.953 & Laclamette Jean-Luc & Molars, DNA & KU189696 \\
\hline MNHN-ZM-2017-2255 & - & 2016.04.15 & Gironde (33) & 33360 & Parempuyre & 44.950 & -0.583 & Laclamette Jean-Luc & Eyes, DNA & - \\
\hline- & YA0131 & 2013.05 .15 & Gironde (33) & 33363 & Sadirac & 44.746 & -0.433 & Laclamette Jean-Luc & Molars, DNA & KU189606 \\
\hline MNHN-ZM-2017-2794 & YA0439 & 2014.08 .29 & Gironde (33) & 33376 & Saint-Aubin-de-Médoc & 44.913 & -0.724 & Laclamette Jean-Luc & Molars, DNA & KU189701 \\
\hline BMNH 19.7.7.1765 & - & 1882.08 .24 & Gironde (33) & 33410 & Cadillac & 44.633 & -0.316 & - & Molars & - \\
\hline BMNH 19.7.7.1967 & - & 1882.08 .24 & Gironde (33) & 33410 & Cadillac & 44.633 & -0.316 & - & Molars & - \\
\hline MNHN-ZM-2017-2792 & YA0122 & 2013.05 .27 & Gironde (33) & 33433 & Saint-Loubes & 44.916 & -0.427 & Laclamette Jean-Luc & Molars, DNA & KU189597 \\
\hline- & YA0123 & 2013.05 .27 & Gironde (33) & 33433 & Saint-Loubes & 44.916 & -0.427 & Laclamette Jean-Luc & Molars, DNA & KU189598 \\
\hline MNHN-ZM-2017-2793 & YA0124 & 2013.05 .27 & Gironde (33) & 33433 & Saint-Loubes & 44.916 & -0.427 & Laclamette Jean-Luc & Molars, DNA & KU189599 \\
\hline MNHN-ZM-2017-2268 & - & 2016.04 .27 & Gironde (33) & 33440 & Ambarès-et-Lagrave & 44.916 & -0.483 & Laclamette Jean-Luc & Eyes, DNA & - \\
\hline- & YA0130 & 2013.05 .01 & Gironde (33) & 33440 & Ambares-et-Lagrave & 44.925 & -0.484 & Laclamette Jean-Luc & Molars, DNA & KU189605 \\
\hline MNHN-ZM-2017-2742 & YA0453 & 2015.01 .25 & Gironde (33) & 33440 & Ambares-et-Lagrave & 44.925 & -0.484 & Laclamette Jean-Luc & Molars & - \\
\hline MNHN-ZM-2017-2743 & YA0454 & 2015.01 .25 & Gironde (33) & 33440 & Ambares-et-Lagrave & 44.925 & -0.484 & Laclamette Jean-Luc & Molars & - \\
\hline MNHN-ZM-2017-2253 & - & 2016.05 .31 & Gironde (33) & 33450 & La Lande-de-Fronsac & 44.983 & -0.383 & Laclamette Jean-Luc & Eyes, DNA & - \\
\hline MNHN-ZM-2017-2266 & - & 2016.04 .25 & Gironde (33) & 33450 & Saint-Sulpice-et-Cameyrac & 44.910 & -0.389 & Laclamette Jean-Luc & Eyes, DNA & - \\
\hline MNHN-ZM-2017-2271 & - & 2016.05 .24 & Gironde (33) & 33450 & Saint-Sulpice-et-Cameyrac & 44.910 & -0.389 & Laclamette Jean-Luc & Eyes, DNA & - \\
\hline MNHN-ZM-2017-2272 & - & 2016.04.07 & Gironde (33) & 33450 & Saint-Sulpice-et-Cameyrac & 44.910 & -0.389 & Laclamette Jean-Luc & Eyes, DNA & - \\
\hline MNHN-ZM-2017-2267 & - & 2016.04 .23 & Gironde (33) & 33460 & Labarde & 45.016 & -0.633 & Laclamette Jean-Luc & Eyes, DNA & - \\
\hline- & YA0488 & 2015.08 .10 & Gironde (33) & 33460 & La Barde, Giscours & 45.015 & -0.638 & Laclamette Jean-Luc & DNA & - \\
\hline MNHN-ZM-2017-2758 & YA0218 & 2013.09.02 & Gironde (33) & 33460 & Cantenac & 45.029 & -0.655 & Laclamette Jean-Luc & Molars, DNA & KU189619 \\
\hline- & YA0466 & 2014.10.31 & Gironde (33) & 33460 & Lamarque & 45.096 & -0.716 & Laclamette Jean-Luc & DNA & - \\
\hline - & YA0468 & 2014.12.04 & Gironde (33) & 33460 & Lamarque & 45.096 & -0.716 & Laclamette Jean-Luc & DNA & - \\
\hline- & YA0469 & 2014.12.04 & Gironde (33) & 33460 & Lamarque & 45.096 & -0.716 & Laclamette Jean-Luc & Eyes & - \\
\hline - & YA0418 & 2013.10 .09 & Gironde (33) & 33460 & Avensan & 45.034 & -0.757 & Laclamette Jean-Luc & Molars, DNA & KU189683 \\
\hline- & YA0419 & 2013.10 .09 & Gironde (33) & 33460 & Avensan & 45.034 & -0.757 & Laclamette Jean-Luc & Molars, DNA & KU189684 \\
\hline MNHN-ZM-2017-2746 & YA0419A & 2013.10 .09 & Gironde (33) & 33460 & Avensan & 45.034 & -0.757 & Laclamette Jean-Luc & Molars & - \\
\hline MNHN-ZM-2017-2747 & YA0419B & 2013.10.09 & Gironde (33) & 33460 & Avensan & 45.034 & -0.757 & Laclamette Jean-Luc & Molars & - \\
\hline
\end{tabular}




\begin{tabular}{|c|c|c|c|c|c|c|c|c|c|c|}
\hline Museum Number & Field Nb & Date & Departement & Post. & Town & Lat. & Long. & Collector & Identification & Genbank \\
\hline MNHN-ZM-2017-2748 & YA0420 & 2013.10.09 & Gironde (33) & 33460 & Avensan & 45.034 & -0.757 & Laclamette Jean-Luc & Molars, DNA & KU189685 \\
\hline MNHN-ZM-2017-2749 & YA0421 & 2013.10 .09 & Gironde (33) & 33460 & Avensan & 45.034 & -0.757 & Laclamette Jean-Luc & Molars, DNA & KU189686 \\
\hline MNHN-ZM-2017-2750 & YA0422 & 2013.10.09 & Gironde (33) & 33460 & Avensan & 45.034 & -0.757 & Laclamette Jean-Luc & Molars, DNA & KU189687 \\
\hline MNHN-ZM-2017-2751 & YA0423 & 2013.10.12 & Gironde (33) & 33460 & Avensan & 45.034 & -0.757 & Laclamette Jean-Luc & Molars, DNA & KU189688 \\
\hline- & YA0471 & 2015.02.19 & Gironde (33) & 33460 & Avensan & 45.034 & -0.757 & Laclamette Jean-Luc & DNA & - \\
\hline - & YA0472 & 2015.02.19 & Gironde (33) & 33460 & Avensan & 45.034 & -0.757 & Laclamette Jean-Luc & DNA & - \\
\hline- & YA0473 & 2015.04 .12 & Gironde (33) & 33470 & Gujan-Mestras & 44.636 & -1.066 & Laclamette Jean-Luc & DNA & - \\
\hline MNHN-ZM-2017-2764 & YA0474 & 2015.04.12 & Gironde (33) & 33470 & Gujan-Mestras & 44.636 & -1.066 & Laclamette Jean-Luc & Molars, DNA & - \\
\hline MNHN-ZM-2017-2765 & YA0480 & 2015.03.29 & Gironde (33) & 33470 & Gujan-Mestras & 44.636 & -1.066 & Laclamette Jean-Luc & Molars & - \\
\hline MNHN-ZM-2017-2766 & YA0481 & 2015.04 .04 & Gironde (33) & 33470 & Gujan-Mestras & 44.636 & -1.066 & Laclamette Jean-Luc & Molars & - \\
\hline MNHN-ZM-2017-2767 & YA0482 & 2015.04 .04 & Gironde (33) & 33470 & Gujan-Mestras & 44.636 & -1.066 & Laclamette Jean-Luc & Molars & - \\
\hline- & YA0483 & 2015.04 .04 & Gironde (33) & 33470 & Gujan-Mestras & 44.636 & -1.066 & Laclamette Jean-Luc & Eyes & - \\
\hline MNHN-ZM-2017-2745 & YA0214 & 2013.08 .26 & Gironde (33) & 33480 & Avensan & 45.034 & -0.757 & Laclamette Jean-Luc & Molars, DNA & KU189615 \\
\hline MNHN-ZM-2017-2756 & YA0464 & 2015.01 .05 & Gironde (33) & 33520 & Bruges & 44.883 & -0.611 & Laclamette Jean-Luc & Molars, DNA & - \\
\hline MNHN-ZM-2017-2757 & YA0465 & 2015.01 .05 & Gironde (33) & 33520 & Bruges & 44.883 & -0.611 & Laclamette Jean-Luc & Molars, DNA & - \\
\hline- & YA0484 & 2015.01 .03 & Gironde (33) & 33520 & Bruges & 44.883 & -0.611 & Laclamette Jean-Luc & Eyes & - \\
\hline MNHN-ZM-MO-1913-232 & - & 1912.12.11 & Gironde (33) & 33570 & Puisseguin & 44.933 & -0.066 & Lassagne Jean & Eyes, DNA & - \\
\hline- & YA0475 & 2014.12.31 & Gironde (33) & 33600 & Pessac & 44.806 & -0.631 & Laclamette Jean-Luc & DNA & - \\
\hline MNHN-ZM-2017-2261 & - & 2016.04 .23 & Gironde (33) & 33610 & Cestas & 44.733 & -0.683 & Laclamette Jean-Luc & Eyes, DNA & - \\
\hline MNHN-ZM-2017-2262 & - & 2016.04 .23 & Gironde (33) & 33610 & Cestas & 44.733 & -0.683 & Laclamette Jean-Luc & Eyes, DNA & - \\
\hline- & YA0460 & 2014.11.15 & Gironde (33) & 33620 & Marcenais & 45.058 & -0.336 & Laclamette Jean-Luc & DNA & - \\
\hline- & YA0461 & 2014.11 .15 & Gironde (33) & 33620 & Marcenais & 45.058 & -0.336 & Laclamette Jean-Luc & DNA & - \\
\hline MNHN-ZM-2017-2780 & YA0435 & 2014.03 .24 & Gironde (33) & 33700 & Mérignac & 44.843 & -0.644 & Laclamette Jean-Luc & Molars, DNA & KU189697 \\
\hline MNHN-ZM-2017-2781 & YA0436 & 2014.03 .24 & Gironde (33) & 33700 & Mérignac & 44.843 & -0.644 & Laclamette Jean-Luc & Molars, DNA & KU189698 \\
\hline MNHN-ZM-2017-2782 & YA0437 & 2014.03 .24 & Gironde (33) & 33700 & Mérignac & 44.843 & -0.644 & Laclamette Jean-Luc & Molars, DNA & KU189699 \\
\hline MNHN-ZM-2017-2783 & YA0438 & 2014.03.24 & Gironde (33) & 33700 & Mérignac & 44.843 & -0.644 & Laclamette Jean-Luc & Molars, DNA & KU189700 \\
\hline- & YA0415 & 2013.09 .12 & Gironde (33) & 33720 & Cerons & 44.632 & -0.335 & Laclamette Jean-Luc & Molars, DNA & KU189680 \\
\hline MNHN-ZM-2017-2761 & YA0215 & 2013.08.29 & Gironde (33) & 33720 & Cerons & 44.631 & -0.337 & Laclamette Jean-Luc & Molars, DNA & KU189616 \\
\hline MNHN-ZM-2017-2762 & YA0216 & 2013.08.29 & Gironde (33) & 33720 & Cerons & 44.631 & -0.337 & Laclamette Jean-Luc & Molars, DNA & KU189617 \\
\hline MNHN-ZM-2017-2789 & YA0211 & 2013.08 .26 & Gironde (33) & 33720 & Podensac & 44.650 & -0.354 & Laclamette Jean-Luc & Molars, DNA & KU189612 \\
\hline MNHN-ZM-2017-2790 & YA0212 & 2013.08.26 & Gironde (33) & 33720 & Podensac & 44.650 & -0.354 & Laclamette Jean-Luc & Molars, DNA & KU189613 \\
\hline MNHN-ZM-2017-2791 & YA0213 & 2013.08.26 & Gironde (33) & 33720 & Podensac & 44.650 & -0.354 & Laclamette Jean-Luc & Molars, DNA & KU189614 \\
\hline MNHN-ZM-2017-2252 & - & 2016.02 .04 & Gironde (33) & 33720 & Landiras & 44.566 & -0.416 & Laclamette Jean-Luc & Eyes, DNA & - \\
\hline MNHN-ZM-2017-2257 & - & 2016.02 .08 & Gironde (33) & 33720 & Landiras & 44.566 & -0.416 & Laclamette Jean-Luc & Eyes, DNA & - \\
\hline MNHN-ZM-2017-2258 & - & 2016.02 .08 & Gironde (33) & 33720 & Landiras & 44.566 & -0.416 & Laclamette Jean-Luc & Eyes, DNA & - \\
\hline MNHN-ZM-2017-2259 & - & 2016.02 .08 & Gironde (33) & 33720 & Landiras & 44.566 & -0.416 & Laclamette Jean-Luc & Eyes, DNA & - \\
\hline MNHN-ZM-2017-2260 & - & 2016.02 .08 & Gironde (33) & 33720 & Landiras & 44.566 & -0.416 & Laclamette Jean-Luc & Eyes, DNA & - \\
\hline MNHN-ZM-2017-2273 & - & 2016.02 .08 & Gironde (33) & 33720 & Landiras & 44.566 & -0.416 & Laclamette Jean-Luc & Eyes, DNA & - \\
\hline MNHN-ZM-2017-2274 & - & 2016.02 .08 & Gironde (33) & 33720 & Landiras & 44.566 & -0.416 & Laclamette Jean-Luc & Eyes, DNA & - \\
\hline MNHN-ZM-2017-2275 & - & 2016.02 .08 & Gironde (33) & 33720 & Landiras & 44.566 & -0.416 & Laclamette Jean-Luc & Eyes, DNA & - \\
\hline MNHN-ZM-2017-2276 & - & 2016.02 .08 & Gironde (33) & 33720 & Landiras & 44.566 & -0.416 & Laclamette Jean-Luc & Eyes, DNA & - \\
\hline MNHN-ZM-2017-2256 & - & 2016.05 .03 & Gironde (33) & 33720 & Cénac & 44.779 & -0.460 & Laclamette Jean-Luc & Eyes, DNA & - \\
\hline MNHN-ZM-2017-2269 & - & 2016.05.17 & Gironde (33) & 33760 & Saint-Genis-du-Bois & 44.700 & -0.183 & Laclamette Jean-Luc & Eyes, DNA & - \\
\hline MNHN-ZM-2017-2270 & - & 2016.02.29 & Gironde (33) & 33870 & Vayres & 44.900 & -0.316 & Laclamette Jean-Luc & Eyes, DNA & - \\
\hline- & YA0470 & 2014.10.31 & Gironde (33) & 33880 & Saint-Caprais-de-Bordeaux & 44.751 & -0.435 & Laclamette Jean-Luc & Eyes & - \\
\hline - & YA0452 & 2015.04 .03 & Gironde (33) & 33880 & Baurech & 44.726 & -0.438 & Laclamette Jean-Luc & Eyes & - \\
\hline MNHN-ZM-2017-2264 & - & 2016.04.07 & Gironde (33) & 33910 & Sablons & 45.033 & -0.183 & Laclamette Jean-Luc & Eyes, DNA & - \\
\hline- & YA0412 & 2013.09 .09 & Gironde (33) & 33910 & Saint-Ciers-d'Abzac & 45.031 & -0.275 & Laclamette Jean-Luc & DNA & KU189677 \\
\hline - & YA0413 & 2013.09.09 & Gironde (33) & 33910 & Saint-Ciers-d'Abzac & 45.031 & -0.275 & Laclamette Jean-Luc & Molars, DNA & KU189678 \\
\hline & YA0414 & 2013.09.09 & Gironde (33) & 33910 & Saint-Ciers-d'Abzac & 45.031 & -0.275 & Laclamette Jean-Luc & Molars, DNA & KU189679 \\
\hline
\end{tabular}




\begin{tabular}{|c|c|c|c|c|c|c|c|c|c|c|}
\hline Museum Number & Field $\mathrm{Nb}$ & Date & Departement & Post. & Town & Lat. & Long. & Collector & Identification & Genbank \\
\hline- & YA0498 & - & Gironde (33) & 33910 & Saint-Ciers-d'Abzac & 45.026 & -0.285 & Frémont Yannick & DNA & - \\
\hline- & YA0499 & - & Gironde (33) & 33910 & Saint-Ciers-d'Abzac & 45.026 & -0.285 & Frémont Yannick & DNA & - \\
\hline MNHN-ZM-2017-2707 & - & - & Gironde (33) & 33910 & Saint-Ciers-d'Abzac & 45.026 & -0.285 & Frémont Yannick & Eyes, DNA & - \\
\hline MNHN-ZM-2017-2708 & - & - & Gironde (33) & 33910 & Saint-Ciers-d'Abzac & 45.026 & -0.285 & Frémont Yannick & Eyes, DNA & - \\
\hline MNHN-ZM-2017-2709 & - & - & Gironde (33) & 33910 & Saint-Ciers-d'Abzac & 45.026 & -0.285 & Frémont Yannick & Eyes, DNA & - \\
\hline - & YA0459 & 2015.04 .04 & Gironde (33) & 33930 & Vandays-Montalivet & 45.356 & -1.059 & Laclamette Jean-Luc & DNA & - \\
\hline MNHN-ZM-2017-2775 & YA0450 & 2014.11 .05 & Gironde (33) & 33950 & Lège-Cap-Ferret & 44.795 & -1.146 & Laclamette Jean-Luc & Molars, DNA & - \\
\hline MNHN-ZM-2017-2776 & YA0451 & 2014.11 .05 & Gironde (33) & 33950 & Lège-Cap-Ferret & 44.795 & -1.146 & Laclamette Jean-Luc & Molars, DNA & - \\
\hline MNHN-ZM-2017-2777 & YA0455 & 2014.11 .05 & Gironde (33) & 33950 & Lège-Cap-Ferret & 44.795 & -1.146 & Laclamette Jean-Luc & Molars & - \\
\hline MNHN-ZM-2017-2778 & YA0456 & 2014.11.05 & Gironde (33) & 33950 & Lège-Cap-Ferret & 44.795 & -1.146 & Laclamette Jean-Luc & Molars & - \\
\hline MNHN-ZM-2017-2779 & YA0489 & 2015.11.05 & Gironde (33) & 33950 & Lège-Cap-Ferret & 44.795 & -1.146 & Laclamette Jean-Luc & Molars & - \\
\hline MNHN-ZM-2017-2277 & - & - & Gironde (33) & - & unknown & unknow! & unknown & Laclamette Jean-Luc & Eyes & - \\
\hline MNHN-ZM-2017-2278 & _- & - & Gironde (33) & - & unknown & unknow & unknown & Laclamette Jean-Luc & Eyes & - \\
\hline MNHN-ZM-2017-2279 & _- & - & Gironde (33) & - & unknown & unknow & unknown & Laclamette Jean-Luc & Eyes & - \\
\hline MNHN-ZM-2017-2280 & - & - & Gironde (33) & - & unknown & unknowl & unknown & Laclamette Jean-Luc & Eyes & - \\
\hline MNHN-ZM-2017-2281 & _- & - & Gironde (33) & - & unknown & unknowl & unknown & Laclamette Jean-Luc & Eyes & _- \\
\hline MNHN-ZM-2017-2282 & - & - & Gironde (33) & - & unknown & unknowi & unknown & Laclamette Jean-Luc & Eyes & - \\
\hline MVZ:Mamm:34255 & - & 1924.05 .30 & Haute-Garonne (31 & 1) 31000 & Toulouse & 43.600 & 1.433 & - & Skull & - \\
\hline MHNG 1476-045 & - & 1960.08 .20 & Haute-Garonne (31 & 1) 31110 & Garin & 42.816 & 0.516 & Chanudet $\mathrm{F}$. & Molars & - \\
\hline BMNH 6.4.1.21 & - & 1905.03 .20 & Haute-Garonne (31 & 1) 31110 & Luchon & 42.783 & 0.600 & 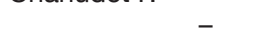 & Molars & - \\
\hline BMNH 6.4.1.23 & - & 1900.01 .20 & Haute-Garonne (31 & 1) 31110 & Luchon & 42.783 & 0.600 & - & Molars & - \\
\hline MNHN-ZM-2013-153 & YA0006 & 2012.04.11 & Haute-Garonne (31 & 1) 31230 & Pitoulet & 43.343 & 0.900 & Laffont Eric & Eyes & - \\
\hline - & YA0431 & 2014.09.01 & Haute-Garonne (31 & 1) 31270 & Cugnaux & 43.536 & 1.334 & Laffon Eric & DNA & KU189695 \\
\hline MNHN-ZM-2013-154 & YA0007 & 2012.04 .11 & Haute-Garonne (31 & 1) 31320 & Mervilla & 43.507 & 1.476 & Laffont Eric & Eyes & - \\
\hline - & YA0430 & 2014.09.01 & Haute-Garonne 31 & 1) 31400 & Toulouse & 43.560 & 1.439 & Laffon Eric & Molars & - \\
\hline NMNH 152324 & 183 & 1900.03 .10 & Haute-Garonne (31 & 1) 31490 & Leguevin & 43.599 & 1.25 & Robert A. & Molars & - \\
\hline MNHN-ZM-2013-152 & YA0005 & 2012.04 .01 & Haute-Garonne (31 & 1) 31600 & Muret-Lherm, airport & 43.449 & 1.262 & Laffont Eric & Eyes & - \\
\hline- & YA0429 & 2014.09 .01 & Haute-Garonne (31 & 1) 31670 & Labège & 43.530 & 1.530 & Laffon Eric & DNA & KU189694 \\
\hline MNHN-ZM-2021-1369 & VN1865 & 2018.08.09 & Haute-Garonne (31 & 1) 31800 & Venerque & 43.434 & 1.444 & Delapré Arnaud & Eyes, DNA & - \\
\hline MNHN-ZM-2021-1370 & VN1885 & aout 2019 & Haute-Garonne (31 & 1) 31810 & Venerque & 43.426 & 1.453 & Delapré Arnaud & Eyes & - \\
\hline MNHN-ZM-2021-1371 & VN1886 & aout 2019 & Haute-Garonne (31 & 1) 31810 & Venerque & 43.426 & 1.453 & Delapré Arnaud & Eyes & - \\
\hline NMNH 152325 & 131 & 1900.02 .11 & Haute-Garonne (31 & 1) - & Forêt de Bouconne & 43.641 & 1.221 & Robert A. & Molars & - \\
\hline NMNH 152326 & 169 & 1900.03 .04 & Haute-Garonne (31 & - & Forêt de Bouconne & 43.641 & 1.221 & Robert A. & Molars & - \\
\hline NMNH 152327 & 172 & 1900.03 .05 & Haute-Garonne (31 & - & Forêt de Bouconne & 43.641 & 1.221 & Robert A. & Molars & - \\
\hline BMNH 6.4.1.24 & - & 1900.01 .13 & Haute-Garonne (31 & _- & Caterille ( = Caserille) & unknow & unknown & 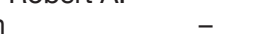 & Molars & _- \\
\hline BMNH 6.4.1.25 & _- & 1900.01 .24 & Haute-Garonne (31 & _- & Caterille ( = Caserille) & unknow & unknown & - & Molars & _- \\
\hline BMNH 6.4.1.26 & - & 1900.01 .24 & Haute-Garonne (31 & - & Caterille ( = Caserille) & unknow! & unknown & - & Molars & - \\
\hline BMNH 6.4.1.27 & - & 1900.01 .30 & Haute-Garonne (31 & - & Caterille ( = Caserille) & unknow! & unknown & - & Molars & - \\
\hline BMNH 70.80 & - & 1970.. & $\begin{array}{l}\text { Haute-Pyrénées } \\
\text { (65) }\end{array}$ & - & unknown & unknow! & unknown & - & Molars & - \\
\hline NMNH 172103 & 7176 & 1906.09.16 & $\begin{array}{l}\text { Hautes-Pyrénées } \\
(65)\end{array}$ & 65120 & Barèges & 42.897 & 0.064 & Miller G. S. & Molars & - \\
\hline BMNH 8.8.4.130 & - & 1906.09.19 & $\begin{array}{l}\text { Hautes-Pyrénées } \\
\text { (65) }\end{array}$ & 65120 & Barèges & 42.897 & 0.064 & - & Molars & - \\
\hline BMNH 8.8.4.131 & - & 1906.09.15 & $\begin{array}{l}\text { Hautes-Pyrénées } \\
\text { (65) }\end{array}$ & 65120 & Barèges & 42.897 & 0.064 & - & Molars & - \\
\hline BMNH 8.8.4.132 & - & 1906.09.18 & $\begin{array}{l}\text { Hautes-Pyrénées } \\
\text { (65) }\end{array}$ & 65120 & Barèges & 42.897 & 0.064 & - & Molars & - \\
\hline MNHN-ZM-MO-1983-663 & - & 1936.07.15 & $\begin{array}{l}\text { Hautes-Pyrénées } \\
\text { (65) }\end{array}$ & - & Gave d'Ossau (1450 m) & 43.194 & -0.607 & Jordan Karl & DNA & KU189581 \\
\hline
\end{tabular}




\begin{tabular}{|c|c|c|c|c|c|c|c|c|c|c|}
\hline Museum Number & Field Nb & Date & Departement & Post. & Town & Lat. & Long. & Collector & Identification & Genbank \\
\hline MHNN.Z.045118 & - & 1924.11 .10 & Haute-Vienne (87) & 87190 & Magnac-Laval & 46.216 & 1.166 & - & Eyes & - \\
\hline MHNN.Z.045119 & - & 1945.03 .23 & Haute-Vienne (87) & 87190 & Magnac-Laval & 46.216 & 1.166 & - & Eyes & - \\
\hline MHNN.Z.045120 & - & 1934.04 .20 & Haute-Vienne (87) & 87190 & Magnac-Laval & 46.216 & 1.166 & - & Eyes & - \\
\hline MHNN.Z.045121 & - & 1934.05 .28 & Haute-Vienne (87) & 87190 & Magnac-Laval & 46.216 & 1.166 & - & Eyes & - \\
\hline MHNN.Z.045122 & - & 1954.06 .12 & Haute-Vienne (87) & 87190 & Magnac-Laval & 46.216 & 1.166 & - & Eyes & - \\
\hline MHNN.Z.045123 & - & 1945.03 .19 & Haute-Vienne (87) & 87190 & Magnac-Laval & 46.216 & 1.166 & - & Eyes & - \\
\hline MHNN.Z.045124 & - & 1937.09 .15 & Haute-Vienne (87) & 87190 & Magnac-Laval & 46.216 & 1.166 & - & Eyes & - \\
\hline MHNN.Z.045125 & - & 1945.03 .25 & Haute-Vienne (87) & 87190 & Magnac-Laval & 46.216 & 1.166 & - & Eyes & - \\
\hline MHNN.Z.045163 & - & 1925.03 .21 & Haute-Vienne (87) & 87210 & Le Dorat & 46.216 & 1.083 & - & Eyes & - \\
\hline MNHN-ZM-2017-2797 & YA0444 & 2015.04 .01 & Haute-Vienne (87) & 87520 & Veyrac, Glâne & 45.933 & 1.088 & Petit Daniel & Molars, DNA & - \\
\hline MNHN-ZM-2017-2796 & YA0443 & 2015.05 .01 & Haute-Vienne (87) & 87520 & Veyrac, Estivaux & 45.905 & 1.092 & Petit Daniel & Molars, DNA & - \\
\hline MNHN-ZM-2017-2251 & - & 2016.05 .02 & Haute-Vienne (87) & 87520 & Les Cosjanots, Veyrac & 45.919 & 1.108 & Petit Daniel & Eyes, DNA & - \\
\hline MNHN-ZM-2017-2250 & - & 2015.10 .05 & Haute-Vienne (87) & 87520 & Nieul & 45.926 & 1.174 & Petit Daniel & Eyes, DNA & - \\
\hline- & VN1918 & 2017.10.07 & Hérault (34) & 34610 & Rosis, Douch & 43.610 & 2.973 & Fabre Pierre-Henri & Eyes & - \\
\hline- & VN1919 & 2017.10.07 & Hérault (34) & 34610 & Rosis, Douch & 43.610 & 2.973 & Fabre Pierre-Henri & Eyes & - \\
\hline MNHN-ZM-2017-2304 & VN1822 & 1905.07 .08 & Indre (36) & 36300 & Rosnay & 46.732 & 1.190 & Boussès Patrick & DNA & - \\
\hline MNHN-ZM-MO-1984-783 & - & - & Indre-et-Loire (37) & 37250 & Veigné & 47.288 & 0.738 & - & Eyes & - \\
\hline - & Saint Gor 1 & - & Landes (40) & 40120 & Saint-Gor & 44.050 & -0.233 & Riols Christian (LPO Aude) & Molars & - \\
\hline- & Saint Gor 2 & - & Landes (40) & 40120 & Saint-Gor & 44.050 & -0.233 & Riols Christian (LPO Aude) & Molars & - \\
\hline BMNH 6.4.1.32 & - & 1900.03 .18 & Landes (40) & 40210 & Solferino & 44.150 & -0.900 & - & Molars & - \\
\hline BMNH 6.4.1.33 & - & 1900.03 .20 & Landes (40) & 40210 & Solferino & 44.150 & -0.900 & - & Molars & - \\
\hline- & - & 2019.04 .25 & Landes (40) & 40273 & Saint-Martin-de-Seignanx & 43.543 & -1.431 & $\begin{array}{l}\text { Étude GREGE - Christine } \\
\text { Fournier-Chambrillon }\end{array}$ & DNA & - \\
\hline MNHN-ZM-2018-2249 & VN1855 & 2018.04 .01 & Loire (42) & 42210 & $\begin{array}{l}\text { Boisset-lès-Montrond (à } \\
1 \text { km de la Loire, rive } \\
\text { gauche) }\end{array}$ & 45.622 & 4.214 & Chassang Pascal & Eyes, DNA & - \\
\hline MHNN Z 25065 & - & 1951.06 .28 & $\begin{array}{l}\text { Loire-Atlantique } \\
\text { (44) }\end{array}$ & 44160 & Pontchâteau & 47.433 & -2.083 & - & Molars, DNA & - \\
\hline MHNN.Z.025066 & - & - & $\begin{array}{l}\text { Loire-Atlantique } \\
\text { (44) }\end{array}$ & 44330 & Vallet & 47.166 & -1.266 & - & Molars & - \\
\hline- & \multicolumn{2}{|l|}{ René Rosoux 1} & Loiret (45) & 45460 & Bray-Saint-Aignan & 47.831 & 2.368 & $\begin{array}{l}\text { Rosoux René, Lemarchand } \\
\text { Charles }\end{array}$ & $\begin{array}{l}\text { published in } \\
\text { Rosoux \& } \\
\text { Lemarchand } \\
(2020)\end{array}$ & - \\
\hline- & \multicolumn{2}{|l|}{ René Rosoux 2} & Loiret (45) & 45460 & Bray-Saint-Aignan & 47.831 & 2.368 & $\begin{array}{l}\text { Rosoux René, Lemarchand } \\
\text { Charles }\end{array}$ & $\begin{array}{l}\text { published in } \\
\text { Rosoux \& } \\
\text { Lemarchand } \\
(2020)\end{array}$ & - \\
\hline- & \multicolumn{2}{|l|}{ René Rosoux 3} & Loiret (45) & 45460 & Bray-Saint-Aignan & 47.831 & 2.368 & $\begin{array}{l}\text { Rosoux René, Lemarchand } \\
\text { Charles }\end{array}$ & $\begin{array}{l}\text { published in } \\
\text { Rosoux \& } \\
\text { Lemarchand } \\
(2020)\end{array}$ & - \\
\hline MNHN-ZM-MO-1983-662 & - & 1936.06.11 & Lot (46) & 46100 & Figeac & 44.600 & 2.033 & Brosset André & DNA & - \\
\hline - & LPO Lot 1 & 2012. & Lot (46) & 46140 & Luzech, Camy & 44.483 & 1.283 & $\begin{array}{l}\text { Nadal Renaud (via Riols } \\
\text { Christian) }\end{array}$ & Molars & - \\
\hline- & LPO Lot 4 & 2011.04 .17 & Lot (46) & 46170 & $\begin{array}{l}\text { Castelnau-Montratier, } \\
\text { chapelle de Russac }\end{array}$ & 44.268 & 1.353 & $\begin{array}{l}\text { Boisguérin Jean-Christophe } \\
\text { (via Riols Christian) }\end{array}$ & Molars & - \\
\hline- & LPO Lot 5 & 2005.09 .01 & Lot (46) & 46220 & Prayssac & 44.500 & 1.200 & $\begin{array}{l}\text { Bernadet M. (via Riols } \\
\text { Christian) }\end{array}$ & Molars & - \\
\hline
\end{tabular}




\begin{tabular}{|c|c|c|c|c|c|c|c|c|c|c|}
\hline Museum Number & Field $\mathbf{N b}$ & Date & Departement & Post. & Town & Lat. & Long. & Collector & Identification & Genbank \\
\hline- & LPO Lot 2 & 2011.05 .31 & Lot (46) & 46310 & Peyrilles, Teulière & 44.616 & 1.416 & $\begin{array}{l}\text { Tesseydre Gilbert (via Riols } \\
\text { Christian) }\end{array}$ & Molars & - \\
\hline- & LPO Lot 3 & 2011.04 .17 & Lot (46) & 46800 & $\begin{array}{l}\text { Saint-Pantaléon, la } \\
\text { Jonquière }\end{array}$ & 44.368 & 1.265 & $\begin{array}{l}\text { Boisguérin Jean-Christophe } \\
\text { (via Riols Christian) }\end{array}$ & Molars & - \\
\hline- & $\begin{array}{c}\text { LPO Aveyron } \\
17\end{array}$ & 2019.04 .13 & Lozère (48) & 48031 & Brion & 44.755 & 3.070 & Cristol Marie-Laure & Eyes & - \\
\hline- & LPO Aveyron 8 & 32018.12 .06 & Lozère (48) & 48100 & $\begin{array}{l}\text { Saint-Laurent-de-Muret, lou } \\
\text { Plonas }\end{array}$ & 44.617 & 3.184 & $\begin{array}{l}\text { Long Benjamain (via Talhoet } \\
\text { Samuel) }\end{array}$ & Eyes & - \\
\hline MNHN-ZM-MO-1990-970 & - & - & Lozère (48) & 48400 & Vébron & 44.240 & 3.578 & Tranier Michel & Molars, DNA & KU189582 \\
\hline MNHN-ZM-MO-1998-401 & - & 1998.09 .08 & Lozère (48) & 48400 & $\begin{array}{l}\text { Vébron, Colline du Puech, } \\
850 \mathrm{~m}\end{array}$ & 44.240 & 3.578 & Tranier Michel & Eyes, DNA & KU189584 \\
\hline MNHN-ZM-MO-2001-514 & - & 2001.06 .21 & Lozère (48) & 48400 & $\begin{array}{l}\text { Vébron, Le Valat de } \\
\text { Broussous }\end{array}$ & 44.240 & 3.578 & Cuisin Jacques & Eyes, DNA & KU189587 \\
\hline MNHN-ZM-2018-2250 & VN1840 & 2017.10.12 & Nièvre (58) & 58230 & Montsauche-les-Settons & 47.215 & 4.024 & Cornette Raphael & Eyes, DNA & - \\
\hline MNHN-ZM-2021-1373 & VN1868 & 2018.10.16 & Nièvre (58) & 58230 & Gouloux, Le bridier & 47.204 & 4.095 & Cornette Raphael & Eyes, DNA & - \\
\hline MNHN-ZM-2021-1374 & VN1882 = TP4 & 2019.05 .21 & Nièvre (58) & 58230 & $\begin{array}{l}\text { Montsauche-les-Settons } \\
\text { (camping du Bridier, Les } \\
\text { Gadreys) }\end{array}$ & 47.203 & 4.096 & $\begin{array}{l}\text { Cornette Raphael Houssin } \\
\text { Céline Delapré Arnaud }\end{array}$ & Eyes, DNA & - \\
\hline MNHN-ZM-2021-137 & VN1884 = TP6 & 2019.05.25 & Nièvre (58) & 58230 & $\begin{array}{l}\text { Montsauche-les-Settons } \\
\text { (camping du Bridier, Les } \\
\text { Gadreys) }\end{array}$ & 47.203 & 4.096 & $\begin{array}{l}\text { Cornette Raphael Houssin } \\
\text { Céline Delapré Arnaud }\end{array}$ & Eyes, DNA & - \\
\hline MNHN-ZM-2021-1372 & VN1867 & 2018.10.15 & Nièvre (58) & 58230 & Gouloux, Le bridier & 47.203 & 4.096 & Cornette Raphael & Eyes, DNA & - \\
\hline MNHN-ZM-2021-1375 & VN1883 = TP5 & 2019.05 .24 & Nièvre (58) & 58230 & $\begin{array}{l}\text { Montsauche-les-Settons } \\
\text { (camping du Bridier, Les } \\
\text { Gadreys) }\end{array}$ & 47.204 & 4.096 & $\begin{array}{l}\text { Cornette Raphael Houssin } \\
\text { Céline Delapré Arnaud }\end{array}$ & Eyes, DNA & - \\
\hline BMNH 34.6.22.2 & - & 1930.09 .10 & Puy-de-Dôme (63) & 63150 & La Bourboule & 45.583 & 2.750 & - & Molars & - \\
\hline $\begin{array}{l}\text { MNHN-ZM-2016-473 } \\
\text { PARATYPE }\end{array}$ & YA0386 & 2014.04 .13 & Puy-de-Dôme (63) & 63190 & Lezoux & 45.828 & 3.380 & Georgeon Jean-Michel & Molars, DNA & KU189653 \\
\hline MNHN-ZM-2021-1378 & $\begin{array}{l}\text { VN1872 }= \\
\text { TMLH3 }\end{array}$ & 2018.04 .01 & Puy-de-Dôme (63) & 63210 & $\begin{array}{l}\text { Olby, Le Monteillet, Le } \\
\text { Moulin }\end{array}$ & 45.753 & 2.827 & $\begin{array}{l}\text { Bachelard Louis (via } \\
\text { Lemarchand Charles) }\end{array}$ & Eyes & - \\
\hline MNHN-ZM-2021-1377 & $\begin{array}{l}\text { VN1871 }= \\
\text { TMLH2 }\end{array}$ & 2018.04 .02 & Puy-de-Dôme (63) & 63210 & Olby, Le Monteillet, Ganatou & 45.752 & 2.830 & $\begin{array}{l}\text { Bachelard Louis (via } \\
\text { Lemarchand Charles) }\end{array}$ & Eyes & - \\
\hline- & $\begin{array}{l}\text { VN1870 = } \\
\text { TMLH1 }\end{array}$ & 2018.03.30 & Puy-de-Dôme (63) & 63210 & $\begin{array}{l}\text { Olby, Le Monteillet, Les } \\
\text { Varennes }\end{array}$ & 45.754 & 2.835 & $\begin{array}{l}\text { Bachelard Louis (via } \\
\text { Lemarchand Charles) }\end{array}$ & Eyes & - \\
\hline MNHN-ZM-2021-1380 & $\begin{array}{l}\text { VN1873 = } \\
\text { TMLH4 }\end{array}$ & 2018.05 .31 & Puy-de-Dôme (63) & 63230 & Pulvérières, Blanchet & 45.906 & 2.909 & $\begin{array}{l}\text { Robert Alain (via Lemarchand } \\
\text { Charles) }\end{array}$ & Eyes & - \\
\hline MNHN-ZM-2021-1381 & $\begin{array}{l}\text { VN1874 }= \\
\text { TMLH5 }\end{array}$ & 2018.05.31 & Puy-de-Dôme (63) & 63230 & Pulvérières, Blanchet & 45.906 & 2.909 & $\begin{array}{l}\text { Robert Alain (via Lemarchand } \\
\text { Charles) }\end{array}$ & Eyes & - \\
\hline MNHN-ZM-2021-1382 & $\begin{array}{c}\text { VN1875 = } \\
\text { TMLH6 }\end{array}$ & 2018.06 .01 & Puy-de-Dôme (63) & 63230 & Pulvérières, Blanchet & 45.906 & 2.909 & $\begin{array}{l}\text { Robert Alain (via Lemarchand } \\
\text { Charles) }\end{array}$ & Eyes & - \\
\hline MNHN-ZM-2021-1383 & $\begin{array}{l}\text { VN1876 }= \\
\text { TMLH7 }\end{array}$ & 2018.06 .01 & Puy-de-Dôme (63) & 63230 & Pulvérières, Blanchet & 45.906 & 2.909 & $\begin{array}{l}\text { Robert Alain (via Lemarchand } \\
\text { Charles) }\end{array}$ & Eyes & - \\
\hline MNHN-ZM-2021-1384 & $\begin{array}{l}\text { VN1877 = } \\
\text { TMLH8 }\end{array}$ & 2018.06 .01 & Puy-de-Dôme (63) & 63230 & Pulvérières, Blanchet & 45.906 & 2.909 & $\begin{array}{l}\text { Robert Alain (via Lemarchand } \\
\text { Charles) }\end{array}$ & Eyes & - \\
\hline MNHN-ZM-2021-1385 & $\begin{array}{l}\text { VN1878 = } \\
\text { TMLH9 }\end{array}$ & 2018.06 .01 & Puy-de-Dôme (63) & 63230 & Pulvérières, Blanchet & 45.906 & 2.909 & $\begin{array}{l}\text { Robert Alain (via Lemarchand } \\
\text { Charles) }\end{array}$ & Eyes & - \\
\hline MNHN-ZM-2021-1386 & $\begin{array}{r}\text { VN1879 = } \\
\text { TMLH10 }\end{array}$ & 2018.06 .01 & Puy-de-Dôme (63) & 63230 & Pulvérières, Blanchet & 45.906 & 2.909 & $\begin{array}{l}\text { Robert Alain (via Lemarchand } \\
\text { Charles) }\end{array}$ & Eyes & - \\
\hline
\end{tabular}




\begin{tabular}{|c|c|c|c|c|c|c|c|c|c|c|}
\hline Museum Number & Field $\mathbf{N b}$ & Date & Departement & Post. & Town & Lat. & Long. & Collector & Identification & Genbank \\
\hline MNHN-ZM-2021-1387 & $\begin{array}{r}\text { VN1880 = } \\
\text { TMLH11 }\end{array}$ & 2018.06 .01 & Puy-de-Dôme (63) & 63230 & Pulvérières, Blanchet & 45.906 & 2.909 & $\begin{array}{l}\text { Robert Alain (via Lemarchand } \\
\text { Charles) }\end{array}$ & Eyes & - \\
\hline MNHN-ZM-2017-2818 & YA0381 & 2014.02.27 & Puy-de-Dôme (63) & 63230 & Vulcania & 45.813 & 2.940 & Georgeon Jean-Michel & Molars, DNA & KU189648 \\
\hline MNHN-ZM-2017-2819 & YA0382 & 2014.02.27 & Puy-de-Dôme (63) & 63230 & Vulcania & 45.813 & 2.940 & Georgeon Jean-Michel & Molars, DNA & KU189649 \\
\hline MNHN-ZM-2017-2820 & YA0383 & 2014.02.27 & Puy-de-Dôme (63) & 63230 & Vulcania & 45.813 & 2.940 & Georgeon Jean-Michel & Molars, DNA & KU189650 \\
\hline MNHN-ZM-2017-2798 & YA0340 & 2013.10.01 & Puy-de-Dôme (63) & 63270 & Busseol & 45.683 & 3.250 & Pradier Bernard & Molars, DNA & KU189621 \\
\hline MNHN-ZM-2017-2799 & YA0341 & 2013.10.02 & Puy-de-Dôme (63) & 63270 & Busseol & 45.683 & 3.250 & Pradier Bernard & Molars, DNA & KU189622 \\
\hline MNHN-ZM-2017-2800 & YA0342 & 2013.10 .02 & Puy-de-Dôme (63) & 63270 & Busseol & 45.683 & 3.250 & Pradier Bernard & Molars, DNA & KU189623 \\
\hline MNHN-ZM-2017-2801 & YA0343 & 2013.10 .02 & Puy-de-Dôme (63) & 63270 & Busseol & 45.683 & 3.250 & Pradier Bernard & Molars, DNA & KU189624 \\
\hline MNHN-ZM-2017-2802 & YA0344 & 2013.10 .02 & Puy-de-Dôme (63) & 63270 & Busseol & 45.683 & 3.250 & Pradier Bernard & Molars, DNA & KU189625 \\
\hline MNHN-ZM-2017-2803 & YA0345 & 2013.10 .03 & Puy-de-Dôme (63) & 63270 & Busseol & 45.683 & 3.250 & Pradier Bernard & Molars, DNA & KU189626 \\
\hline MNHN-ZM-2018-2211 & - & 2018.03.07 & Puy-de-Dôme (63) & 63270 & Busseol & 45.683 & 3.250 & Pradier Bernard & Eyes & - \\
\hline MNHN-ZM-2018-2212 & - & 2018.03.07 & Puy-de-Dôme (63) & 63270 & Busseol & 45.683 & 3.250 & Pradier Bernard & Eyes & - \\
\hline MNHN-ZM-2018-2213 & - & 2018.03 .07 & Puy-de-Dôme (63) & 63270 & Busseol & 45.683 & 3.250 & Pradier Bernard & Eyes & - \\
\hline MNHN-ZM-2018-2214 & - & 2018.03 .07 & Puy-de-Dôme (63) & 63270 & Busseol & 45.683 & 3.250 & Pradier Bernard & Eyes & - \\
\hline MNHN-ZM-2018-2215 & - & 2018.03.07 & Puy-de-Dôme (63) & 63270 & Busseol & 45.683 & 3.250 & Pradier Bernard & Eyes & - \\
\hline MNHN-ZM-2018-2216 & - & 2018.03.07 & Puy-de-Dôme (63) & 63270 & Busseol & 45.683 & 3.250 & Pradier Bernard & Eyes & - \\
\hline MNHN-ZM-2018-2217 & - & 2018.03.07 & Puy-de-Dôme (63) & 63270 & Busseol & 45.683 & 3.250 & Pradier Bernard & Eyes & - \\
\hline MNHN-ZM-2018-2218 & - & 2018.03.07 & Puy-de-Dôme (63) & 63270 & Busseol & 45.683 & 3.250 & Pradier Bernard & Eyes & - \\
\hline MNHN-ZM-2018-2220 & - & 2018.03 .06 & Puy-de-Dôme (63) & 63270 & Busseol & 45.683 & 3.250 & Pradier Bernard & Eyes & - \\
\hline MNHN-ZM-2018-2221 & - & 2018.03 .06 & Puy-de-Dôme (63) & 63270 & Busseol & 45.683 & 3.250 & Pradier Bernard & Eyes & - \\
\hline MNHN-ZM-2018-2222 & - & 2018.03 .06 & Puy-de-Dôme (63) & 63270 & Busseol & 45.683 & 3.250 & Pradier Bernard & Eyes & - \\
\hline MNHN-ZM-2018-2223 & - & 2018.03 .06 & Puy-de-Dôme (63) & 63270 & Busseol & 45.683 & 3.250 & Pradier Bernard & Eyes & - \\
\hline MNHN-ZM-2018-2224 & - & 2018.03 .06 & Puy-de-Dôme (63) & 63270 & Busseol & 45.683 & 3.250 & Pradier Bernard & Eyes & - \\
\hline MNHN-ZM-2018-2225 & - & 2018.03 .06 & Puy-de-Dôme (63) & 63270 & Busseol & 45.683 & 3.250 & Pradier Bernard & Eyes & - \\
\hline $\begin{array}{l}\text { MNHN-ZM-2016-472 } \\
\text { PARATYPE }\end{array}$ & YA0346 & 2013.10 .06 & Puy-de-Dôme (63) & 63320 & Creste & 45.533 & 3.033 & Pradier Bernard & Molars, DNA & KU189627 \\
\hline MNHN-ZM-2017-2806 & YA0347 & 2013.10 .06 & Puy-de-Dôme (63) & 63320 & Creste & 45.533 & 3.033 & Pradier Bernard & Molars, DNA & KU189628 \\
\hline- & YA0348 & 2013.10 .06 & Puy-de-Dôme (63) & 63320 & Creste & 45.533 & 3.033 & Desandre Bernard & Molars, DNA & KU189629 \\
\hline MNHN-ZM-2017-2807 & YA0349 & 2013.10 .15 & Puy-de-Dôme (63) & 63320 & Creste & 45.550 & 3.050 & Pradier Bernard & Molars, DNA & KU189630 \\
\hline MNHN-ZM-2017-2808 & YA0350 & 2013.10 .15 & Puy-de-Dôme (63) & 63320 & Creste & 45.550 & 3.050 & Pradier Bernard & Molars, DNA & KU189631 \\
\hline MNHN-ZM-2017-2809 & YA0351 & 2013.10 .15 & Puy-de-Dôme (63) & 63320 & Creste & 45.550 & 3.050 & Pradier Bernard & Molars, DNA & KU189632 \\
\hline MNHN-ZM-2017-2810 & YA0352 & 2013.10 .15 & Puy-de-Dôme (63) & 63320 & Creste & 45.550 & 3.050 & Pradier Bernard & Molars, DNA & KU189633 \\
\hline MNHN-ZM-2017-2811 & YA0353 & 2013.10 .16 & Puy-de-Dôme (63) & 63320 & Creste & 45.550 & 3.050 & Pradier Bernard & Molars, DNA & KU189634 \\
\hline MNHN-ZM-2017-2812 & YA0354 & 2013.10 .16 & Puy-de-Dôme (63) & 63320 & Creste & 45.550 & 3.050 & Pradier Bernard & Molars, DNA & KU189635 \\
\hline MNHN-ZM-2017-2813 & YA0355 & 2013.10 .16 & Puy-de-Dôme (63) & 63320 & Creste & 45.550 & 3.050 & Pradier Bernard & Molars, DNA & KU189636 \\
\hline MNHN-ZM-2017-2814 & YA0356 & 2013.10 .16 & Puy-de-Dôme (63) & 63320 & Creste & 45.550 & 3.050 & Pradier Bernard & Molars, DNA & KU189637 \\
\hline MNHN-ZM-2017-2815 & YA0357 & 2013.10 .16 & Puy-de-Dôme (63) & 63320 & Creste & 45.550 & 3.050 & Pradier Bernard & Molars, DNA & KU189638 \\
\hline MNHN-ZM-2017-2816 & YA0358 & 2013.10 .18 & Puy-de-Dôme (63) & 63320 & Creste & 45.550 & 3.050 & Pradier Bernard & Molars, DNA & KU189639 \\
\hline- & YA0359 & 2013.10 .18 & Puy-de-Dôme (63) & 63320 & Creste & 45.550 & 3.050 & Desandre Bernard & Molars, DNA & KU189640 \\
\hline MNHN-ZM-2018-2219 & - & 2018.01 .23 & Puy-de-Dôme (63) & 63320 & Creste & 45.900 & 3.066 & Pradier Bernard & Eyes & - \\
\hline MNHN-ZM-2017-2804 & YA0384 & 2014.03 .14 & Puy-de-Dôme (63) & 63320 & Champeix & 45.589 & 3.129 & Georgeon Jean-Michel & Molars, DNA & KU189651 \\
\hline MNHN-ZM-2017-2805 & YA0385 & 2014.03 .14 & Puy-de-Dôme (63) & 63320 & Champeix & 45.589 & 3.129 & Georgeon Jean-Michel & Molars, DNA & KU189652 \\
\hline MNHN-ZM-MO-1986-98 & - & - & Puy-de-Dôme (63) & 63610 & Besse-en-Chandesse & 45.509 & 2.931 & Heim de Balsac Henri & Molars & - \\
\hline MNHN-ZM-2018-2226 & - & 2017.09.29 & Puy-de-Dôme (63) & 63610 & $\begin{array}{l}\text { Saint-Pierre-Colamine, } \\
\text { Lomprat }\end{array}$ & 45.883 & 2.966 & Pradier Bernard & Eyes & - \\
\hline MNHN-ZM-2018-2227 & - & 2017.09 .29 & Puy-de-Dôme (63) & 63610 & $\begin{array}{l}\text { Saint-Pierre-Colamine, } \\
\text { Lomprat }\end{array}$ & 45.883 & 2.966 & Pradier Bernard & Eyes & - \\
\hline MNHN-ZM-2018-2228 & - & 2017.09.29 & Puy-de-Dôme (63) & 63610 & $\begin{array}{l}\text { Saint-Pierre-Colamine, } \\
\text { Lomprat }\end{array}$ & 45.883 & 2.966 & Pradier Bernard & Eyes & - \\
\hline
\end{tabular}




\begin{tabular}{|c|c|c|c|c|c|c|c|c|c|c|}
\hline Museum Number & Field $\mathbf{N b}$ & Date & Departement & Post. & Town & Lat. & Long. & Collector & Identification & Genbank \\
\hline MNHN-ZM-2018-2229 & - & 2017.09 .29 & Puy-de-Dôme (63) & 63610 & $\begin{array}{l}\text { Saint-Pierre-Colamine, } \\
\text { Lomprat }\end{array}$ & 45.883 & 2.966 & Pradier Bernard & Eyes & - \\
\hline MNHN-ZM-2018-2230 & - & 2017.09.29 & Puy-de-Dôme (63) & 63610 & $\begin{array}{l}\text { Saint-Pierre-Colamine, } \\
\text { Lomprat }\end{array}$ & 45.883 & 2.966 & Pradier Bernard & Eyes & - \\
\hline MNHN-ZM-2018-2231 & - & 2017.09.29 & Puy-de-Dôme (63) & 63610 & $\begin{array}{l}\text { Saint-Pierre-Colamine, } \\
\text { Lomprat }\end{array}$ & 45.883 & 2.966 & Pradier Bernard & Eyes & - \\
\hline MNHN-ZM-2018-2232 & - & 2017.09.29 & Puy-de-Dôme (63) & 63610 & $\begin{array}{l}\text { Saint-Pierre-Colamine, } \\
\text { Lomprat }\end{array}$ & 45.883 & 2.966 & Pradier Bernard & Eyes & - \\
\hline MNHN-ZM-2018-2233 & - & 2017.09.29 & Puy-de-Dôme (63) & 63610 & $\begin{array}{l}\text { Saint-Pierre-Colamine, } \\
\text { Lomprat }\end{array}$ & 45.883 & 2.966 & Pradier Bernard & Eyes & - \\
\hline MNHN-ZM-2018-2234 & - & 2017.09.29 & Puy-de-Dôme (63) & 63610 & $\begin{array}{l}\text { Saint-Pierre-Colamine, } \\
\text { Lomprat }\end{array}$ & 45.883 & 2.966 & Pradier Bernard & Eyes & - \\
\hline MNHN-ZM-2018-2235 & - & 2017.09.29 & Puy-de-Dôme (63) & 63610 & $\begin{array}{l}\text { Saint-Pierre-Colamine, } \\
\text { Lomprat }\end{array}$ & 45.883 & 2.966 & Pradier Bernard & Eyes & - \\
\hline MNHN-ZM-2018-2236 & - & 2017.09.29 & Puy-de-Dôme (63) & 63610 & $\begin{array}{l}\text { Saint-Pierre-Colamine, } \\
\text { Lomprat }\end{array}$ & 45.883 & 2.966 & Pradier Bernard & Eyes & - \\
\hline MNHN-ZM-2018-2237 & - & 2017.09.29 & Puy-de-Dôme (63) & 63610 & $\begin{array}{l}\text { Saint-Pierre-Colamine, } \\
\text { Lomprat }\end{array}$ & 45.883 & 2.966 & Pradier Bernard & Eyes & - \\
\hline MNHN-ZM-2017-2817 & YA0380 & 2014.02.20 & Puy-de-Dôme (63) & 63920 & Peschadoires & 45.827 & 3.493 & Georgeon Jean-Michel & Molars, DNA & KU189647 \\
\hline MNHN-ZM-MO-1993-19 & - & 1960.04 & Pyrénées & - & unknown & unknown & unknown & Lamotte Maxime & Eyes & - \\
\hline- & Bayonne 3 & 2012.07.17 & $\begin{array}{l}\text { Pyrénées- } \\
\text { Atlantiques (64) }\end{array}$ & 64100 & Plaine d'Ansot, Bayonne & 43.470 & -1.483 & Eric Guiho (Musée Bayonne) & DNA & - \\
\hline- & Bayonne 1 & 2009.10.01 & $\begin{array}{l}\text { Pyrénées- } \\
\text { Atlantiques (64) }\end{array}$ & 64150 & Mourenx & 43.379 & -0.606 & Eric Guiho (Musée Bayonne) & DNA & - \\
\hline- & Bayonne 2 & 2009.10.01 & $\begin{array}{l}\text { Pyrénées- } \\
\text { Atlantiques (64) }\end{array}$ & 64150 & Mourenx & 43.379 & -0.606 & Eric Guiho (Musée Bayonne) & DNA & - \\
\hline MNHN-ZM-2021-1388 & VN1881 & 2018.07.19 & $\begin{array}{l}\text { Pyrénées- } \\
\text { Atlantiques (64) }\end{array}$ & 64440 & $\begin{array}{l}\text { Eaux-Bonnes, lieu-dit } \\
\text { Gravette, Bois des crétets }\end{array}$ & 42.950 & -0.333 & Grisvard Pierre & Molars & - \\
\hline MNHN-ZM-2021-1389 & VN1860 & 2018.06 .01 & $\begin{array}{l}\text { Pyrénées- } \\
\text { Orientales (66) }\end{array}$ & 66360 & Col de Mantet, Py & 42.617 & 2.321 & Benumes Jérémy & Eyes, DNA & - \\
\hline MNHN-ZM-2017-2821 & YA0117 & 2008.07.07 & $\begin{array}{l}\text { Pyrénées- } \\
\text { Orientales (66) }\end{array}$ & 66360 & Py & 42.496 & 2.350 & Guisset Claude & Molars, DNA & KU189596 \\
\hline MNHN-ZM-2021-1393 & VN1861 & 2018.06.04 & $\begin{array}{l}\text { Pyrénées- } \\
\text { Orientales (66) }\end{array}$ & 66360 & Mantet, La Farga & 42.500 & 2.359 & Feliu Carlos & Eyes, DNA & - \\
\hline MNHN-ZM-2021-1390 & VN1862 & 2018.06.01 & $\begin{array}{l}\text { Pyrénées- } \\
\text { Orientales (66) }\end{array}$ & 66360 & Mantet, La Farga & 42.500 & 2.359 & Feliu Carlos & Eyes, DNA & - \\
\hline- & YA0501 & 2016.02.22 & $\begin{array}{l}\text { Pyrénées- } \\
\text { Orientales (66) }\end{array}$ & 66360 & Sahorre & 42.533 & 2.362 & Benumes Jérémy & DNA & - \\
\hline - & YA0503 & 2016.03.04 & $\begin{array}{l}\text { Pyrénées- } \\
\text { Orientales (66) }\end{array}$ & 66360 & Sahorre & 42.533 & 2.362 & Benumes Jérémy & DNA & - \\
\hline- & 2003101508 & - & $\begin{array}{l}\text { Pyrénées- } \\
\text { Orientales (66) }\end{array}$ & 66360 & Py Natural Reserve & 42.469 & 2.363 & - & DNA & - \\
\hline MNHN-ZM-2017-3172 & - & 1905.07.09 & $\begin{array}{l}\text { Pyrénées- } \\
\text { Orientales (66) }\end{array}$ & 66360 & Py Natural Reserve & 42.469 & 2.363 & Hugot Jean-Pierre & Eyes, DNA & - \\
\hline- & YA0502 & 2016.06.24 & $\begin{array}{l}\text { Pyrénées- } \\
\text { Orientales (66) }\end{array}$ & 66500 & Nohèdes & 42.623 & 2.289 & Coulon Florine & DNA & - \\
\hline MNHN-ZM-2021-1391 & VN1858 & 2018.06.01 & $\begin{array}{l}\text { Pyrénées- } \\
\text { Orientales (66) }\end{array}$ & 66500 & Conat-Betllans & 42.617 & 2.321 & Champagnat Alain & Eyes, DNA & - \\
\hline MNHN-ZM-2021-1392 & VN1859 & 2018.06.01 & $\begin{array}{l}\text { Pyrénées- } \\
\text { Orientales (66) }\end{array}$ & 66500 & Conat-Betllans & 42.617 & 2.321 & Champagnat Alain & Eyes, DNA & - \\
\hline
\end{tabular}




\begin{tabular}{|c|c|c|c|c|c|c|c|c|c|c|}
\hline Museum Number & Field $\mathbf{N b}$ & Date & Departement & Post. & Town & Lat. & Long. & Collector & Identification & Genbank \\
\hline- & YA0374 & - & $\begin{array}{l}\text { Pyrénées- } \\
\text { Orientales (66) }\end{array}$ & 66500 & Mosset & 42.669 & 2.348 & Ribas Alexis & DNA & KU189641 \\
\hline- & YA0375 & - & $\begin{array}{l}\text { Pyrénées- } \\
\text { Orientales (66) }\end{array}$ & 66500 & Mosset & 42.669 & 2.348 & Ribas Alexis & DNA & KU189642 \\
\hline- & YA0376 & - & $\begin{array}{l}\text { Pyrénées- } \\
\text { Orientales (66) }\end{array}$ & 66500 & Mosset & 42.669 & 2.348 & Ribas Alexis & DNA & KU189643 \\
\hline- & YA0377 & - & $\begin{array}{l}\text { Pyrénées- } \\
\text { Orientales (66) }\end{array}$ & 66500 & Mosset & 42.669 & 2.348 & Ribas Alexis & DNA & KU189644 \\
\hline- & YA0378 & - & $\begin{array}{l}\text { Pyrénées- } \\
\text { Orientales (66) }\end{array}$ & 66500 & Mosset & 42.669 & 2.348 & Ribas Alexis & DNA & KU189645 \\
\hline- & YA0379 & - & $\begin{array}{l}\text { Pyrénées- } \\
\text { Orientales (66) }\end{array}$ & 66500 & Mosset & 42.669 & 2.348 & Ribas Alexis & DNA & KU189646 \\
\hline- & YA0500 & 2016.07 .25 & $\begin{array}{l}\text { Pyrénées- } \\
\text { Orientales (66) }\end{array}$ & 66500 & Conat-Betllans & 42.612 & 2.351 & Morichon David & DNA & - \\
\hline- & $\begin{array}{r}\text { 2007062CONAT } \\
=2007062201\end{array}$ & - & $\begin{array}{l}\text { Pyrénées- } \\
\text { Orientales (66) }\end{array}$ & 66500 & Conat Natural Reserve & 42.614 & 2.357 & - & DNA & - \\
\hline- & YA0441 & 2014.08 .01 & $\begin{array}{l}\text { Pyrénées- } \\
\text { Orientales (66) }\end{array}$ & 66500 & Campôme & 42.651 & 2.376 & Pagès Gabriel & DNA & - \\
\hline BMNH 8.8.4.133 & - & 1906.09 .05 & $\begin{array}{l}\text { Pyrénées- } \\
\text { Orientales (66) }\end{array}$ & 66760 & Porta & 42.527 & 1.826 & - & Molars & - \\
\hline BMNH 8.9.1.37 & - & 1906.09 .03 & $\begin{array}{l}\text { Pyrénées- } \\
\text { Orientales (66) }\end{array}$ & 66760 & Porta & 42.527 & 1.826 & - & Molars & - \\
\hline- & $\begin{array}{c}\text { LPO Aveyron } \\
18\end{array}$ & 2019.06 .05 & Tarn (81) & 81140 & Puycelci, Sainte-Catherine & 43.980 & 1.666 & Grèzes Jean-Philippe & Eyes & - \\
\hline MHNT 440-1 & - & 1905.06 .27 & Tarn (81) & 81500 & Garrigues & 43.694 & 1.719 & - & DNA & - \\
\hline MHNT 440-2 & - & 1905.06.27 & Tarn (81) & 81500 & Garrigues & 43.694 & 1.719 & - & DNA & - \\
\hline- & $\begin{array}{c}\text { LPO Aveyron } \\
10\end{array}$ & 2018.11 .24 & Tarn (81) & 81800 & Rabastens, Guillart & 43.842 & 1.731 & Grèzes Jean-Philippe & Eyes & - \\
\hline MHNT 789 & - & 1905.07.03 & $\begin{array}{l}\text { Tarn-et-Garonne } \\
\text { (82) }\end{array}$ & 82600 & Mas-Grenier & 43.891 & 1.197 & - & DNA & - \\
\hline MHNT OST AC 692 & - & - & $\begin{array}{l}\text { Tarn-et-Garonne } \\
\text { (82) }\end{array}$ & 82600 & Mas-Grenier & 43.891 & 1.197 & - & Molars & - \\
\hline MNHN-ZM-2006-384 & - & - & $\begin{array}{l}\text { Tarn-et-Garonne } \\
\text { (82) }\end{array}$ & 82600 & Mas-Grenier & 43.900 & 1.200 & - & Molars & - \\
\hline MVZ:Mamm:122043 & - & 1949.02 .01 & $\begin{array}{l}\text { Tarn-et-Garonne } \\
\text { (82) }\end{array}$ & 82600 & Mas-Grenier & 43.900 & 1.200 & - & Molars & - \\
\hline - & YA0442 & 2015.05 .01 & $\begin{array}{l}\text { Tarn-et-Garonne } \\
\text { (82) }\end{array}$ & 82800 & Bioule & 44.090 & 1.539 & Petit Daniel & Eyes & - \\
\hline MNHN-ZM-MO-1984-786 & - & - & unknown & - & unknown & unknow & nunknow & Didier Robert & Eyes & - \\
\hline BMNH 8.8.4.134 & - & 1908.04 .02 & $\operatorname{Var}(83)$ & 83700 & Saint-Raphaël, Valescure & 43.455 & 6.790 & 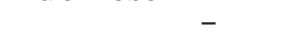 & Molars & - \\
\hline BMNH 8.8.4.135 & - & 1908.04 .14 & $\operatorname{Var}(83)$ & 83700 & Saint-Raphaël, Agay & 43.432 & 6.855 & - & Molars & - \\
\hline MNHN-ZM-2017-2822 & YA0396 & - & Vendée (85) & 85200 & Fontenay-le-Comte (L'Orbul) & 46.466 & -0.816 & Derosier Michel & Molars, DNA & KU189662 \\
\hline MNHN-ZM-2017-2823 & YA0397 & - & Vendée (85) & 85200 & Fontenay-le-Comte (L'Orbul) & 46.466 & -0.816 & Derosier Michel & Molars, DNA & KU189663 \\
\hline MNHN-ZM-2017-2824 & YA0398 & - & Vendée (85) & 85200 & Fontenay-le-Comte (L'Orbul) & 46.466 & -0.816 & Derosier Michel & Molars, DNA & KU189664 \\
\hline MNHN-ZM-2017-2825 & YA0399 & - & Vendée (85) & 85200 & Fontenay-le-Comte (L'Orbul) & 46.466 & -0.816 & Derosier Michel & Molars, DNA & KU189665 \\
\hline MNHN-ZM-2017-2826 & YA0400 & - & Vendée (85) & 85200 & Fontenay-le-Comte (L'Orbul) & 46.466 & -0.816 & Derosier Michel & Molars, DNA & KU189666 \\
\hline MNHN-ZM-2017-2827 & YA0401 & - & Vendée (85) & 85200 & Fontenay-le-Comte (L'Orbul) & 46.466 & -0.816 & Derosier Michel & Molars, DNA & KU189667 \\
\hline MNHN-ZM-2017-2828 & YA0402 & - & Vendée (85) & 85200 & Fontenay-le-Comte (L'Orbul) & 46.466 & -0.816 & Derosier Michel & Molars, DNA & KU189668 \\
\hline MNHN-ZM-2017-2829 & YA0403 & - & Vendée (85) & 85200 & Fontenay-le-Comte (L'Orbul) & 46.466 & -0.816 & Derosier Michel & Molars, DNA & KU189669 \\
\hline
\end{tabular}




\begin{tabular}{|c|c|c|c|c|c|c|c|c|c|c|}
\hline Museum Number & Field $\mathbf{N b}$ & Date & Departement & Post. & Town & Lat. & Long. & Collector & Identification & Genbank \\
\hline MNHN-ZM-2017-2830 & YA0404 & - & Vendée (85) & 85200 & Fontenay-le-Comte (L’Orbul) & 46.466 & -0.816 & Derosier Michel & Molars, DNA & KU189670 \\
\hline MNHN-ZM-2017-2831 & YA0405 & - & Vendée (85) & 85200 & Fontenay-le-Comte (L'Orbul) & 46.466 & -0.816 & Derosier Michel & Molars & - \\
\hline- & YA0406 & - & Vendée (85) & 85200 & Fontenay-le-Comte (L'Orbul) & 46.466 & -0.816 & Derosier Michel & Molars, DNA & KU189671 \\
\hline MNHN-ZM-MO-1986-100 & - & - & Vendée (85) & 85330 & Île de Noirmoutier & 47.001 & -2.247 & - & Molars & - \\
\hline- & $\begin{array}{l}\text { Scorbé- } \\
\text { Clairvaux } 1\end{array}$ & 2019.04.12 & Vienne (86) & 86140 & Scorbé-Clairvaux & 46.803 & 0.455 & Ladagnous Alain & Eyes & - \\
\hline MNHN-ZM-2021-1495 & $\begin{array}{l}\text { Scorbé- } \\
\text { Clairvaux } 2\end{array}$ & 2019.04.01 & Vienne (86) & 86140 & Scorbé-Clairvaux & 46.803 & 0.455 & Ladagnous Alain & Molars & - \\
\hline MNHN-ZM-2021-1496 & $\begin{array}{l}\text { Scorbé- } \\
\text { Clairvaux } 3\end{array}$ & 2019.04 .01 & Vienne (86) & 86140 & Scorbé-Clairvaux & 46.803 & 0.455 & Ladagnous Alain & Molars & - \\
\hline MNHN-ZM-2021-1497 & $\begin{array}{l}\text { Scorbé- } \\
\text { Clairvaux } 4\end{array}$ & 2019.04 .01 & Vienne (86) & 86140 & Scorbé-Clairvaux & 46.803 & 0.455 & Ladagnous Alain & Molars & - \\
\hline MNHN-ZM-2021-1498 & $\begin{array}{l}\text { Scorbé- } \\
\text { Clairvaux } 5\end{array}$ & 2019.04 .01 & Vienne (86) & 86140 & Scorbé-Clairvaux & 46.803 & 0.455 & Ladagnous Alain & Molars & - \\
\hline MNHN-ZM-2021-1394 & VN1887 & 2019.04.01 & Vienne (86) & 86140 & Scorbé-Clairvaux & 46.803 & 0.455 & Ladagnous Alain & Eyes & - \\
\hline MNHN-ZM-2021-1395 & VN1888 & 2019.04 .01 & Vienne (86) & 86140 & Scorbé-Clairvaux & 46.803 & 0.455 & Ladagnous Alain & Eyes & - \\
\hline MNHN-ZM-2018-2263 & - & 1905.07 .10 & Vienne (86) & 86150 & Moussac & 46.281 & 2.566 & Nicolas Daniel & Eyes, DNA & - \\
\hline MNHN-ZM-2018-2264 & - & 1905.07 .10 & Vienne (86) & 86150 & Moussac & 46.281 & 2.566 & Nicolas Daniel & Eyes, DNA & - \\
\hline MNHN-ZM-2016-471 & VN1789 & - & Vienne (86) & 86280 & Saint-Benoit & 46.545 & 0.347 & Nicolas Violaine & Eyes, DNA & KU189595 \\
\hline- & VN1766 & - & Vienne (86) & 86280 & Saint-Benoit & 46.545 & 0.347 & Nicolas Daniel & DNA & KU189594 \\
\hline MNHN-ZM-2021-1415 & G12 & 2019.03.07 & $\begin{array}{l}\text { Hautes-Pyrénées } \\
\text { (65) }\end{array}$ & 65400 & Gaillagos & 42.980 & -0.166 & Duplantier Jean-Marc & Eyes & - \\
\hline MNHN-ZM-2021-1416 & G13 & 2019.05 .19 & $\begin{array}{l}\text { Hautes-Pyrénées } \\
\text { (65) }\end{array}$ & 65400 & Gaillagos & 42.980 & -0.166 & Duplantier Jean-Marc & Eyes & - \\
\hline MNHN-ZM-2021-1417 & G14 & 2020.01 .13 & $\begin{array}{l}\text { Hautes-Pyrénées } \\
\text { (65) }\end{array}$ & 65400 & Gaillagos & 42.980 & -0.166 & Duplantier Jean-Marc & Eyes & - \\
\hline MNHN-ZM-2021-1418 & G15 & 2020.01 .18 & $\begin{array}{l}\text { Hautes-Pyrénées } \\
\text { (65) }\end{array}$ & 65400 & Gaillagos & 42.980 & -0.166 & Duplantier Jean-Marc & Eyes & - \\
\hline MNHN-ZM-2021-1419 & G16 & 2020.03 .02 & $\begin{array}{l}\text { Hautes-Pyrénées } \\
\text { (65) }\end{array}$ & 65400 & Gaillagos & 42.980 & -0.166 & Duplantier Jean-Marc & Eyes & - \\
\hline- & VN1920 & 2019.09 .08 & Gers (32) & 32120 & Taybosc & 43.796 & 0.7476 & Catil Jean-Michel & Eyes & - \\
\hline- & VN1921 & 2019.03 .30 & Gers (32) & 32400 & Saint-Mont & 43.650 & -0.1556 & Barthe Laurent & Eyes & - \\
\hline MNHN-ZM-2017-724 & - & - & Vendée (85) & 85350 & Île-d’Yeu & 46.725 & -2.349 & - & Molars & - \\
\hline
\end{tabular}




\begin{tabular}{|c|c|c|c|c|c|c|c|c|c|c|}
\hline Museum Number & Field $\mathbf{N b}$ & Date & Departement & Post. & Town & Lat. & Long. & Collector & Identification & Genbank \\
\hline MNHN-ZM-MO-1932-3836 & - & 1909.07. & Ain (01) & 01170 & Col de la faucille & 46.366 & 6.033 & Mottaz Charles & Molars & - \\
\hline MNHN-ZM-2017-2832 & YA0335 & 2013.10.16 & Ain (01) & 01290 & Grieges & 46.259 & 4.854 & Moncel Gwendoline & DNA & KU189566 \\
\hline MNHN-ZM-2017-2833 & YA0336 & 2013.10 .16 & Ain (01) & 01290 & Grieges & 46.259 & 4.854 & Moncel Gwendoline & Molars, DNA & KU189567 \\
\hline MNHN-ZM-2017-2837 & YA0324 & 2013.09 .12 & Ain (01) & 01290 & Pont-de-Veyle & 46.268 & 4.880 & Moncel Gwendoline & Molars, DNA & KU189560 \\
\hline MNHN-ZM-2017-2838 & YA0325 & 2013.09.12 & Ain (01) & 01290 & Pont-de-Veyle & 46.268 & 4.880 & Moncel Gwendoline & Molars, DNA & KU189561 \\
\hline - & YA0326 & 2013.09.12 & Ain (01) & 01290 & Pont-de-Veyle & 46.268 & 4.880 & Moncel Gwendoline & Molars & - \\
\hline MNHN-ZM-2017-2839 & YA0327 & 2013.09.12 & Ain (01) & 01290 & Pont-de-Veyle & 46.268 & 4.880 & Moncel Gwendoline & Molars & - \\
\hline MNHN-ZM-2017-2840 & YA0328 & 2013.09.12 & Ain (01) & 01290 & Pont-de-Veyle & 46.268 & 4.880 & Moncel Gwendoline & Molars & - \\
\hline MNHN-ZM-2017-2844 & YA0333 & 2013.09 .27 & Ain (01) & 01290 & Pont-de-Veyle & 46.268 & 4.880 & Moncel Gwendoline & Molars & - \\
\hline MNHN-ZM-2017-2841 & YA0329 & 2013.09 .12 & Ain (01) & 01290 & Pont-de-Veyle & 46.263 & 4.884 & Moncel Gwendoline & Molars, DNA & KU189562 \\
\hline MNHN-ZM-2017-2842 & YA0330 & 2013.09 .12 & Ain (01) & 01290 & Pont-de-Veyle & 46.263 & 4.884 & Moncel Gwendoline & Molars, DNA & KU189563 \\
\hline MNHN-ZM-2017-2843 & YA0331 & 2013.09.12 & Ain (01) & 01290 & Pont-de-Veyle & 46.263 & 4.884 & Moncel Gwendoline & Molars & - \\
\hline MNHN-ZM-2017-2834 & YA0320 & 2013.08.28 & Ain (01) & 01290 & Pont-de-Veyle & 46.262 & 4.888 & Moncel Gwendoline & DNA & KU189558 \\
\hline MNHN-ZM-2017-2835 & YA0321 & 2013.08.28 & Ain (01) & 01290 & Pont-de-Veyle & 46.262 & 4.888 & Moncel Gwendoline & DNA & KU189559 \\
\hline MNHN-ZM-2017-2836 & YA0322 & 2013.08.28 & Ain (01) & 01290 & Pont-de-Veyle & 46.262 & 4.888 & Moncel Gwendoline & Molars & - \\
\hline MNHN-ZM-2017-2845 & YA0337 & 2013.10.16 & Ain (01) & 01290 & Pont-de-Veyle & 46.262 & 4.888 & Moncel Gwendoline & Molars & - \\
\hline MHNG 1811-057 & M874 & 2001.03 .28 & Ain (01) & 01550 & Pougny & 46.133 & 5.951 & Studer J. & Molars, DNA & - \\
\hline MHNL 40000790 & - & - & Ain (01) & 01330 & Villars-les-Dombes & 46.000 & 5.016 & Côte Claudius & Eyes & - \\
\hline MVZ:Mamm:103930 & - & 1945.07 .03 & Aisne (02) & 02400 & Château-Thierry & 49.050 & 3.400 & - & Molars & - \\
\hline MNHN-ZM-MO-1990-943 & - & - & Aisne (02) & 02408 & Laon & 49.563 & 3.624 & Cassonnet Gilles & Eyes & - \\
\hline MNHN-ZM-MO-2004-1 & - & 2002.09 .01 & Aisne (02) & 02408 & Laon & 49.563 & 3.624 & Cassonnet Gilles & Eyes & - \\
\hline MNHN-ZM-MO-1986-414 & - & - & Aisne (02) & 02140 & Saint-Gobert (Château) & 49.800 & 3.814 & Taquet Philippe & Eyes, DNA & KU189428 \\
\hline MNHN-ZM-MO-1997-1869 & - & - & Allier (03) & 03210 & $\begin{array}{l}\text { Agonges, Le grand } \\
\text { Monceau }\end{array}$ & 46.836 & 3.301 & Ineich Ivan & Eyes & - \\
\hline MNHN-ZM-MO-1997-1870 & - & - & Allier (03) & 03210 & $\begin{array}{l}\text { Agonges, Le grand } \\
\text { Monceau }\end{array}$ & 46.836 & 3.301 & Ineich Ivan & Eyes & - \\
\hline MNHN-ZM-MO-1997-1868 & - & - & Allier (03) & 03210 & $\begin{array}{l}\text { Agonges, Le grand } \\
\text { Monceau }\end{array}$ & 46.836 & 3.301 & Ineich Ivan & Eyes, DNA & KU189438 \\
\hline MZS Mam03920 & - & - & Alsace region & - & unknown & unknown & unknown & - & Molars & - \\
\hline MZS Mam03926 & - & - & Bas-Rhin (67) & 67400 & Geispolsheim & 48.516 & 7.650 & - & Molars & - \\
\hline MZS Mam03901 & - & - & Bas-Rhin (67) & 67400 & Geispolsheim & 48.516 & 7.650 & - & Molars, DNA & - \\
\hline MZS Mam03899 & - & - & Bas-Rhin (67) & 67380 & Lingolsheim & 48.581 & 7.702 & - & Molars & - \\
\hline MZS Mam03902 & - & - & Bas-Rhin (67) & 67380 & Lingolsheim & 48.581 & 7.702 & - & Molars & - \\
\hline MZS Mam03903 & - & - & Bas-Rhin (67) & 67380 & Lingolsheim & 48.581 & 7.702 & - & Molars & - \\
\hline MZS Mam03904 & - & - & Bas-Rhin (67) & 67380 & Lingolsheim & 48.581 & 7.702 & - & Molars & - \\
\hline MZS Mam03906 & - & - & Bas-Rhin (67) & 67380 & Lingolsheim & 48.581 & 7.702 & - & Molars & - \\
\hline MZS Mam03911 & - & - & Bas-Rhin (67) & 67380 & Lingolsheim & 48.581 & 7.702 & - & Molars & - \\
\hline MZS Mam03912 & - & - & Bas-Rhin (67) & 67380 & Lingolsheim & 48.581 & 7.702 & - & Molars & - \\
\hline MZS Mam03914 & - & - & Bas-Rhin (67) & 67380 & Lingolsheim & 48.581 & 7.702 & - & Molars & - \\
\hline MZS Mam03917 & - & - & Bas-Rhin (67) & 67380 & Lingolsheim & 48.581 & 7.702 & - & Molars & - \\
\hline MZS Mam03922 & - & - & Bas-Rhin (67) & 67380 & Lingolsheim & 48.581 & 7.702 & - & Molars & - \\
\hline MZS Mam03900 & - & - & Bas-Rhin (67) & 67380 & Lingolsheim & 48.581 & 7.702 & - & Molars, DNA & - \\
\hline MZS Mam03908 & - & - & Bas-Rhin (67) & 67380 & Lingolsheim & 48.581 & 7.702 & - & Molars, DNA & - \\
\hline MZS Mam03925 & - & - & Bas-Rhin (67) & 67530 & Mont Sainte-Odile & 48.437 & 7.404 & - & Molars, DNA & - \\
\hline MZS mam04364 & - & - & Bas-Rhin (67) & 67000 & Strasbourg & 48.573 & 7.752 & - & Eyes & - \\
\hline MZS Mam03919 & - & - & Bas-Rhin (67) & 67000 & Strasbourg & 48.573 & 7.752 & - & Molars & - \\
\hline BMNH 65.3519 & - & 1964.08 .08 & $\begin{array}{l}\text { Bouches-du-Rhône } \\
\text { (13) }\end{array}$ & 13200 & Tour du Valat & 43.508 & 4.667 & - & Molars & - \\
\hline MNHN-ZM-MO-1993-4220 & - & 1991.11.10 & Calvados (14) & 14600 & Honfleur & 49.419 & 0.232 & Komerovsky Isabelle & Eyes, DNA & KU189433 \\
\hline
\end{tabular}




\begin{tabular}{|c|c|c|c|c|c|c|c|c|c|c|}
\hline Museum Number & Field $\mathbf{N b}$ & Date & Departement & Post. & Town & Lat. & Long. & Collector & Identification & Genbank \\
\hline MNHN-ZM-MO-1993-4221 & - & 1991.11.11 & Calvados (14) & 14600 & Honfleur & 49.419 & 0.232 & Komerovsky Isabelle & Eyes, DNA & KU189434 \\
\hline MNHN-ZM-MO-1967-1430 & - & 1966.06 .12 & Côte-d’Or (21) & 21520 & Louesme & 47.897 & 4.759 & Pfeffer Pierre & Molars, DNA & KU189427 \\
\hline MNHN-ZM-2021-1396 & VN1902 & 2020.05 .15 & Côtes d'armor (22) & 22160 & Callac & 48.400 & -3.433 & Lagrue Denis & Eyes & - \\
\hline MNHN-ZM-2021-1404 & VN1903 & 2020.06 .29 & Côtes d'armor (22) & 22160 & Callac & 48.400 & -3.433 & Lagrue Denis & Eyes & - \\
\hline MNHN-ZM-2021-1405 & VN1904 & 2020.05 .15 & Côtes d'armor (22) & 22160 & Callac & 48.400 & -3.433 & Lagrue Denis & Eyes & - \\
\hline MNHN-ZM-2021-1406 & VN1905 & 2020.07 .03 & Côtes d'armor (22) & 22160 & Callac & 48.400 & -3.433 & Lagrue Denis & Eyes & - \\
\hline MNHN-ZM-2021-1407 & VN1906 & 2020.07 .09 & Côtes d'armor (22) & 22160 & Callac & 48.400 & -3.433 & Lagrue Denis & Eyes & - \\
\hline- & VN1907 & $2020 .$. & Côtes d'armor (22) & 22160 & Callac & 48.400 & -3.433 & Lagrue Denis & Eyes & - \\
\hline MNHN-ZM-2021-1402 & VN1908 & 2020.04 .19 & Côtes d'armor (22) & 22160 & Callac & 48.400 & -3.433 & Lagrue Denis & Eyes & - \\
\hline MNHN-ZM-2021-1403 & VN1909 & 2020.03 .30 & Côtes d'armor (22) & 22160 & Callac & 48.400 & -3.433 & Lagrue Denis & Eyes & - \\
\hline MNHN-ZM-2021-1406 & VN1896 & - & Côtes d'armor (22) & 22160 & Callac, Le Peulven & 48.409 & -3.421 & Lagrue Denis & Eyes & - \\
\hline MNHN-ZM-2021-1407 & VN1897 & - & Côtes d'armor (22) & 22160 & Callac, Le Peulven & 48.409 & -3.421 & Lagrue Denis & Eyes & - \\
\hline- & YA0496 & 2016.04 .12 & Côtes d'armor (22) & 22160 & Callac, Le Peulven & 48.409 & -3.424 & Lagrue Denis & Eyes & - \\
\hline MNHN-ZM-2021-1397 & VN1910 & 2020.06 .20 & Côtes d'armor (22) & 22160 & Duault & 48.366 & -3.433 & Lagrue Denis & Eyes & - \\
\hline MNHN-ZM-2021-1398 & VN1911 & 2020.06.20 & Côtes d'armor (22) & 22160 & Duault & 48.366 & -3.433 & Lagrue Denis & Eyes & - \\
\hline MNHN-ZM-2021-1399 & VN1912 & 2020.06.20 & Côtes d'armor (22) & 22160 & Duault & 48.366 & -3.433 & Lagrue Denis & Eyes & - \\
\hline - & VN1913 & 2020.06.20 & Côtes d'armor (22) & 22160 & Duault & 48.366 & -3.433 & Lagrue Denis & Eyes & - \\
\hline MNHN-ZM-2021-1400 & VN1914 & 2020.06.20 & Côtes d'armor (22) & 22160 & Duault & 48.366 & -3.433 & Lagrue Denis & Eyes & - \\
\hline MNHN-ZM-2021-1401 & VN1915 & 2020.06 .23 & Côtes d'armor (22) & 22160 & Duault & 48.366 & -3.433 & Lagrue Denis & Eyes & - \\
\hline - & YA0161 & 2013.06 .07 & Côtes d'armor (22) & 22690 & La Vicomté-sur-Rance & 48.569 & -1.996 & Burgot François & Molars, DNA & KU189489 \\
\hline MNHN-ZM-2017-2846 & YA0173 & 2013.06 .07 & Côtes d'armor (22) & 22690 & La Vicomté-sur-Rance & 48.569 & -1.996 & Burgot François & Molars, DNA & KU189498 \\
\hline MNHN-ZM-2017-2847 & YA0180 & 2013.06.07 & Côtes d'armor (22) & 22690 & La Vicomté-sur-Rance & 48.569 & -1.996 & Burgot François & Molars, DNA & KU189499 \\
\hline MNHN-ZM-2017-2848 & YA0186 & 2013.06.07 & Côtes d'armor (22) & 22690 & La Vicomté-sur-Rance & 48.569 & -1.996 & Burgot François & Molars, DNA & KU189501 \\
\hline MNHN-ZM-MO-1992-1451 & - & 1992.08.13 & Côtes d'armor (22) & 22250 & Matignon & 48.600 & -2.300 & Erard Christian & Eyes, DNA & KU189430 \\
\hline - & YA0181 & 2013.06.04 & Côtes d'armor (22) & 22690 & Pleudihen-sur-Rance & 48.510 & -1.952 & Burgot François & Molars & - \\
\hline MNHN-ZM-2017-2849 & YA0181.1 & 2013.06.04 & Côtes d'armor (22) & 22690 & Pleudihen-sur-Rance & 48.510 & -1.952 & Burgot François & Molars & - \\
\hline MNHN-ZM-2017-2850 & YA0181.2 & 2013.06.04 & Côtes d'armor (22) & 22690 & Pleudihen-sur-Rance & 48.510 & -1.952 & Burgot François & Molars & - \\
\hline MNHN-ZM-2018-603 & - & 2017.12.06 & Côtes d'armor (22) & 22650 & Ploubalay & 48.583 & -2.150 & Burgot François & Eyes, DNA & - \\
\hline MNHN-ZM-2018-604 & - & 2017.12.06 & Côtes d'armor (22) & 22650 & Ploubalay & 48.583 & -2.150 & Burgot François & Eyes, DNA & - \\
\hline MNHN-ZM-2017-2862 & YA0171 & 2013.06.11 & Côtes d'armor (22) & 22430 & Plouër-sur-Rance & 48.527 & -2.003 & Burgot François & Molars, DNA & KU189496 \\
\hline MNHN-ZM-2017-2863 & YA0172 & 2013.06 .11 & Côtes d'armor (22) & 22430 & Plouër-sur-Rance & 48.527 & -2.003 & Burgot François & Molars, DNA & KU189497 \\
\hline MNHN-ZM-2017-2854 & YA0167 & 2013.06 .11 & Côtes d'armor (22) & 22490 & Plouër-sur-Rance & 48.527 & -2.003 & Burgot François & Molars & - \\
\hline MNHN-ZM-2017-2861 & YA0170 & 2013.06 .11 & Côtes d'armor (22) & 22490 & Plouër-sur-Rance & 48.527 & -2.003 & Burgot François & Molars, DNA & KU189495 \\
\hline MNHN-ZM-2017-2855 & YA0174 & 2013.06 .11 & Côtes d'armor (22) & 22490 & Plouër-sur-Rance & 48.527 & -2.003 & Burgot François & Molars & - \\
\hline MNHN-ZM-2017-2856 & YA0175 & 2013.06.03 & Côtes d'armor (22) & 22490 & Plouër-sur-Rance & 48.527 & -2.003 & Burgot François & Molars & - \\
\hline MNHN-ZM-2017-2857 & YA0176 & 2013.06 .03 & Côtes d'armor (22) & 22490 & Plouër-sur-Rance & 48.527 & -2.003 & Burgot François & Molars & - \\
\hline MNHN-ZM-2017-2858 & YA0177 & 2013.06 .03 & Côtes d'armor (22) & 22490 & Plouër-sur-Rance & 48.527 & -2.003 & Burgot François & Molars & - \\
\hline MNHN-ZM-2017-2859 & YA0178 & 2013.06 .03 & Côtes d'armor (22) & 22490 & Plouër-sur-Rance & 48.527 & -2.003 & Burgot François & Molars & - \\
\hline MNHN-ZM-2017-2860 & YA0179 & 2013.06.03 & Côtes d'armor (22) & 22490 & Plouër-sur-Rance & 48.527 & -2.003 & Burgot François & Molars & - \\
\hline MNHN-ZM-2018-594 & - & 2017.09 .28 & Côtes d'armor (22) & 22490 & Plouër-sur-Rance & 48.527 & -2.003 & Burgot François & Eyes, DNA & - \\
\hline MNHN-ZM-2018-598 & - & 2017.11 .10 & Côtes d'armor (22) & 22490 & Plouër-sur-Rance & 48.527 & -2.003 & Burgot François & Eyes, DNA & - \\
\hline MNHN-ZM-2018-599 & - & 2017.11 .10 & Côtes d'armor (22) & 22490 & Plouër-sur-Rance & 48.527 & -2.003 & Burgot François & Eyes, DNA & - \\
\hline MNHN-ZM-2018-595 & - & 2017.10 .05 & Côtes d'armor (22) & 22491 & Plouër-sur-Rance & 48.527 & -2.003 & Burgot François & Eyes, DNA & - \\
\hline- & YA0004 & 2012.03 .19 & Côtes d'armor (22) & 22160 & Plusquellec & 48.402 & -3.464 & Quemener Léon & Eyes & - \\
\hline MNHN-ZM-MO-1932-1659 & - & 1904.10 .15 & Doubs (25) & 25460 & Etupes & 47.500 & 6.866 & Mottaz Charles & Molars & - \\
\hline MNHN-ZM-MO-1932-3818 & - & 1907.11 .08 & Doubs (25) & 25460 & Etupes & 47.500 & 6.866 & Mottaz Charles & Molars & - \\
\hline MNHN-ZM-MO-1932-3822 & - & 1904.10.15 & Doubs (25) & 25460 & Etupes & 47.500 & 6.866 & Mottaz Charles & Molars & - \\
\hline MNHN-ZM-MO-1932-3837 & - & 1907.11.08 & Doubs (25) & 25460 & Etupes & 47.500 & 6.866 & Mottaz Charles & Molars & - \\
\hline MNHN-ZM-MO-1932-3852 & - & 1904.09.26 & Doubs (25) & 25460 & Etupes & 47.500 & 6.866 & Mottaz Charles & Molars & - \\
\hline
\end{tabular}




\begin{tabular}{|c|c|c|c|c|c|c|c|c|c|}
\hline Museum Number & Field Nb & Date & Departement & Post. & Town & Lat. & Long. & Identification & Genbank \\
\hline MNHN-ZM-2017-2864 & YA0225 & 2013.09.24 & Essonne (91) & 91099 & Boutigny & 48.437 & 2.380 & Dormion Jérôme $\quad$ Molars, DNA & KU189526 \\
\hline MNHN-ZM-MO-1993-616 & - & 1964.05 .26 & Essonne (91) & 91800 & Brunoy & 48.700 & 2.500 & Saint Girons Marie-Charlotte Molars & - \\
\hline MNHN-ZM-MO-1993-617 & - & 1964.08.20 & Essonne (91) & 91800 & Brunoy & 48.700 & 2.500 & Saint Girons Marie-Charlotte Molars & - \\
\hline MNHN-ZM-MO-1993-618 & - & 1965.04 .06 & Essonne (91) & 91800 & Brunoy & 48.700 & 2.500 & Saint Girons Marie-Charlotte Molars & - \\
\hline MNHN-ZM-MO-1993-619 & - & 1965.05 .03 & Essonne (91) & 91800 & Brunoy & 48.700 & 2.500 & Saint Girons Marie-Charlotte Molars & - \\
\hline MNHN-ZM-MO-1993-620 & - & 1965.05 .04 & Essonne (91) & 91800 & Brunoy & 48.700 & 2.500 & Saint Girons Marie-Charlotte Molars & - \\
\hline MNHN-ZM-MO-1993-622 & - & 1965.05 .15 & Essonne (91) & 91800 & Brunoy & 48.700 & 2.500 & Saint Girons Marie-Charlotte Molars & - \\
\hline MNHN-ZM-MO-1993-623 & - & 1965.05 .21 & Essonne (91) & 91800 & Brunoy & 48.700 & 2.500 & Saint Girons Marie-Charlotte Molars & - \\
\hline MNHN-ZM-MO-1993-624 & - & 1965.06 .01 & Essonne (91) & 91800 & Brunoy & 48.700 & 2.500 & Saint Girons Marie-Charlotte Molars & - \\
\hline MNHN-ZM-MO-1993-625 & - & 1965.06 .04 & Essonne (91) & 91800 & Brunoy & 48.700 & 2.500 & Saint Girons Marie-Charlotte Molars & - \\
\hline MNHN-ZM-MO-1993-626 & - & 1965.06 .05 & Essonne (91) & 91800 & Brunoy & 48.700 & 2.500 & Saint Girons Marie-Charlotte Molars & - \\
\hline MNHN-ZM-MO-1993-627 & - & 1965.07 .23 & Essonne (91) & 91800 & Brunoy & 48.700 & 2.500 & Saint Girons Marie-Charlotte Molars & - \\
\hline MNHN-ZM-MO-1993-631 & - & 1965.12 .21 & Essonne (91) & 91800 & Brunoy & 48.700 & 2.500 & Saint Girons Marie-Charlotte Molars & - \\
\hline MNHN-ZM-MO-1993-632 & - & 1965.12 .22 & Essonne (91) & 91800 & Brunoy & 48.700 & 2.500 & Saint Girons Marie-Charlotte Molars & - \\
\hline MNHN-ZM-MO-1993-633 & - & 1965.12 .22 & Essonne (91) & 91800 & Brunoy & 48.700 & 2.500 & Saint Girons Marie-Charlotte Molars & - \\
\hline MNHN-ZM-MO-1993-634 & - & 1965.12 .22 & Essonne (91) & 91800 & Brunoy & 48.700 & 2.500 & Saint Girons Marie-Charlotte Molars & - \\
\hline MNHN-ZM-MO-1993-637 & - & 1965.02 .04 & Essonne (91) & 91800 & Brunoy & 48.700 & 2.500 & Saint Girons Marie-Charlotte Molars & - \\
\hline MNHN-ZM-MO-1993-638 & - & 1966.02 .07 & Essonne (91) & 91800 & Brunoy & 48.700 & 2.500 & Saint Girons Marie-Charlotte Molars & - \\
\hline MNHN-ZM-MO-1993-639 & - & 1966.02 .07 & Essonne (91) & 91800 & Brunoy & 48.700 & 2.500 & Saint Girons Marie-Charlotte Molars & - \\
\hline MNHN-ZM-MO-1993-640 & - & 1966.02 .08 & Essonne (91) & 91800 & Brunoy & 48.700 & 2.500 & Saint Girons Marie-Charlotte Molars & - \\
\hline MNHN-ZM-MO-1993-641 & - & 1966.02 .09 & Essonne (91) & 91800 & Brunoy & 48.700 & 2.500 & Saint Girons Marie-Charlotte Molars & - \\
\hline MNHN-ZM-MO-1993-642 & - & 1966.02 .11 & Essonne (91) & 91800 & Brunoy & 48.700 & 2.500 & Saint Girons Marie-Charlotte Molars & - \\
\hline MNHN-ZM-MO-1993-643 & - & 1966.03 .03 & Essonne (91) & 91800 & Brunoy & 48.700 & 2.500 & Saint Girons Marie-Charlotte Molars & - \\
\hline MNHN-ZM-MO-1993-644 & - & 1966.03 .05 & Essonne (91) & 91800 & Brunoy & 48.700 & 2.500 & Saint Girons Marie-Charlotte Molars & - \\
\hline MNHN-ZM-MO-1993-645 & - & 1966.03 .08 & Essonne (91) & 91800 & Brunoy & 48.700 & 2.500 & Saint Girons Marie-Charlotte Molars & - \\
\hline MNHN-ZM-MO-1993-646 & - & 1966.03.14 & Essonne (91) & 91800 & Brunoy & 48.700 & 2.500 & Saint Girons Marie-Charlotte Molars & - \\
\hline MNHN-ZM-MO-1993-647 & - & 1967.01.17 & Essonne (91) & 91800 & Brunoy & 48.700 & 2.500 & Saint Girons Marie-Charlotte Molars & - \\
\hline MNHN-ZM-MO-1993-648 & - & 1967.01 .27 & Essonne (91) & 91800 & Brunoy & 48.700 & 2.500 & Saint Girons Marie-Charlotte Molars & - \\
\hline MNHN-ZM-MO-1993-649 & - & 1967.01 .27 & Essonne (91) & 91800 & Brunoy & 48.700 & 2.500 & Saint Girons Marie-Charlotte Molars & - \\
\hline MNHN-ZM-MO-1993-650 & - & 1967.01 .27 & Essonne (91) & 91800 & Brunoy & 48.700 & 2.500 & Saint Girons Marie-Charlotte Molars & - \\
\hline MNHN-ZM-MO-1993-651 & - & 1967.01 .27 & Essonne (91) & 91800 & Brunoy & 48.700 & 2.500 & Saint Girons Marie-Charlotte Molars & - \\
\hline MNHN-ZM-MO-1993-652 & - & 1967.01 .27 & Essonne (91) & 91800 & Brunoy & 48.700 & 2.500 & Saint Girons Marie-Charlotte Molars & - \\
\hline MNHN-ZM-MO-1993-654 & - & 1967.02 .20 & Essonne (91) & 91800 & Brunoy & 48.700 & 2.500 & Saint Girons Marie-Charlotte Molars & - \\
\hline MNHN-ZM-MO-1993-655 & - & 1905.05 .20 & Essonne (91) & 91800 & Brunoy & 48.700 & 2.500 & Saint Girons Marie-Charlotte Molars & - \\
\hline MNHN-ZM-MO-1993-657 & - & 1967.02.22 & Essonne (91) & 91800 & Brunoy & 48.700 & 2.500 & Saint Girons Marie-Charlotte Molars & - \\
\hline MNHN-ZM-MO-1993-658 & - & 1959.06.06 & Essonne (91) & 91800 & Brunoy & 48.700 & 2.500 & Saint Girons Marie-Charlotte Molars & - \\
\hline MNHN-ZM-MO-1993-659 & - & 1959.07.29 & Essonne (91) & 91800 & Brunoy & 48.700 & 2.500 & Saint Girons Marie-Charlotte Molars & - \\
\hline MNHN-ZM-MO-1993-660 & - & 1967.03.15 & Essonne (91) & 91800 & Brunoy & 48.700 & 2.500 & Saint Girons Marie-Charlotte Molars & - \\
\hline MNHN-ZM-MO-1993-662 & - & 1967.03 .14 & Essonne (91) & 91800 & Brunoy & 48.700 & 2.500 & Saint Girons Marie-Charlotte Molars & - \\
\hline MNHN-ZM-MO-1993-663 & - & 1967.02 .23 & Essonne (91) & 91800 & Brunoy & 48.700 & 2.500 & Saint Girons Marie-Charlotte Molars & - \\
\hline MNHN-ZM-MO-1993-664 & - & - & Essonne (91) & 91800 & Brunoy & 48.700 & 2.500 & Saint Girons Marie-Charlotte Molars & - \\
\hline MNHN-ZM-MO-1993-665 & - & 1968.02 .28 & Essonne (91) & 91800 & Brunoy & 48.700 & 2.500 & Saint Girons Marie-Charlotte Molars & - \\
\hline MNHN-ZM-MO-1993-666 & - & 1968.02 .29 & Essonne (91) & 91800 & Brunoy & 48.700 & 2.500 & Saint Girons Marie-Charlotte Molars & - \\
\hline MNHN-ZM-MO-1993-667 & - & 1968.02 .28 & Essonne (91) & 91800 & Brunoy & 48.700 & 2.500 & Saint Girons Marie-Charlotte Molars & - \\
\hline MNHN-ZM-MO-1993-668 & - & 1968.03 .05 & Essonne (91) & 91800 & Brunoy & 48.700 & 2.500 & Saint Girons Marie-Charlotte Molars & - \\
\hline MNHN-ZM-MO-1993-669 & - & 1968.03.27 & Essonne (91) & 91800 & Brunoy & 48.700 & 2.500 & Saint Girons Marie-Charlotte Molars & - \\
\hline MNHN-ZM-MO-1993-670 & - & 1969.01 .12 & Essonne (91) & 91800 & Brunoy & 48.700 & 2.500 & Saint Girons Marie-Charlotte Molars & - \\
\hline MNHN-ZM-MO-1993-671 & - & 1969.01 .13 & Essonne (91) & 91800 & Brunoy & 48.700 & 2.500 & Saint Girons Marie-Charlotte Molars & - \\
\hline MNHN-ZM-MO-1993-672 & - & 1969.01.14 & Essonne (91) & 91800 & Brunoy & 48.700 & 2.500 & Saint Girons Marie-Charlotte Molars & - \\
\hline MNHN-ZM-MO-1993-674 & - & 1969.01 .08 & Essonne (91) & 91800 & Brunoy & 48.700 & 2.500 & Saint Girons Marie-Charlotte Molars & - \\
\hline MNHN-ZM-MO-1993-675 & - & 1969.01 .20 & Essonne (91) & 91800 & Brunoy & 48.700 & 2.500 & Saint Girons Marie-Charlotte Molars & - \\
\hline
\end{tabular}




\begin{tabular}{|c|c|c|c|c|c|c|c|c|c|c|}
\hline Museum Number & Field Nb & Date & Departement & Post. & Town & Lat. & Long. & Collector & Identification & Genbank \\
\hline MNHN-ZM-MO-1993-676 & - & 1969.01 .20 & Essonne (91) & 91800 & Brunoy & 48.700 & 2.500 & \multicolumn{2}{|c|}{ Saint Girons Marie-Charlotte Molars } & - \\
\hline MNHN-ZM-MO-1993-677 & - & 1968.12.27 & Essonne (91) & 91800 & Brunoy & 48.700 & 2.500 & \multicolumn{2}{|c|}{ Saint Girons Marie-Charlotte Molars } & - \\
\hline MNHN-ZM-MO-1993-678 & - & 1969.01.16 & Essonne (91) & 91800 & Brunoy & 48.700 & 2.500 & \multicolumn{2}{|c|}{ Saint Girons Marie-Charlotte Molars } & - \\
\hline MNHN-ZM-MO-1993-679 & - & 1969.01 .16 & Essonne (91) & 91800 & Brunoy & 48.700 & 2.500 & \multirow{2}{*}{\multicolumn{2}{|c|}{$\begin{array}{l}\text { Saint Girons Marie-Charlotte Molars } \\
\text { Saint Girons Marie-Charlotte Molars }\end{array}$}} & - \\
\hline MNHN-ZM-MO-1993-709 & - & - & Essonne (91) & 91800 & Brunoy & 48.700 & 2.500 & & & - \\
\hline MNHN-ZM-2005-38 & - & 1962.03.15 & Essonne (91) & 91800 & Brunoy & 48.698 & 2.504 & Petter Francis & Eyes & - \\
\hline MNHN-ZM-2017-2865 & YA0206 & 2013.08 .07 & Essonne (91) & 91190 & Gif-sur-Yvette & 48.701 & 2.134 & Dormion Jérôme & Molars, DNA & KU189518 \\
\hline MNHN-ZM-2017-2866 & YA0207 & 2013.08.07 & Essonne (91) & 91190 & Gif-sur-Yvette & 48.701 & 2.134 & Dormion Jérôme & Molars & - \\
\hline MNHN-ZM-2017-2867 & YA0221 & 2013.09 .24 & Essonne (91) & 91190 & Gif-sur-Yvette & 48.701 & 2.134 & Dormion Jérôme & Molars & - \\
\hline MNHN-ZM-2017-2868 & YA0222 & 2013.09 .24 & Essonne (91) & 91190 & Gif-sur-Yvette & 48.701 & 2.134 & Dormion Jérôme & Molars, DNA & KU189523 \\
\hline MNHN-ZM-2017-2869 & YA0223 & 2013.09 .24 & Essonne (91) & 91190 & Gif-sur-Yvette & 48.701 & 2.134 & Dormion Jérôme & Molars, DNA & KU189524 \\
\hline MNHN-ZM-2017-2870 & YA0224 & 2013.09 .24 & Essonne (91) & 91190 & Gif-sur-Yvette & 48.701 & 2.134 & Dormion Jérôme & Molars, DNA & KU189525 \\
\hline- & YA0055 & 2012.10 .18 & Essonne (91) & 91490 & Oncy, École & 48.381 & 2.475 & Dormion Jérôme & DNA & KU189459 \\
\hline MNHN-ZM-2017-2871 & YA0208 & 2013.08 .07 & Essonne (91) & 91640 & Vaugrigneuse & 48.603 & 2.120 & Dormion Jérôme & Molars, DNA & KU189519 \\
\hline MNHN-ZM-2017-2872 & YA0209 & 2013.08 .07 & Essonne (91) & 91640 & Vaugrigneuse & 48.603 & 2.120 & Dormion Jérôme & Molars, DNA & KU189520 \\
\hline MNHN-ZM-2017-2873 & YA0210 & 2013.08.07 & Essonne (91) & 91640 & Vaugrigneuse & 48.603 & 2.120 & Dormion Jérôme & Molars, DNA & KU189521 \\
\hline MNHN-ZM-MO-1983-777 & - & - & Essonne (91) & 91640 & Vaugrineuse & 48.603 & 2.120 & Métivier Bernard & Eyes & - \\
\hline MNHN-ZM-MO-1983-778 & - & - & Essonne (91) & 91640 & Vaugrineuse & 48.603 & 2.120 & Métivier Bernard & Eyes & - \\
\hline MNHN-ZM-MO-1993-3218 & - & 1982.12 .30 & Essonne (91) & 91640 & Vaugrineuse & 48.603 & 2.120 & Métivier Bernard & Eyes & - \\
\hline MNHN-ZM-MO-1993-3219 & - & 1982.12 .30 & Essonne (91) & 91640 & Vaugrineuse & 48.603 & 2.120 & Métivier Bernard & Eyes & - \\
\hline MNHN-ZM-MO-1993-3220 & - & 1983.03 & Essonne (91) & 91640 & Vaugrineuse & 48.603 & 2.120 & Métivier Bernard & Eyes & - \\
\hline MNHN-ZM-MO-1993-3221 & - & 1982.. & Essonne (91) & 91640 & Vaugrineuse & 48.603 & 2.120 & Métivier Bernard & Eyes & - \\
\hline MNHN-ZM-MO-1993-3222 & - & $1982 .$. & Essonne (91) & 91640 & Vaugrineuse & 48.603 & 2.120 & Métivier Bernard & Eyes & - \\
\hline MNHN-ZM-MO-1993-3234 & - & 1980.11 & Essonne (91) & 91640 & Vaugrineuse & 48.603 & 2.120 & Métivier Bernard & Eyes & - \\
\hline MNHN-ZM-MO-1993-3235 & - & 1980.11. & Essonne ( & 91640 & Vaugrineus & 48.603 & 2.120 & vier Bernard & Ey & - \\
\hline MNHN-ZM-MO-1998-402 & - & 1985.06 .19 & Esso & 91640 & Vaug & 48.603 & 2.120 & Métivier Bernard & Ey & - \\
\hline- & VN1916 & 1991.04. & Esso & 91640 & Vaus & 48.603 & 2.120 & ard & Ey & - \\
\hline MNHN-ZM-2021-1408 & VN1917 & 1991.04. & Essonne (91) & 91640 & Vaugrineuse & 48.603 & 2.120 & Métivier Bernard & Eyes & - \\
\hline MNHN-ZM-MO-1990-660 & - & 1983.10 .23 & Essonne (91) & 91640 & $\begin{array}{l}\text { Vaugrineuse, Hameau de } \\
\text { l'Orme Gras }\end{array}$ & 48.599 & 2.116 & Métivier Bernard & Molars & - \\
\hline MNHN-ZM-MO-1993-1708 & - & 1979.04 .11 & Essonne (91) & 91640 & $\begin{array}{l}\text { Vaugrineuse, Hameau de } \\
\text { l'Orme Gras }\end{array}$ & 48.603 & 2.120 & Métivier Bernard & Eyes & - \\
\hline MNHN-ZM-MO-1953-829 & - & - & Essonne (91) & 91370 & Verrières-le-Buisson & 48.750 & 2.266 & Albisson & Molars & - \\
\hline MHNN.Z.025635 & - & - & t-Loir (28) & 28000 & & 48.446 & 1.489 & - & Mola & - \\
\hline MHNN.Z.025640 & - & - & Eure-et-Loir (28) & 28000 & Chartres & 48.446 & 1.489 & - & Molars & - \\
\hline MHNN.Z.025642 & - & - & Eure-et-Loir (28) & 28000 & & 48.446 & 1.489 & - & Molars & - \\
\hline MHNN.Z.025646 & - & - & Eure-et-Loir (28) & 28000 & Chartres & 48.446 & 1.489 & - & Molars & - \\
\hline MNHN SPOT4238 & - & - & Eure-et-Loir (28) & 28290 & Courtalain & 48.083 & 1.150 & - & DNA & KF801511 \\
\hline MNHN-ZM-MO-1933-1657 & - & - & Gard (30) & 30190 & Saint-Geniès-de-Malgoires & 43.950 & 4.216 & Mottaz Charles & Eyes & - \\
\hline MNHN-ZM-MO-1986-99 & - & 1930.04 .14 & & 30190 & Saint-Geniès-de-Malgoires & 43.950 & 4.216 & Heim de Balsac Henri & Molars, DNA & - \\
\hline NMNH 172105 & 7597 & 1908.04 .23 & Gard (30) & 30800 & Saint-Gilles & 43.683 & 4.433 & Miller G. S. & Molars & - \\
\hline MHNN.Z.025638 & - & - & Haute-Garonne (31) & 31110 & $\begin{array}{l}\text { Juzet-de-Luchon, Prairie } \\
\text { de la source ferrugineuse } \\
\text { de sémoles }\end{array}$ & 42.816 & 0.616 & (1) & Molars & - \\
\hline - & YA0017 & 2012.08.01 & & 52501 & Charmoy & 47.808 & 5.617 & & DNA & \\
\hline - & YA0057 & 2012.09 .18 & Haute-Marne (52) & 52500 & La Ferté-sur-Ama & 47.875 & 5.712 & Desandre Bernard & DNA & KU189461 \\
\hline MNHN-ZM-2013-160 & YA0058 & 2012.12 .19 & Haute-Marne (52) & 52500 & La Ferté-sur-Amance & 47.875 & 5.712 & Desandre Bernard & Eyes, DNA & KU189462 \\
\hline MNHN-ZM-2017-2877 & & 2013.10 .01 & Hautes-Alpes (05) & 05320 & & 45.053 & 6.286 & Giroud Michèle & DNA & KU189569 \\
\hline- & YA0369 & 2013.10 .01 & Hautes-Alpes (05) & 05320 & La Grave & 45.053 & 6.286 & Giroud Michèle & Molars, DNA & KU189572 \\
\hline
\end{tabular}




\begin{tabular}{|c|c|c|c|c|c|c|c|c|c|c|}
\hline Museum Number & Field $\mathbf{N b}$ & Date & Departement & Post. & Town & Lat. & Long. & Collector & Identification & Genbank \\
\hline MNHN-ZM-2017-2883 & YA0370 & 2013.10 .01 & Hautes-Alpes (05) & 05320 & La Grave & 45.053 & 6.286 & Giroud Michèle & Molars, DNA & KU189573 \\
\hline MNHN-ZM-2017-2884 & YA0371 & 2013.10 .01 & Hautes-Alpes (05) & 05320 & La Grave & 45.053 & 6.286 & Giroud Michèle & Molars, DNA & KU189574 \\
\hline MNHN-ZM-2017-2880 & YA0366 & 2013.10.01 & Hautes-Alpes (05) & 05320 & La Grave & 45.055 & 6.300 & Giroud Michèle & DNA & KU189570 \\
\hline MNHN-ZM-2017-2874 & YA0360 & 2013.10 .01 & Hautes-Alpes (05) & 05320 & La Grave & 45.046 & 6.306 & Giroud Michèle & Molars, DNA & KU189568 \\
\hline MNHN-ZM-2017-2876 & YA0362 & 2013.10.01 & Hautes-Alpes (05) & 05320 & La Grave & 45.046 & 6.306 & Giroud Michèle & Molars & - \\
\hline MNHN-ZM-2017-2878 & YA0364 & 2013.10.01 & Hautes-Alpes (05) & 05320 & La Grave & 45.046 & 6.306 & Giroud Michèle & Molars & - \\
\hline MNHN-ZM-2017-2879 & YA0365 & 2013.10 .01 & Hautes-Alpes (05) & 05320 & La Grave & 45.046 & 6.306 & Giroud Michèle & Molars & - \\
\hline MNHN-ZM-2017-2881 & YA0367 & 2013.10 .01 & Hautes-Alpes (05) & 05320 & La Grave & 45.036 & 6.399 & Giroud Michèle & Molars, DNA & KU189571 \\
\hline MNHN-ZM-MO-1994-3085 & - & - & Haute-Saône (70) & 70100 & Gray & 47.450 & 5.583 & Houin René & Molars & - \\
\hline MNHN-ZM-MO-1994-3086 & - & - & Haute-Saône (70) & 70100 & Gray & 47.450 & 5.583 & Houin René & Molars & - \\
\hline MHNG 3002-007 & M2195 & 2016.06 .26 & Haute-Savoie (74) & 74420 & Boëge & 46.218 & 6.350 & Cibois $A$. & Molars & - \\
\hline BMNH 5.11.18.4 & - & 1905.06 .10 & Haute-Savoie (74) & 74380 & Cranves-Sales & 46.183 & 6.300 & encen & Molars & - \\
\hline MHNG 1981-060 & M1704 & 2012.06 .02 & Haute-Savoie (74) & 74350 & Menthonnex-en-Bornes & 46.059 & 6.178 & Reuteler C. & Molars, DNA & - \\
\hline MHNG 1940-046 & M1276A & 2006.08.06 & Haute-Savoie (74) & 74430 & $\begin{array}{l}\text { Saint-Jean-d'Aulps, } \\
\text { Essert-la-Pierre }\end{array}$ & 46.216 & 6.673 & Gillioz M. & Molars, DNA & - \\
\hline MNHN-ZM-MO-1943-179 & - & 1943.07. & Haute-Savoie (74) & 74340 & Samoens & 46.077 & 6.724 & Villiers André & Molars & - \\
\hline BMNH 97.1.9.1 & - & 96.11 .21 & aute-Savoie (74) & 74910 & Seyssel, Montauban & 45.959 & 5.836 & - & & - \\
\hline MZS Mam03896 & - & - & Haut-Rhin (68) & 68370 & Orbey, Lac Blanc & 48.136 & 7.088 & - & Molars, DNA & - \\
\hline MZS Mam03898 & - & - & Haut-Rhin (68) & 68370 & Orbey, Lac Blanc & 48.136 & 7.088 & - & Molars, DNA & - \\
\hline MZS Mam03909 & - & - & Haut-Rhin (68) & 68370 & Orbey, Lac Blanc & 48.136 & 7.088 & - & Molars, DNA & - \\
\hline MNHN-ZM-2013-158 & YA0014 & 2012.06 & Île de France & - & unknown & unknown & unknown & n Dormion Jérôme & Eyes & - \\
\hline MNHN-ZM-2013-159 & YA0015 & 2012.06 & Île de France & - & unknown & unknown & unknown & n Dormion Jérôme & Ey & - \\
\hline MNHN-ZM-2017-2885 & YA0159 & 2013.06 .07 & ne (35) & 35125 & -Pican & 48.553 & -1.699 & Burgot François & lars & - \\
\hline MNHN-ZM-2017-2886 & YA0160 & 2013.06 .07 & Ille-et-Vilaine (35) & 35125 & r-Pican & 48.553 & -1.699 & Burgot François & DN & KU189488 \\
\hline- & YA0163 & 2013.06.07 & Ille-et-Vilaine (35) & 35125 & r-Pican & 48.553 & -1.699 & Burgot François & Molars, DNA & KU189491 \\
\hline MNHN-ZM-2017-2887 & YA01 & 2013.06 .07 & ilaine (35) & 35125 & Pican & 48.553 & -1.699 & rançois & Molars, DNA & KU189492 \\
\hline 888 & YA01 & 2.06 .23 & 35) & 35310 & -Montfort & 067 & -1.892 & Bertrand & rs, DNA & KU189469 \\
\hline MNHN-ZM-2017-2889 & YA0157 & 2013.06 .27 & Vilaine (35) & 35120 & $\mathrm{LaB}$ & 48.512 & -1.660 & Burgot François & Molars & - \\
\hline MNHN-ZM-2017-2890 & & 3.06 .27 & & 35120 & & 512 & -1.660 & Burgot François & ars, DNA & KU189487 \\
\hline- & YA0168 & 2013.06 .27 & Ille-et-Vilaine (35) & 35120 & La Boussac & 48.512 & -1.660 & Burgot François & Molars, DNA & KU189493 \\
\hline MNHN-ZM-2018-601 & - & 2017.12.04 & Ille-et-Vilaine (35) & 35870 & Le Minihic-sur-Rance & 48.523 & -1.573 & Burgot François & Eyes, DNA & - \\
\hline MNHN-ZM-2018-602 & - & 2017.12.04 & Ille-et-Vilaine (35) & 35870 & Le Minihic-sur-Rance & 48.523 & -1.573 & Burgot François & s, DNA & - \\
\hline- & YA0162 & 2013.06.04 & & 35120 & & 48.570 & -1.769 & François & rs, DNA & KU189490 \\
\hline MNHN-ZM-2018-597 & - & 10.2017 & Vilaine (35) & 35540 & & 48.474 & -1.409 & inçois & Eyes, DNA & - \\
\hline - & YA0156 & 3.06 .21 & & 35730 & & 48.579 & -2.059 & ançois & s, DNA & KU189486 \\
\hline MNHN-ZM-2018-600 & - & 7.11 .13 & Ille-et-Vilaine (35) & 35730 & & 48.579 & -2.059 & François & S, DNA & - \\
\hline MNHN-ZM-2017-2894 & YA0154 & 2013.06.26 & Ille-et-Vilaine (35) & 35800 & Briac & 48.619 & -2.132 & t François & Molars, DNA & KU189484 \\
\hline- & YA0155 & 3.06 .26 & Ille-et-Vilaine (35) & 35800 & & 48.619 & -2.132 & t François & Molars, DNA & KU189485 \\
\hline MNHN-ZM-2018-596 & - & 17.10 .06 & -Vilaine (35) & 35800 & Briac & 48.619 & -2.132 & Burgot François & Eyes, DNA & - \\
\hline MNHN-ZM-2017-2895 & YA0183 & 2013.05 .11 & e-et-Vilaine (35) & & & & -1.972 & Burgot François & Molars & - \\
\hline MNHN-ZM-2017-2897 & YA0185 & 2013.05.11 & Ille-et-Vilaine (35) & 35350 & Saint-Jouan-des-Guerets & 48.599 & -1.972 & Burgot François & Molars, DNA & KU189500 \\
\hline MNHN-ZM-2018-605 & - & 2017.12.26 & Ille-et-Vilaine (35) & & & & -1.669 & Burgot François & Eyes, DNA & - \\
\hline MNHN-ZM-2018-606 & - & 2017.12.26 & Ille-et-Vilaine (35) & 35800 & Saint-Lunaire & 48.582 & -1.669 & Burgot François & Eyes, DNA & - \\
\hline MNHN-ZM-2017-2891 & YA0150 & 2013.07.01 & Ille-et-Vilaine (35) & 35400 & Saint-Malo & 48.649 & -2.025 & Burgot François & Molars, DNA & KU189480 \\
\hline MNHN-ZM-2017-2892 & YA0151 & 2013.07 .01 & Ille-et-Vilaine (35) & 35400 & Saint-Malo & 48.649 & -2.025 & Burgot François & Molars, DNA & KU189481 \\
\hline MNHN-ZM-2017-2893 & YA0169 & 2013.07 .01 & Ille-et-Vilaine (35) & 35400 & Saint-Malo & 48.649 & -2.025 & Burgot François & Molars, DNA & KU189494 \\
\hline MNHN-ZM-MO-1983-4 & - & 1959.08 .10 & Ille-et-Vilaine (35) & 35290 & Saint-Méen-le-Grand & 48.183 & -2.200 & Saint Girons Marie-Charlotte & Molars & - \\
\hline MNHN-ZM-2017-2898 & YA0152 & 2013.07 .01 & Ille-et-Vilaine (35) & 35350 & Saint-Méloir-des-Ondes & 48.637 & -1.903 & Burgot François & Molars, DNA & KU189482 \\
\hline MNHN-ZM-2017-2899 & YA0153 & 2013.07.01 & Ille-et-Vilaine (35) & 35350 & Saint-Méloir-des-Ondes & 48.637 & -1.903 & Burgot François & Molars, DNA & KU189483 \\
\hline
\end{tabular}




\begin{tabular}{|c|c|c|c|c|c|c|c|c|c|c|}
\hline Museum Number & Field $\mathbf{N b}$ & Date & Departement & Post. & Town & Lat. & Long. & Collector & Identification & Genbank \\
\hline MNHN-ZM-MO-2003-485 & - & 2003.04 .27 & Indre-et-Loire (37) & 37530 & $\begin{array}{l}\text { Cangey, La garenne de } \\
\text { Saint-Thomas }\end{array}$ & 47.466 & 1.060 & Tranier Michel & Eyes, DNA & KU189440 \\
\hline MHNN Z 45169 & - & - & Indre-et-Loire (37) & 37000 & environs de Tours & 47.383 & 0.683 & - & Eyes & - \\
\hline- & - & 1905.07.11 & Indre-et-Loire (37) & 37700 & $\begin{array}{l}\text { La Ville-aux-Dames, île de } \\
\text { la métairie }\end{array}$ & 47.403 & 0.769 & $\begin{array}{l}\text { Etude GREGE - Christine } \\
\text { Fournier-Chambrillon }\end{array}$ & DNA & - \\
\hline MNHN-ZM-MO-1984-785 & - & 1905.03 .11 & Indre-et-Loire (37) & - & unknown & unknown & unknown & ר - & Eyes & - \\
\hline- & FRA2 & - & Isère (38) & 38000 & Grenoble & 45.170 & 5.720 & - & DNA & KF801514 \\
\hline- & FRA3 & - & Isère (38) & 38000 & Grenoble & 45.170 & 5.720 & - & DNA & KF801515 \\
\hline MHNGr 0s-1860 & - & 1975.05 .17 & Isère (38) & 38510 & Mépieu & 45.750 & 5.450 & Noblet J.F. & Molars & - \\
\hline MHNGr Os-1857 & - & End XXeme & Isère (38) & 38380 & $\begin{array}{l}\text { Saint-Pierre-de- } \\
\text { Chartreuse, couvent } \\
\text { grande chartreuse }\end{array}$ & 45.348 & 5.791 & Noblet J.F. & Molars, DNA & - \\
\hline- & FRA1 & - & Isère (38) & - & Trieves & 44.800 & 5.666 & - & DNA & FN640550 \\
\hline MNHN-ZM-MO-1983-661 & - & 1967.12.31 & Isère & - & Vercors & 45.105 & 5.523 & Brosset André & Eyes & - \\
\hline MNHN-ZM-MO-1993-629 & - & - & ère (38) & - & Vercors & 45.105 & 5.523 & Saint Girons Marie-Charlotte & Molars & - \\
\hline MNHN-ZM-MO-1993-630 & - & - & Isère (38) & - & Vercors & 45.105 & 5.523 & Saint Girons Marie-Charlotte & Molars & - \\
\hline MNHN-ZM-2017-2900 & YA0332 & 2013.09.17 & Isère (38) & 38280 & Villette-d'Anthon & 45.779 & 5.122 & Moncel Gwendoline & Molars, DNA & KU189564 \\
\hline MNHN-ZM-2017-2901 & YA0334 & 2013.10 .10 & & 38280 & & 45.779 & 5.122 & Moncel Gwendoline & Molars, DNA & KU189565 \\
\hline MNHN-ZM-MO-1961-966 & - & 1961.08 .06 & Loire (42) & 42370 & Saint-Haon-le-Châtel & 46.066 & 3.916 & Bourlière Fr. & Molars & - \\
\hline MNHN-ZM-MO-1986-101 & - & - & Loire-Atlantique (44) & ) - & DeLisle? & unknown & unknown & ר - & Molars & - \\
\hline MNHN-ZM-MO-1993-615 & - & 1963.04.11 & Loire-Atlantique (44) & 44390 & Puceul & 47.516 & -1.616 & Saint Girons Marie-Charlotte & Molars & - \\
\hline MHNN Z 25056 & - & 48.12 .14 & lantique (44) & 44980 & -Luce-sur-Loire & 47.250 & -1.500 & - & Molars, DNA & - \\
\hline MNHN-ZM-2021-1409 & VN1922 & 2008.09 .21 & Loire & 45430 & Chécy (bord du canal) & 47.900 & 2.017 & Centre de soins LPO & Eyes & - \\
\hline $3-614$ & - & 99.20 & & 45320 & & & & Saint Girons Marie- & Molars, DNA & - \\
\hline MHNN.Z.2011-2 & - & 09.07.05 & 5) & 45620 & Isd & 47.666 & 2.250 & - & Eyes, DNA & - \\
\hline MNHN-ZM-2018 & VN1857 & 2018.05 .15 & her (41) & 41500 & Voyer», Villexanton & 47.745 & 1.456 & Houssin Céline & DNA & - \\
\hline MNHN-ZM-MO-1992-636 & - & 1992.05 .10 & her (41) & 41150 & Mesland & 47.510 & 1.123 & Tranier Michel & s, DNA & KU189431 \\
\hline INHN-ZM-MO-1 & - & 942.10 .28 & & 41250 & & 47.566 & 1.600 & det Paul & & - \\
\hline MNHN-ZM-MO-1942-402 & - & 42.11 .23 & & 41250 & & 47.566 & 1.600 & udet Paul & Mo & - \\
\hline NMNH 233837 & 208 & 1919.06 .12 & & 41110 & -Aignan & & & & & - \\
\hline- & Sassay 1 & 2019.05 .12 & 41) & 41700 & & 47.395 & 1.442 & s Michel & Molars & - \\
\hline MHNL 40002091 & - & - & er (41) & - & ne, Loir-et-Cher & & 1.7 & & Ey & - \\
\hline MNHN-ZM-2021-1410 & VN1894 & 2019.05.19 & Manc & 50560 & Gouville-sur-mer & 49.099 & -1.572 & Veron Géraldine & Eyes & - \\
\hline MNHN-ZM-MO-1986-96 & - & - & $\begin{array}{l}\text { Meurthe-et-Moselle } \\
\text { (54) }\end{array}$ & 54370 & Buré & 48.700 & 6.583 & Heim de Balsac Henri & Molars & - \\
\hline MNHN-ZM-MO-1986-97 & - & - & $\begin{array}{l}\text { Meurthe-et-Moselle } \\
\text { (54) }\end{array}$ & 54370 & Buré & 48.700 & 6.583 & Heim de Balsac Henri & Molars & - \\
\hline Museum Nancy 2016.0.837 & - & 1956.06.10 & $\begin{array}{l}\text { Meurthe-et-Moselle } \\
\text { (54) }\end{array}$ & 54280 & Seichamps & 48.716 & 6.266 & - & Eyes & - \\
\hline MNHN-ZM-MO-1993-680 & - & - & Morbihan (56) & 56360 & & & -3.186 & Saint Girons Ma & & - \\
\hline MNHN-ZM-MO-1993-681 & - & - & & 56360 & & 47.333 & -3.186 & Saint Girons Ma & Molars & - \\
\hline MNHN-ZM-MO-1993-682 & - & - & & 56360 & & 47.333 & -3.186 & Saint Girons $\mathrm{Ma}$ & Molars & - \\
\hline MNHN-ZM-2017-2902 & YA0146 & 2013.06 .01 & Morbihan (56) & 56130 & Férel & 47.482 & -2.342 & Dupont Yves & Molars, DNA & KU189476 \\
\hline MNHN-ZM-2017-2903 & YA0144 & 2013.06 .01 & & 56780 & Isle-aux-Moines & 47.597 & & Dupont Yves & Molars, DNA & KU189474 \\
\hline MNHN-ZM-2017-2904 & YA0148 & 013.06 .01 & Morb & 56260 & & 47.574 & -2.195 & Dupont Yves & Molars, DNA & KU189478 \\
\hline MNHN-ZM-2017-2905 & YA0139 & 2013.06 .01 & & 56190 & & 47.553 & -2.482 & Dupont Yves & Molars, DNA & KU189470 \\
\hline MNHN-ZM-2017-2906 & YA0140 & 2013.06 .01 & & 56190 & & 47.553 & -2.482 & Dupont Yves & Molars, DNA & KU189471 \\
\hline MNHN-ZM-2017-2907 & YA0141 & 2013.06 .01 & & 56190 & & 47.553 & -2.482 & Dupont Yves & Molars, DNA & KU189472 \\
\hline- & YA0142 & 2013.06 .01 & Morbihan (56) & 56190 & Muzillac & 47.553 & -2.482 & Dupont Yves & Molars, DNA & KU189473 \\
\hline
\end{tabular}




\begin{tabular}{|c|c|c|c|c|c|c|c|c|c|c|}
\hline Museum Number & Field $\mathbf{N b}$ & Date & Departement & Post. & Town & Lat. & Long. & Collector & Identification & Genbank \\
\hline MNHN-ZM-2017-2908 & YA0143 & 2013.06 .01 & Morbihan (56) & 56190 & Muzillac & 47.553 & -2.482 & Dupont Yves & Molars & - \\
\hline MNHN-ZM-2017-2909 & YA0145 & 2013.06 .01 & Morbihan (56) & 56190 & Muzillac & 47.553 & -2.482 & Dupont Yves & Molars, DNA & KU189475 \\
\hline MNHN-ZM-2017-2910 & YA0147 & 2013.06 .01 & Morbihan (56) & 56190 & Muzillac & 47.553 & -2.482 & Dupont Yves & Molars, DNA & KU189477 \\
\hline MNHN-ZM-2017-2911 & YA0149 & 2013.06 .01 & Morbihan (56) & 56190 & Noyal-Muzillac & 47.592 & -2.457 & Dupont Yves & Molars, DNA & KU189479 \\
\hline MNHN-ZM-2017-2912 & YA0387 & - & Morbihan (56) & 56680 & Plouhinec & 47.698 & -3.274 & Deputte Bertrand & Molars & - \\
\hline MNHN-ZM-2013-155 & YA0009 & 2012.04 .13 & Morbihan (56) & 56680 & Plouhinec & 47.698 & -3.274 & Deputte Bertrand & Eyes & - \\
\hline BMNH 21.7.4.7 & - & 1915.12.15 & Nord (59) & 59280 & Armentières, Fort Rompu & 50.683 & 2.883 & - & Molars & - \\
\hline MNHN-ZM-MO-1993-4222 & - & - & Nord (59) & 59188 & Villers-en-Cauchis & 50.226 & 3.401 & Komerovsky Isabelle & Eyes, DNA & KU189432 \\
\hline MNHN-ZM-MO-1993-4222 & - & 1993.08 .05 & Nord (59) & 59188 & Villers-en-Cauchis & 50.226 & 3.401 & Komerovsky Isabelle & Eyes & - \\
\hline MNHN-ZM-2017-2913 & YA0087 & 2013.03 .15 & Oise (60) & 60000 & Beauvais & 49.452 & 2.058 & Dormion Jérôme & Molars, DNA & KU189463 \\
\hline MNHN-ZM-2017-2914 & YA0088 & 2013.03 .15 & Oise (60) & 60000 & Beauvais & 49.452 & 2.058 & Dormion Jérôme & Molars, DNA & KU189464 \\
\hline MNHN-ZM-2017-2915 & YA0089 & 2013.03 .15 & Oise (60) & 60000 & Beauvais & 49.452 & 2.058 & Dormion Jérôme & Molars, DNA & KU189465 \\
\hline- & YA0090 & 2013.03 .15 & Oise (60) & 60000 & Beauvais & 49.452 & 2.058 & Dormion Jérôme & Molars, DNA & KU189466 \\
\hline MNHN-ZM-2017-2916 & YA0091 & 2013.03 .15 & Oise (60) & 60000 & Beauvais & 49.452 & 2.058 & Dormion Jérôme & Molars & - \\
\hline MNHN-ZM-2017-2917 & YA0092 & 2013.03 .15 & Oise (60) & 60000 & Beauvais & 49.452 & 2.058 & Dormion Jérôme & Molars, DNA & KU189467 \\
\hline MNHN-ZM-2017-2918 & YA0093 & 2013.03.15 & Oise (60) & 60000 & Beauvais & 49.452 & 2.058 & Dormion Jérôme & Molars, DNA & KU189468 \\
\hline MNHN-ZM-2017-2919 & YA0094 & 2013.03 .15 & Oise (60) & 60000 & Beauvais & 49.452 & 2.058 & Dormion Jérôme & Mandibles & - \\
\hline MNHN-ZM-2017-2920 & YA0095 & 2013.03.15 & Oise (60) & 60000 & Beauvais & 49.452 & 2.058 & Dormion Jérôme & Molars & - \\
\hline MNHN-ZM-2017-2921 & YA0096 & 2013.03 .15 & Oise (60) & 60000 & Beauvais & 49.452 & 2.058 & Dormion Jérôme & Molars & - \\
\hline MNHN-ZM-2017-2922 & YA0097 & 2013.03 .15 & Oise (60) & 60000 & Beauvais & 49.452 & 2.058 & Dormion Jérôme & Mandibles & - \\
\hline MNHN-ZM-2017-2923 & YA0098 & 2013.03 .15 & Oise (60) & 60000 & Beauvais & 49.452 & 2.058 & Dormion Jérôme & Molars & - \\
\hline MNHN-ZM-2017-2924 & YA0099 & 2013.03 .15 & Oise (60) & 60000 & Beauvais & 49.452 & 2.058 & Dormion Jérôme & Molars & - \\
\hline MNHN-ZM-2017-2925 & YA0100 & 2013.03.15 & Oise (60) & 60000 & Beauvais & 49.452 & 2.058 & Dormion Jérôme & Molars & - \\
\hline MNHN-ZM-2017-2926 & YA0101 & 2013.03 .15 & Oise (60) & 60000 & Beauvais & 49.452 & 2.058 & Dormion Jérôme & Molars & - \\
\hline MNHN-ZM-2017-2927 & YA0102 & 2013.03 .15 & Oise (60) & 60000 & Beauvais & 49.452 & 2.058 & Dormion Jérôme & Molars & - \\
\hline MNHN-ZM-2017-2928 & YA0103 & 2013.03 .15 & Oise (60) & 60000 & Beauvais & 49.452 & 2.058 & Dormion Jérôme & Molars & - \\
\hline MNHN-ZM-2017-2929 & YA0104 & 2013.03.15 & Oise (60) & 60000 & Beauvais & 49.452 & 2.058 & Dormion Jérôme & Molars & - \\
\hline MNHN-ZM-2017-2930 & YA0105 & 2013.03 .15 & Oise (60) & 60000 & Beauvais & 49.452 & 2.058 & Dormion Jérôme & Molars & - \\
\hline MNHN-ZM-2017-2931 & YA0106 & 2013.03 .15 & Oise (60) & 60000 & Beauvais & 49.452 & 2.058 & Dormion Jérôme & Molars & - \\
\hline MNHN-ZM-2017-2932 & YA0107 & 2013.03 .15 & Oise (60) & 60000 & Beauvais & 49.452 & 2.058 & Dormion Jérôme & Molars & - \\
\hline MNHN-ZM-2017-2933 & YA0108 & 2013.03 .15 & Oise (60) & 60000 & Beauvais & 49.452 & 2.058 & Dormion Jérôme & Molars & - \\
\hline MNHN-ZM-2017-2934 & YA0109 & 2013.03 .15 & Oise (60) & 60000 & Beauvais & 49.452 & 2.058 & Dormion Jérôme & Molars & - \\
\hline MNHN-ZM-2017-2935 & YA0110 & 2013.03 .15 & Oise (60) & 60000 & Beauvais & 49.452 & 2.058 & Dormion Jérôme & Molars & - \\
\hline MNHN-ZM-2017-2936 & YA0111 & 2013.03 .15 & Oise (60) & 60000 & Beauvais & 49.452 & 2.058 & Dormion Jérôme & Molars & - \\
\hline MNHN-ZM-2017-2937 & YA0112 & 2013.03 .15 & Oise (60) & 60000 & Beauvais & 49.452 & 2.058 & Dormion Jérôme & Molars & - \\
\hline MNHN-ZM-2017-2938 & YA0113 & 2013.03 .15 & Oise (60) & 60000 & Beauvais & 49.452 & 2.058 & Dormion Jérôme & Molars & - \\
\hline MNHN-ZM-2017-2939 & YA0114 & 2013.03 .15 & Oise (60) & 60000 & Beauvais & 49.452 & 2.058 & Dormion Jérôme & Mandibles & - \\
\hline MNHN-ZM-2017-2940 & YA0115 & 2013.03 .15 & Oise (60) & 60000 & Beauvais & 49.452 & 2.058 & Dormion Jérôme & Molars & - \\
\hline MNHN-ZM-2017-2941 & YA0116 & 2013.03 .15 & Oise (60) & 60000 & Beauvais & 49.452 & 2.058 & Dormion Jérôme & Molars & - \\
\hline- & YA0054 & 2012.10 .18 & Oise (60) & 60141 & Chantilly & 49.193 & 2.468 & Dormion Jérôme & DNA & KU189458 \\
\hline MNHN-ZM-2018-2251 & - & 2018.05.16 & Oise (60) & 60510 & La Neuville-en-Hez & 49.408 & 2.327 & $\begin{array}{l}\text { de Massary Jean- } \\
\text { Christophe (via Haffner } \\
\text { Patrick) }\end{array}$ & Eyes & - \\
\hline MNHN-ZM-2017-2942 & YA0187 & 2013.08 .07 & Oise (60) & 60128 & Plailly & 49.103 & 2.586 & Dormion Jérôme & Molars, DNA & KU189502 \\
\hline MNHN-ZM-2017-2943 & YA0188 & 2013.08.07 & Oise (60) & 60128 & Plailly & 49.103 & 2.586 & Dormion Jérôme & Molars, DNA & KU189503 \\
\hline MNHN-ZM-AC-2000-362 & - & - & Oise (60) & - & unknown & unknown & unknown & - & Molars & - \\
\hline MNHN-ZM-2014-854 & VN1790 & - & Paris (75) & 75012 & Bois de Vincennes & 48.816 & 2.416 & Geigl Eva-Maria & Eyes, DNA & KU189441 \\
\hline MNHN-ZM-2017-2944 & YA0284 & 2013.07.29 & Pas-de-Calais (62) & 62810 & Barly & 50.250 & 2.547 & Cairey-Remonnay Frédéric & $\begin{array}{l}\text { Mandibles, } \\
\text { DNA }\end{array}$ & KU189541 \\
\hline - & YA0285 & 2013.07.29 & Pas-de-Calais (62) & 62810 & Barly & 50.250 & 2.547 & Cairey-Remonnay Frédéric & Molars, DNA & KU189542 \\
\hline
\end{tabular}




\begin{tabular}{|c|c|c|c|c|c|c|c|c|c|c|}
\hline Museum Number & Field $\mathbf{N b}$ & Date & Departement & Post. & Town & Lat. & Long. & Collector & Identification & Genbank \\
\hline MNHN-ZM-2017-2945 & YA0286 & 2013.07 .29 & Pas-de-Calais (62) & 62810 & Barly & 50.250 & 2.547 & Cairey-Remonnay Frédéric & $\begin{array}{l}\text { Mandibles, } \\
\text { DNA }\end{array}$ & KU189543 \\
\hline MNHN-ZM-2017-2946 & YA0287 & 2013.07.29 & Pas-de-Calais (62) & 62810 & Barly & 50.250 & 2.547 & Cairey-Remonnay Frédéric & Molars & - \\
\hline MNHN-ZM-2017-2947 & YA0317 & 2013.06.27 & Pas-de-Calais (62) & 62142 & Belle-et-Houllefort & 50.745 & 1.759 & Cairey-Remonnay Frédéric & Molars, DNA & KU189555 \\
\hline MNHN-ZM-2017-2948 & YA0318 & 2013.06.27 & Pas-de-Calais (62) & 62142 & Belle-et-Houllefort & 50.745 & 1.759 & Cairey-Remonnay Frédéric & Molars, DNA & KU189556 \\
\hline MNHN-ZM-2017-2949 & YA0319 & 2013.06 .27 & Pas-de-Calais (62) & 62142 & Belle-et-Houllefort & 50.745 & 1.759 & Cairey-Remonnay Frédéric & Molars, DNA & KU189557 \\
\hline MNHN-ZM-2017-2950 & YA0309 & 2013.06 .10 & Pas-de-Calais (62) & 62340 & Bonningues-lès-Calais & 50.889 & 1.773 & Cairey-Remonnay Frédéric & Molars, DNA & KU189549 \\
\hline MNHN-ZM-2017-2951 & YA0310 & 2013.06 .10 & Pas-de-Calais (62) & 62340 & Bonningues-lès-Calais & 50.889 & 1.773 & Cairey-Remonnay Frédéric & Molars, DNA & KU189550 \\
\hline BMNH 64.270 & - & 1963.08 .23 & Pas-de-Calais (62) & - & Cap Gris-Nez & 50.866 & 1.583 & - & Molars & - \\
\hline BMNH 64.271 & - & 1963.08 .27 & Pas-de-Calais (62) & - & Cap Gris-Nez & 50.866 & 1.583 & - & Molars & - \\
\hline BMNH 64.272 & - & 1963.08 .30 & Pas-de-Calais (62) & - & Cap Gris-Nez & 50.866 & 1.583 & - & Molars & - \\
\hline BMNH 64.273 & - & 1963.09 .02 & Pas-de-Calais (62) & - & Cap Gris-Nez & 50.866 & 1.583 & - & Molars & - \\
\hline BMNH 67.281 & - & 1964.07 .25 & Pas-de-Calais (62) & - & Cap Gris-Nez & 50.866 & 1.583 & - & Molars & - \\
\hline BMNH 67.282 & - & 1964.07.27 & Pas-de-Calais (62) & - & Cap Gris-Nez & 50.866 & 1.583 & - & Molars & - \\
\hline BMNH 67.284 & - & 1964.07.30 & Pas-de-Calais (62) & - & Cap Gris-Nez & 50.866 & 1.583 & - & Molars & - \\
\hline BMNH 67.285 & - & 1964.07.30 & Pas-de-Calais (62) & - & Cap Gris-Nez & 50.866 & 1.583 & - & Molars & - \\
\hline MNHN-ZM-2016-476 & YA0296 & 2013.08 .13 & Pas-de-Calais (62) & 62132 & Fienne & 50.800 & 1.829 & Cairey-Remonnay Frédéric & Molars, DNA & KU189545 \\
\hline MNHN-ZM-2017-2952 & YA0297 & 2013.08 .13 & Pas-de-Calais (62) & 62132 & Fienne & 50.800 & 1.829 & Cairey-Remonnay Frédéric & Molars, DNA & KU189546 \\
\hline MNHN-ZM-2017-2953 & YA0298 & 2013.08 .13 & Pas-de-Calais (62) & 62132 & Fienne & 50.800 & 1.829 & Cairey-Remonnay Frédéric & Molars & - \\
\hline MNHN-ZM-2017-2954 & YA0299 & 2013.09 .16 & Pas-de-Calais (62) & 62132 & Fienne & 50.800 & 1.829 & Cairey-Remonnay Frédéric & Molars & - \\
\hline MNHN-ZM-2017-2955 & YA0268 & 2013.08 .02 & Pas-de-Calais (62) & 62182 & Hendecourt-les-Cagnicour & rt50.209 & 2.948 & Cairey-Remonnay Frédéric & Molars, DNA & - \\
\hline MNHN-ZM-2017-2956 & YA0269 & 2013.08.02 & Pas-de-Calais (62) & 62182 & Hendecourt-les-Cagnicou & rt50.209 & 2.948 & Cairey-Remonnay Frédéric & Mandibles & - \\
\hline MNHN-ZM-2017-2957 & YA0270 & 2013.08.02 & Pas-de-Calais (62) & 62182 & Hendecourt-les-Cagnicour & rt50.209 & 2.948 & Cairey-Remonnay Frédéric & $\begin{array}{l}\text { Mandibles, } \\
\text { DNA }\end{array}$ & - \\
\hline MNHN-ZM-2017-2958 & YA0288 & 2013.07 .30 & Pas-de-Calais (62) & 62182 & Hendecourt-les-Cagnicour & rt50.209 & 2.948 & Cairey-Remonnay Frédéric & Molars & - \\
\hline & YA0289 & 2013.07.30 & Pas-de-Calais (62) & 62182 & Hendecourt-les-Cagnicou & rt50.209 & 2.948 & Cairey-Remonnay Frédéric & Molars & - \\
\hline MNHN-ZM-2017-2959 & YA0290 & 2013.07.30 & Pas-de-Calais (62) & 62182 & Hendecourt-les-Cagnicou & $r+50.209$ & 2.948 & Cairey-Remonnay Frédéric & Molars & - \\
\hline MNHN-ZM-2017-2960 & YA0291 & 2013.07.30 & Pas-de-Calais (62) & 62182 & Hendecourt-les-Cagnicour & rt50.209 & 2.948 & Cairey-Remonnay Frédéric & Molars & - \\
\hline MNHN-ZM-2017-2961 & YA0293 & 2013.08.02 & Pas-de-Calais (62) & 62182 & Hendecourt-les-Cagnicou & rt50.209 & 2.948 & Cairey-Remonnay Frédéric & Molars & - \\
\hline MNHN-ZM-2017-2962 & YA0294 & 2013.08.02 & Pas-de-Calais (62) & 62182 & Hendecourt-les-Cagnicou & rt50.209 & 2.948 & Cairey-Remonnay Frédéric & Molars & - \\
\hline MNHN-ZM-2017-2963 & YA0295 & 2013.08.02 & Pas-de-Calais (62) & 62182 & Hendecourt-les-Cagnicou & rt50.209 & 2.948 & Cairey-Remonnay Frédéric & Molars & - \\
\hline MNHN-ZM-2017-2964 & YA0271 & 2013.06 .20 & Pas-de-Calais (62) & 62630 & Hubersent & 50.581 & 1.724 & Cairey-Remonnay Frédéric & Molars, DNA & - \\
\hline MNHN-ZM-2017-2965 & YA0272 & 2013.06.20 & Pas-de-Calais (62) & 62630 & Hubersent & 50.581 & 1.724 & Cairey-Remonnay Frédéric & $\begin{array}{l}\text { Mandibles, } \\
\text { DNA }\end{array}$ & - \\
\hline MNHN-ZM-2017-2966 & YA0273 & 2013.06.20 & Pas-de-Calais (62) & 62630 & Hubersent & 50.581 & 1.724 & Cairey-Remonnay Frédéric & $\begin{array}{l}\text { Mandibles, } \\
\text { DNA }\end{array}$ & - \\
\hline MNHN-ZM-2017-2967 & YA0274 & 2013.06 .20 & Pas-de-Calais (62) & 62630 & Hubersent & 50.581 & 1.724 & Cairey-Remonnay Frédéric & Molars & - \\
\hline MNHN-ZM-2017-2968 & YA0275 & 2013.06.20 & Pas-de-Calais (62) & 62630 & Hubersent & 50.581 & 1.724 & Cairey-Remonnay Frédéric & Molars & _- \\
\hline MNHN-ZM-2017-2969 & YA0276 & 2013.06 .20 & Pas-de-Calais (62) & 62630 & Hubersent & 50.581 & 1.724 & Cairey-Remonnay Frédéric & Molars & - \\
\hline MNHN-ZM-2017-2970 & YA0277 & 2013.06 .20 & Pas-de-Calais (62) & 62630 & Hubersent & 50.581 & 1.724 & Cairey-Remonnay Frédéric & Molars & - \\
\hline MNHN-ZM-2017-2971 & YA0278 & 2013.06 .20 & Pas-de-Calais (62) & 62630 & Hubersent & 50.581 & 1.724 & Cairey-Remonnay Frédéric & Molars & - \\
\hline MNHN-ZM-2017-2972 & YA0279 & 2013.06 .27 & Pas-de-Calais (62) & 62630 & Hubersent & 50.581 & 1.724 & Cairey-Remonnay Frédéric & Molars & - \\
\hline MNHN-ZM-2017-2973 & YA0280 & 2013.06 .27 & Pas-de-Calais (62) & 62630 & Hubersent & 50.581 & 1.724 & Cairey-Remonnay Frédéric & Molars & - \\
\hline- & YA0281 & 2013.06 .27 & Pas-de-Calais (62) & 62630 & Hubersent & 50.581 & 1.724 & Cairey-Remonnay Frédéric & Molars & - \\
\hline- & YA0282 & 2013.06.27 & Pas-de-Calais (62) & 62630 & Hubersent & 50.581 & 1.724 & Cairey-Remonnay Frédéric & Molars & - \\
\hline MNHN-ZM-2017-2974 & YA0283 & 2013.06.27 & Pas-de-Calais (62) & 62630 & Hubersent & 50.581 & 1.724 & Cairey-Remonnay Frédéric & Molars & - \\
\hline MNHN-ZM-2017-2975 & YA0302 & 2013.06.27 & Pas-de-Calais (62) & 62630 & Hubersent & 50.581 & 1.724 & Cairey-Remonnay Frédéric & Molars & - \\
\hline MNHN-ZM-2017-2976 & YA0303 & 2013.06.27 & Pas-de-Calais (62) & 62630 & Hubersent & 50.581 & 1.724 & Cairey-Remonnay Frédéric & Molars & - \\
\hline MNHN-ZM-2017-2977 & YA0304 & 2013.06.27 & Pas-de-Calais (62) & 62630 & Hubersent & 50.581 & 1.724 & Cairey-Remonnay Frédéric & Molars & - \\
\hline MNHN-ZM-2017-2978 & YA0305 & 2013.06.27 & Pas-de-Calais (62) & 62630 & Hubersent & 50.581 & 1.724 & Cairey-Remonnay Frédéric & Molars & - \\
\hline
\end{tabular}




\begin{tabular}{|c|c|c|c|c|c|c|c|c|c|c|}
\hline Museum Number & Field $\mathrm{Nb}$ & Date & Departement & Post. & Town & Lat. & Long. & Collector & Identification & Genbank \\
\hline MNHN-ZM-2017-2979 & YA0306 & 2013.06.27 & Pas-de-Calais (62) & 62630 & Hubersent & 50.581 & 1.724 & Cairey-Remonnay Frédéric & Molars & - \\
\hline MNHN-ZM-2017-2980 & YA0307 & 2013.06 .27 & Pas-de-Calais (62) & 62630 & Hubersent & 50.581 & 1.724 & Cairey-Remonnay Frédéric & Molars & - \\
\hline MNHN-ZM-2017-2981 & YA0308 & 2013.06 .27 & Pas-de-Calais (62) & 62630 & Hubersent & 50.581 & 1.724 & Cairey-Remonnay Frédéric & Mandibles & - \\
\hline MNHN-ZM-2017-2982 & YA0262 & 2013.09 .13 & Pas-de-Calais (62) & 62720 & Rinxent & 50.806 & 1.739 & Cairey-Remonnay Frédéric & Molars, DNA & - \\
\hline MNHN-ZM-2017-2983 & YA0263 & 2013.09 .13 & Pas-de-Calais (62) & 62720 & Rinxent & 50.806 & 1.739 & Cairey-Remonnay Frédéric & Molars, DNA & - \\
\hline MNHN-ZM-2017-2984 & YA0264 & 2013.09.13 & Pas-de-Calais (62) & 62720 & Rinxent & 50.806 & 1.739 & Cairey-Remonnay Frédéric & $\begin{array}{l}\text { Mandibles, } \\
\text { DNA }\end{array}$ & - \\
\hline MNHN-ZM-2017-2985 & YA0265 & 2013.09.20 & Pas-de-Calais (62) & 62720 & Rinxent & 50.806 & 1.739 & Cairey-Remonnay Frédéric & Molars & - \\
\hline MNHN-ZM-2017-2986 & YA0266 & 2013.09 .20 & Pas-de-Calais (62) & 62720 & Rinxent & 50.806 & 1.739 & Cairey-Remonnay Frédéric & Molars & - \\
\hline MNHN-ZM-2017-2987 & YA0267 & 2013.09.20 & Pas-de-Calais (62) & 62720 & Rinxent & 50.806 & 1.739 & Cairey-Remonnay Frédéric & Molars & - \\
\hline MNHN-ZM-2017-2988 & YA0312 & 2013.06 .07 & Pas-de-Calais (62) & 62530 & Servins & 50.413 & 2.636 & Cairey-Remonnay Frédéric & Molars, DNA & KU189552 \\
\hline MNHN-ZM-2017-2989 & YA0313 & 2013.06.07 & Pas-de-Calais (62) & 62530 & Servins & 50.413 & 2.636 & Cairey-Remonnay Frédéric & Molars, DNA & KU189553 \\
\hline MNHN-ZM-2017-2990 & YA0314 & 2013.06.07 & Pas-de-Calais (62) & 62530 & Servins & 50.413 & 2.636 & Cairey-Remonnay Frédéric & Molars, DNA & KU189554 \\
\hline MNHN-ZM-2017-2991 & YA0315 & 2013.06.07 & Pas-de-Calais (62) & 62530 & Servins & 50.413 & 2.636 & Cairey-Remonnay Frédéric & Molars & - \\
\hline MNHN-ZM-2017-2992 & YA0316 & 2013.06.07 & Pas-de-Calais (62) & 62530 & Servins & 50.413 & 2.636 & Cairey-Remonnay Frédéric & Molars & - \\
\hline MNHN-ZM-2017-2993 & YA0292 & 2013.07.31 & Pas-de-Calais (62) & 62180 & Tigny-Noyelle & 50.353 & 1.706 & Cairey-Remonnay Frédéric & Molars, DNA & KU189544 \\
\hline MNHN-ZM-2017-2994 & YA0300 & 2013.08 .10 & Pas-de-Calais (62) & 62126 & Wimille & 50.800 & 1.829 & Cairey-Remonnay Frédéric & Molars, DNA & KU189547 \\
\hline MNHN-ZM-2017-2995 & YA0301 & 2013.08.10 & Pas-de-Calais (62) & 62126 & Wimille & 50.800 & 1.829 & Cairey-Remonnay Frédéric & Molars, DNA & KU189548 \\
\hline- & YA0372 & - & $\begin{array}{l}\text { Pyrénées-Orientales } \\
\text { (66) }\end{array}$ & s66500 & Mosset & 42.669 & 2.348 & Ribas Alexis & DNA & KU189575 \\
\hline- & YA0373 & - & $\begin{array}{l}\text { Pyrénées-Orientales } \\
\text { (66) }\end{array}$ & s66500 & Mosset & 42.669 & 2.348 & Ribas Alexis & DNA & KU189576 \\
\hline MHNL 40000794 & - & 1886.10 .24 & Rhône (69) & 69130 & Ecully & 45.766 & 4.766 & Chantre Ernest & Eyes & - \\
\hline MHNL 40000786 & - & - & & 69000 & environs de Lyon & 45.750 & 4.850 & - & Eyes & - \\
\hline MHNL 40002764 & - & - & 69) & 69000 & environs de Lyon & 45.750 & 4.850 & - & Eyes & - \\
\hline MHNL 40000787 & - & 1905.03.17 & Rhône (69) & 69480 & Morancé & 45.900 & 4.700 & - & Eyes & - \\
\hline MHNL 40002792 & - & 1949.. & Rhône (69) & 69140 & Rillieux-la-Pape & 45.816 & 4.900 & Gagneux Claudius & Eyes & - \\
\hline- & YA0189 & 2013.08 .07 & Saône-et-Loire (71) & 71452 & Saint-Martin-de-Salencey & 46.521 & 4.500 & Dormion Jérôme & Molars, DNA & KU189504 \\
\hline MNHN-ZM-2017-2996 & YA0220 & 2013.09 .24 & Seine-et-Marne (77) & 77058 & $y$-Saint-Georges & 48.842 & 2.698 & Dormion Jérôme & Molars, DNA & KU189522 \\
\hline MNHN-ZM-2017-2997 & YA0190 & 2013.08.07 & Seine-et-Marne (77) & 77650 & naison & 48.483 & 3.251 & Dormion Jérôme & Molars, DNA & KU189505 \\
\hline MNHN-ZM-MO-1959-1796 & - & 1959.06 .07 & t-Marne (77) & 77170 & Coubert & 48.666 & 2.700 & Pujol Raymond & Molars & - \\
\hline MNHN-ZM-MO-1959-1797 & - & 1959.06 .07 & -Marne (77) & 77170 & & 48.666 & 2.700 & Pujol Raymond & Molars & - \\
\hline MNHN-ZM-MO-1961-743 & - & 1960.06. & Seine-et-Marne (77) & 77170 & Coubert & 48.666 & 2.700 & Pujol Raymond & Molars & - \\
\hline MNHN-ZM-2013-157 & YA0013 & 2012.06 & t-Marne $(77)$ & 77190 & narie-les-Lys & 48.515 & 2.634 & n Jérôme & & - \\
\hline MNHN-ZM-2017-2998 & YA0191 & 2013.08.07 & arne (77) & 77188 & & 48.485 & 2.759 & Dormion Jérôme & Molars, DNA & KU189506 \\
\hline MNHN-ZM-2017-2999 & YA0192 & 2013.08.07 & arne (77) & 77188 & & 48.485 & 2.759 & & & KU189507 \\
\hline MNHN-ZM-2017-3000 & YA0193 & 2013.08.07 & Seine-et-Marne (77) & 77188 & Fon & 48.485 & 2.759 & Dormion Jérôme & Molars, DNA & KU189508 \\
\hline MNHN-ZM-MO-2001-2084 & - & 1986.08. & Seine-et-Marne (77) & 77166 & $\begin{array}{l}\text { Grisy-Suisnes, La petite } \\
\text { Gray }\end{array}$ & 48.683 & 2.666 & Pujol Raymond & Eyes & - \\
\hline MNHN-ZM-MO-1967-1429 & - & 1966.03.16 & t-Marne (77) & 77400 & Lagny-sur-Marne & 48.866 & 2.716 & & & - \\
\hline MNHN-ZM-MO-1967-1431 & - & 1966.06 .12 & & 77400 & & 48.866 & 2.716 & & & - \\
\hline MNHN-ZM-2017-3001 & YA0194 & 2013.08.07 & Seine-et-Marne (77) & 77249 & & 48.743 & 2.614 & Dormion Jérôme & Molars & - \\
\hline MNHN-ZM-MO-1933-2056 & - & - & Seine-et-Marne (77) & 77000 & & 48.533 & 2.666 & Mottaz Charles & Molars & - \\
\hline- & YA0018 & 2012.10 .18 & t-Marne (77) & 77330 & $\mathrm{O}$ & 48.763 & 2.671 & Dormion Jérôme & Eyes & - \\
\hline - & YA0019 & 2012.10 .18 & Seine-et-Marne (77) & 77330 & & 48.763 & 2.671 & Dormion Jérôme & DNA & KU189443 \\
\hline - & YA0020 & 2012.10 .18 & Seine-et-Marne (77) & 77330 & & 48.763 & 2.671 & Dormion Jérôme & Ey & - \\
\hline - & YA0021 & 2012.10 .18 & Seine-et-Marne (77) & 77330 & Ozoir-la-Ferrière & 48.763 & 2.671 & Dormion Jérôme & $\mathrm{DN}$ & KU18944 \\
\hline - & YA0022 & 2012.10 .18 & Seine-et-Marne (77) & 77330 & & 48.763 & 2.671 & Dormion Jérôme & Ey & - \\
\hline - & YA0023 & 2012.10 .18 & Seine-et-Marne (77) & 77330 & Ozoir-la-Ferrière & 48.763 & 2.671 & Dormion Jérôme & Eyes & - \\
\hline
\end{tabular}




\begin{tabular}{|c|c|c|c|c|c|c|c|c|c|c|}
\hline \multirow{2}{*}{$\frac{\text { Museum Number }}{-}$} & \multirow{2}{*}{$\begin{array}{c}\text { Field } \mathbf{~ N b} \\
\text { YA0024 }\end{array}$} & \multirow{2}{*}{$\begin{array}{l}\text { Date } \\
2012.10 .18\end{array}$} & \multirow{2}{*}{$\begin{array}{l}\text { Departement } \\
\text { Seine-et-Marne (7 }\end{array}$} & \multirow{2}{*}{$\begin{array}{l}\text { Post. } \\
77330\end{array}$} & \multirow{2}{*}{$\begin{array}{l}\text { Town } \\
\text { Ozoir-la-Ferrière }\end{array}$} & \multirow{2}{*}{$\begin{array}{l}\text { Lat. } \\
48.763\end{array}$} & \multirow{2}{*}{$\begin{array}{l}\text { Long. } \\
2.671\end{array}$} & \multirow{2}{*}{$\begin{array}{l}\text { Collector } \\
\text { Dormion Jérôme }\end{array}$} & \multicolumn{2}{|c|}{ Identification Genbank } \\
\hline & & & & & & & & & Eyes & - \\
\hline- & YA0025 & 2012.10 .18 & Seine-et-Marne $(7$ & 77330 & Ozoir-la-Ferrière & 48.763 & 2.671 & Dormion Jérôme & Eyes & - \\
\hline- & YA0026 & 2012.10 .18 & Seine-et-Marne $(7$ & 77330 & Ozoir-la-Ferrière & 48.763 & 2.671 & Dormion Jérôme & Eyes & - \\
\hline - & YA0027 & 2012.10 .18 & Seine-et-Marne $(7$ & 7) 77330 & Ozoir-la-Ferrière & 48.763 & 2.671 & Dormion Jérôme & DNA & KU189445 \\
\hline - & YA0028 & 2012.10 .18 & Seine-et-Marne $(7$ & 77330 & Ozoir-la-Ferrière & 48.763 & 2.671 & Dormion Jérôme & DNA & KU189446 \\
\hline - & YA0029 & 2012.10 .18 & Seine-et-Marne $(7$ & 77330 & Ozoir-la-Ferrière & 48.763 & 2.671 & Dormion Jérôme & DNA & KU189447 \\
\hline - & YA0030 & 2012.10 .18 & Seine-et-Marne $(7$ & 77330 & Ozoir-la-Ferrière & 48.763 & 2.671 & Dormion Jérôme & DNA & KU189448 \\
\hline - & YA0031 & 2012.10 .18 & Seine-et-Marne $(7$ & 77330 & Ozoir-la-Ferrière & 48.763 & 2.671 & Dormion Jérôme & Eyes & - \\
\hline- & YA0032 & 2012.10 .18 & Seine-et-Marne (7 & 77330 & Ozoir-la-Ferrière & 48.763 & 2.671 & Dormion Jérôme & DNA & KU189449 \\
\hline - & YA0033 & 2012.10.18 & Seine-et-Marne $(7$ & 77330 & Ozoir-la-Ferrière & 48.763 & 2.671 & Dormion Jérôme & Eyes & - \\
\hline - & YA0034 & 2012.10 .18 & Seine-et-Marne (7 & 77330 & Ozoir-la-Ferrière & 48.763 & 2.671 & Dormion Jérôme & DNA & KU189450 \\
\hline- & YA0035 & 2012.10 .18 & Seine-et-Marne ( 7 & 7) 77330 & Ozoir-la-Ferrière & 48.763 & 2.671 & Dormion Jérôme & Eyes & - \\
\hline- & YA0036 & 2012.10 .18 & Seine-et-Marne $(7$ & 7) 77330 & Ozoir-la-Ferrière & 48.763 & 2.671 & Dormion Jérôme & DNA & KU189451 \\
\hline - & YA0037 & 2012.10 .18 & Seine-et-Marne $(7$ & 7) 77330 & Ozoir-la-Ferrière & 48.763 & 2.671 & Dormion Jérôme & DNA & KU189452 \\
\hline- & YA0038 & 2012.10 .18 & Seine-et-Marne $(7$ & 7) 77330 & Ozoir-la-Ferrière & 48.763 & 2.671 & Dormion Jérôme & DNA & KU189453 \\
\hline - & YA0039 & 2012.10.18 & Seine-et-Marne $(7$ & 7) 77330 & Ozoir-la-Ferrière & 48.763 & 2.671 & Dormion Jérôme & Eyes & - \\
\hline - & YA0040 & 2012.10.18 & Seine-et-Marne $(7$ & 7) 77330 & Ozoir-la-Ferrière & 48.763 & 2.671 & Dormion Jérôme & DNA & KU189454 \\
\hline - & YA0041 & 2012.10 .18 & Seine-et-Marne $(7$ & 7) 77330 & Ozoir-la-Ferrière & 48.763 & 2.671 & Dormion Jérôme & Eyes & - \\
\hline- & YA0042 & 2012.10 .18 & Seine-et-Marne $(7$ & 77330 & Ozoir-la-Ferrière & 48.763 & 2.671 & Dormion Jérôme & DNA & KU189455 \\
\hline - & YA0043 & 2012.10 .18 & Seine-et-Marne $(7$ & 7) 77330 & Ozoir-la-Ferrière & 48.763 & 2.671 & Dormion Jérôme & DNA & KU189456 \\
\hline- & YA0044 & 2012.10 .18 & Seine-et-Marne ( 7 & 77330 & Ozoir-la-Ferrière & 48.763 & 2.671 & Dormion Jérôme & DNA & KU189457 \\
\hline- & YA0045 & 2012.10 .18 & Seine-et-Marne ( 7 & 77330 & Ozoir-la-Ferrière & 48.763 & 2.671 & Dormion Jérôme & Eyes & - \\
\hline- & YA0046 & 2012.10 .18 & Seine-et-Marne ( 7 & 7) 77330 & Ozoir-la-Ferrière & 48.763 & 2.671 & Dormion Jérôme & Eyes & - \\
\hline - & YA0047 & 2012.10 .18 & Seine-et-Marne $(7$ & 7) 77330 & Ozoir-la-Ferrière & 48.763 & 2.671 & Dormion Jérôme & Eyes & - \\
\hline - & YA0048 & 2012.10 .18 & Seine-et-Marne $(7$ & 7) 77330 & Ozoir-la-Ferrière & 48.763 & 2.671 & Dormion Jérôme & Eyes & - \\
\hline - & YA0049 & 2012.10 .18 & Seine-et-Marne $(7$ & 7) 77330 & Ozoir-la-Ferrière & 48.763 & 2.671 & Dormion Jérôme & Eyes & - \\
\hline - & YA0050 & 2012.10 .18 & Seine-et-Marne $(7$ & 7) 77330 & Ozoir-la-Ferrière & 48.763 & 2.671 & Dormion Jérôme & Eyes & - \\
\hline - & YA0051 & 2012.10 .18 & Seine-et-Marne $(7$ & 7) 77330 & Ozoir-la-Ferrière & 48.763 & 2.671 & Dormion Jérôme & Eyes & - \\
\hline - & YA0052 & 2012.10 .18 & Seine-et-Marne $(7$ & 77330 & Ozoir-la-Ferrière & 48.763 & 2.671 & Dormion Jérôme & Eyes & - \\
\hline - & YA0053 & 2012.10.18 & Seine-et-Marne $(7$ & 77330 & Ozoir-la-Ferrière & 48.763 & 2.671 & Dormion Jérôme & Eyes & - \\
\hline - & YA0059 & 2013.02.21 & Seine-et-Marne $(7$ & 7) 77330 & Ozoir-la-Ferrière & 48.763 & 2.671 & Dormion Jérôme & Eyes & - \\
\hline - & YA0060 & 2013.02.21 & Seine-et-Marne $(7$ & 7) 77330 & Ozoir-la-Ferrière & 48.763 & 2.671 & Dormion Jérôme & Eyes & - \\
\hline - & YA0061 & 2013.02.21 & Seine-et-Marne $(7$ & 7) 77330 & Ozoir-la-Ferrière & 48.763 & 2.671 & Dormion Jérôme & Eyes & - \\
\hline - & YA0062 & 2013.02 .21 & Seine-et-Marne ( 7 & 7) 77330 & Ozoir-la-Ferrière & 48.763 & 2.671 & Dormion Jérôme & Eyes & - \\
\hline- & YA0063 & 2013.02 .21 & Seine-et-Marne $(7$ & 7) 77330 & Ozoir-la-Ferrière & 48.763 & 2.671 & Dormion Jérôme & Eyes & - \\
\hline - & YA0064 & 2013.02 .21 & Seine-et-Marne $(7$ & 77330 & Ozoir-la-Ferrière & 48.763 & 2.671 & Dormion Jérôme & Eyes & - \\
\hline - & YA0065 & 2013.02 .21 & Seine-et-Marne $(7$ & 7) 77330 & Ozoir-la-Ferrière & 48.763 & 2.671 & Dormion Jérôme & Eyes & - \\
\hline - & YA0066 & 2013.02.21 & Seine-et-Marne $(7$ & 7) 77330 & Ozoir-la-Ferrière & 48.763 & 2.671 & Dormion Jérôme & Eyes & - \\
\hline - & YA0067 & 2013.02.21 & Seine-et-Marne $(7$ & 77330 & Ozoir-la-Ferrière & 48.763 & 2.671 & Dormion Jérôme & Eyes & - \\
\hline - & YA0068 & 2013.02.21 & Seine-et-Marne (7 & 77330 & Ozoir-la-Ferrière & 48.763 & 2.671 & Dormion Jérôme & Eyes & - \\
\hline - & YA0069 & 2013.02.21 & Seine-et-Marne $(7$ & 77330 & Ozoir-la-Ferrière & 48.763 & 2.671 & Dormion Jérôme & Eyes & - \\
\hline - & YA0070 & 2013.02.21 & Seine-et-Marne (7 & 77330 & Ozoir-la-Ferrière & 48.763 & 2.671 & Dormion Jérôme & Eyes & - \\
\hline - & YA0071 & 2013.02.21 & Seine-et-Marne $(7$ & 77330 & Ozoir-la-Ferrière & 48.763 & 2.671 & Dormion Jérôme & Eyes & - \\
\hline - & YA0072 & 2013.02 .21 & Seine-et-Marne ( 7 & 77330 & Ozoir-la-Ferrière & 48.763 & 2.671 & Dormion Jérôme & Eyes & - \\
\hline - & YA0073 & 2013.02 .21 & Seine-et-Marne ( 7 & 77330 & Ozoir-la-Ferrière & 48.763 & 2.671 & Dormion Jérôme & Eyes & - \\
\hline - & YA0074 & 2013.02 .21 & Seine-et-Marne $(7$ & 77330 & Ozoir-la-Ferrière & 48.763 & 2.671 & Dormion Jérôme & Eyes & - \\
\hline - & YA0075 & 2013.02 .21 & Seine-et-Marne $(7$ & 77330 & Ozoir-la-Ferrière & 48.763 & 2.671 & Dormion Jérôme & Eyes & - \\
\hline - & YA0076 & 2013.02 .21 & Seine-et-Marne $(7$ & 7) 77330 & Ozoir-la-Ferrière & 48.763 & 2.671 & Dormion Jérôme & Eyes & - \\
\hline - & YA0077 & 2013.02.21 & Seine-et-Marne $(7$ & 7) 77330 & Ozoir-la-Ferrière & 48.763 & 2.671 & Dormion Jérôme & Eyes & - \\
\hline - & YA0078 & 2013.02.21 & Seine-et-Marne $(7$ & 7) 77330 & Ozoir-la-Ferrière & 48.763 & 2.671 & Dormion Jérôme & Eyes & - \\
\hline
\end{tabular}




\begin{tabular}{|c|c|c|c|c|c|c|c|c|c|c|}
\hline Museum Number & Field $\mathbf{N b}$ & Date & Departement & Post. & Town & Lat. & Long. & Collector & \multicolumn{2}{|c|}{ Identification Genbank } \\
\hline- & YA0079 & 2013.02 .21 & Seine-et-Marne (77) & 77330 & Ozoir-la-Ferrière & 48.763 & 2.671 & Dormion Jérôme & Eyes & - \\
\hline - & YA0080 & 2013.02.21 & Seine-et-Marne (77) & 77330 & Ozoir-la-Ferrière & 48.763 & 2.671 & Dormion Jérôme & Eyes & - \\
\hline - & YA0081 & 2013.02 .21 & Seine-et-Marne (77) & 77330 & Ozoir-la-Ferrière & 48.763 & 2.671 & Dormion Jérôme & Eyes & - \\
\hline - & YA0082 & 2013.02 .21 & Seine-et-Marne (77) & 77330 & Ozoir-la-Ferrière & 48.763 & 2.671 & Dormion Jérôme & Eyes & - \\
\hline - & YA0083 & 2013.02 .21 & Seine-et-Marne (77) & 77330 & Ozoir-la-Ferrière & 48.763 & 2.671 & Dormion Jérôme & Eyes & - \\
\hline - & YA0084 & 2013.02.21 & Seine-et-Marne (77) & 77330 & Ozoir-la-Ferrière & 48.763 & 2.671 & Dormion Jérôme & Eyes & - \\
\hline - & YA0085 & 2013.02.21 & Seine-et-Marne (77) & 77330 & Ozoir-la-Ferrière & 48.763 & 2.671 & Dormion Jérôme & Eyes & - \\
\hline- & YA0086 & 2013.02.21 & Seine-et-Marne (77) & 77330 & Ozoir-la-Ferrière & 48.763 & 2.671 & Dormion Jérôme & Molars & - \\
\hline MNHN-ZM-2017-3002 & YA0234 & 2013.09.24 & Seine-et-Marne (77) & 77330 & Ozoir-la-Ferrière & 48.763 & 2.671 & Dormion Jérôme & Molars & - \\
\hline MNHN-ZM-2017-3003 & YA0235 & 2013.09.24 & Seine-et-Marne (77) & 77330 & Ozoir-la-Ferrière & 48.763 & 2.671 & Dormion Jérôme & Molars & - \\
\hline MNHN-ZM-2017-3004 & YA0236 & 2013.09.24 & Seine-et-Marne (77) & 77330 & Ozoir-la-Ferrière & 48.763 & 2.671 & Dormion Jérôme & Molars & - \\
\hline MNHN-ZM-2017-3005 & YA0237 & 2013.09 .24 & Seine-et-Marne (77) & 77330 & Ozoir-la-Ferrière & 48.763 & 2.671 & Dormion Jérôme & Molars & - \\
\hline MNHN-ZM-2017-3006 & YA0238 & 2013.09.24 & Seine-et-Marne (77) & 77330 & Ozoir-la-Ferrière & 48.763 & 2.671 & Dormion Jérôme & Molars & - \\
\hline MNHN-ZM-2017-3007 & YA0239 & 2013.09 .24 & Seine-et-Marne (77) & 77330 & Ozoir-la-Ferrière & 48.763 & 2.671 & Dormion Jérôme & Molars & - \\
\hline MNHN-ZM-2017-3008 & YA0240 & 2013.09 .24 & Seine-et-Marne (77) & 77330 & Ozoir-la-Ferrière & 48.763 & 2.671 & Dormion Jérôme & Molars & - \\
\hline MNHN-ZM-2017-3009 & YA0241 & 2013.09 .24 & Seine-et-Marne (77) & 77330 & Ozoir-la-Ferrière & 48.763 & 2.671 & Dormion Jérôme & Molars & - \\
\hline MNHN-ZM-2017-3010 & YA0242 & 2013.09 .24 & Seine-et-Marne (77) & 77330 & Ozoir-la-Ferrière & 48.763 & 2.671 & Dormion Jérôme & Molars & - \\
\hline MNHN-ZM-2017-3011 & YA0243 & 2013.09 .24 & Seine-et-Marne (77) & 77330 & Ozoir-la-Ferrière & 48.763 & 2.671 & Dormion Jérôme & Molars & - \\
\hline MNHN-ZM-2017-3012 & YA0244 & 2013.09.24 & Seine-et-Marne (77) & 77330 & Ozoir-la-Ferrière & 48.763 & 2.671 & Dormion Jérôme & Molars & - \\
\hline MNHN-ZM-2017-3013 & YA0245 & 2013.09.24 & Seine-et-Marne (77) & 77330 & Ozoir-la-Ferrière & 48.763 & 2.671 & Dormion Jérôme & Molars & - \\
\hline MNHN-ZM-2017-3014 & YA0246 & 2013.09.24 & Seine-et-Marne (77) & 77330 & Ozoir-la-Ferrière & 48.763 & 2.671 & Dormion Jérôme & Molars & - \\
\hline MNHN-ZM-2017-3015 & YA0247 & 2013.09.24 & Seine-et-Marne (77) & 77330 & Ozoir-la-Ferrière & 48.763 & 2.671 & Dormion Jérôme & Molars & - \\
\hline MNHN-ZM-2017-3016 & YA0248 & 2013.09.24 & Seine-et-Marne (77) & 77330 & Ozoir-la-Ferrière & 48.763 & 2.671 & Dormion Jérôme & Molars & - \\
\hline MNHN-ZM-2017-3017 & YA0249 & 2013.09.24 & Seine-et-Marne (77) & 77330 & Ozoir-la-Ferrière & 48.763 & 2.671 & Dormion Jérôme & Molars & - \\
\hline MNHN-ZM-2017-3018 & YA0250 & 2013.09 .24 & Seine-et-Marne (77) & 77330 & Ozoir-la-Ferrière & 48.763 & 2.671 & Dormion Jérôme & Molars & - \\
\hline MNHN-ZM-2017-3019 & YA0251 & 2013.09.24 & Seine-et-Marne (77) & 77330 & Ozoir-la-Ferrière & 48.763 & 2.671 & Dormion Jérôme & Molars & _- \\
\hline MNHN-ZM-2017-3020 & YA0252 & 2013.09 .24 & Seine-et-Marne (77) & 77330 & Ozoir-la-Ferrière & 48.763 & 2.671 & Dormion Jérôme & Molars & - \\
\hline MNHN-ZM-2017-3021 & YA0253 & 2013.09 .24 & Seine-et-Marne (77) & 77330 & Ozoir-la-Ferrière & 48.763 & 2.671 & Dormion Jérôme & Molars & - \\
\hline MNHN-ZM-2017-3022 & YA0254 & 2013.09 .24 & Seine-et-Marne (77) & 77330 & Ozoir-la-Ferrière & 48.763 & 2.671 & Dormion Jérôme & Molars & - \\
\hline MNHN-ZM-2017-3023 & YA0255 & 2013.09.24 & Seine-et-Marne (77) & 77330 & Ozoir-la-Ferrière & 48.763 & 2.671 & Dormion Jérôme & Molars & - \\
\hline MNHN-ZM-2017-3024 & YA0256 & 2013.09.24 & Seine-et-Marne (77) & 77330 & Ozoir-la-Ferrière & 48.763 & 2.671 & Dormion J & Molars & - \\
\hline MNHN-ZM-2017-3025 & YA0257 & 2013.09.24 & Seine-et-Marne (77) & 77330 & Ozoir-la-Ferrière & 48.763 & 2.671 & Dormion Jérôme & Molars & - \\
\hline- & YA0258 & 2013.09 .24 & Seine-et-Marne (77) & 77330 & Ozoir-la-Ferrière & 48.763 & 2.671 & Dormion Jérôme & Molars & - \\
\hline MNHN-ZM-2017-3026 & YA0259 & 2013.09.24 & Seine-et-Marne (77) & 77330 & Ozoir-la-Ferrière & 48.763 & 2.671 & Dormion Jérôme & Mandibles & - \\
\hline MNHN-ZM-2017-3027 & YA0260 & 2013.09 .24 & Seine-et-Marne (77) & 77330 & Ozoir-la-Ferrière & 48.763 & 2.671 & Dormion Jérôme & Molars & - \\
\hline MNHN-ZM-2017-3028 & YA0261 & 2013.09 .24 & Seine-et-Marne (77) & 77330 & Ozoir-la-Ferrière & 48.763 & 2.671 & Dormion Jérôme & Molars & - \\
\hline Museum Bourges 11.Tal.3 & - & 1905.03 .20 & Seine-Maritime (76) & 76210 & Bolbec & 49.566 & 0.483 & - & Eyes, DNA & - \\
\hline MNHN-ZM-MO-1998-400 & - & 1998.08.18 & Somme $(80)$ & 80310 & Le Mesge & 49.945 & 2.053 & Tranier Michel & Eyes & - \\
\hline MNHN-ZM-2017-3029 & YA0311 & 2013.06.24 & Somme $(80)$ & 80120 & Nampont-Saint-Martin & 50.350 & 1.743 & Cairey-Remonnay Frédéric & Molars, DNA & KU189551 \\
\hline MNHN-ZM-2017-3030 & YA0233 & 2013.09 .24 & Somme $(80)$ & 80680 & Rumigny & 49.808 & 2.279 & Dormion Jérôme & Molars, DNA & KU189532 \\
\hline MHNL 50002702 & - & 1990.. & unknown & - & unknown & unknown & unknown & 1 & Molars & - \\
\hline MHNT OST 2002-93 & - & - & unknown & - & unknown & unknown & unknown & - & Molars & - \\
\hline MNHN-ZM-MO-1932-3813 & - & 1908.10 .28 & unknown & - & unknown & unknown & unknown & Mottaz Charles & Molars & - \\
\hline MNHN-ZM-MO-1932-3815 & - & 1908.10.28 & unknown & - & unknown & unknown & unknown & Mottaz Charles & Molars & - \\
\hline MNHN-ZM-MO-1932-3817 & - & 1908.10.28 & unknown & _- & unknown & unknown & unknown & Mottaz Charles & Molars & - \\
\hline MNHN-ZM-MO-1932-3820 & - & 1908.10.28 & unknown & _- & unknown & unknown & unknown & Mottaz Charles & Molars & _- \\
\hline MNHN-ZM-MO-1932-3826 & - & 1908.10 .28 & unknown & - & unknown & unknown & unknown & Mottaz Charles & Molars & _- \\
\hline MNHN-ZM-MO-1932-3853 & - & 1908.10 & unknown & - & unknown & unknown & unknown & Mottaz Charles & Molars & - \\
\hline MNHN-ZM-MO-1962-2039 & - & - & unknown & - & unknown & unknown & unknown & Cantuel Paul & Molars & - \\
\hline MNHN-ZM-MO-1962-2040 & - & - & unknown & - & unknown & unknown & unknown & Cantuel Paul & Molars & - \\
\hline
\end{tabular}




\begin{tabular}{|c|c|c|c|c|c|c|c|c|c|c|}
\hline Museum Number & Field Nb & Date & Departement & Post. & Town & Lat. & Long. & Collector & Identification & Genbank \\
\hline MNHN-ZM-MO-1962-2041 & - & - & unknown & - & unknown & unknown & unknown & Cantuel Paul & Molars & - \\
\hline MNHN-ZM-MO-1962-2042 & - & - & unknown & - & unknown & unknown & unknown & Cantuel Paul & Molars & - \\
\hline MNHN-ZM-MO-1962-2043 & - & - & unknown & - & unknown & unknown & unknown & Cantuel Paul & Molars & - \\
\hline MNHN-ZM-MO-1962-2045 & - & - & unknown & - & unknown & unknown & unknown & Cantuel Paul & Molars & - \\
\hline MNHN-ZM-MO-1962-2046 & - & - & unknown & - & unknown & unknown & unknown & Cantuel Paul & Molars & - \\
\hline MNHN-ZM-MO-1962-2047 & - & - & unknown & - & unknown & unknown & unknown & Cantuel Paul & Molars & - \\
\hline MNHN-ZM-MO-1962-2048 & - & 1908.10 .01 & unknown & - & unknown & unknown & unknown & Cantuel Paul & Molars & - \\
\hline MNHN-ZM-MO-1962-2049 & - & - & unknown & - & unknown & unknown & unknown & Cantuel Paul & Molars & - \\
\hline MNHN-ZM-MO-2003-134 & - & - & unknown & - & unknown & unknown & unknown & Molez Gaëtan & Molars & - \\
\hline MNHN-ZM-MO-2003-135 & - & - & unknown & - & unknown & unknown & unknown & Molez Gaëtan & Molars & - \\
\hline MHNL 50002701 & - & 1990.. & unknown & - & unknown & unknown & unknown & - & Molars, DNA & - \\
\hline MHNL 50002703 & - & 1990.. & unknown & - & unknown & unknown & unknown & - & Molars, DNA & - \\
\hline MHNL 50002705 & - & 1990.. & unknown & - & unknown & unknown & unknown & - & Molars, DNA & - \\
\hline MHNL 50002706 & - & 1990.. & unknown & - & unknown & unknown & unknown & - & Molars, DNA & - \\
\hline MNHN-ZM-MO-1944-8 & - & - & Val-de-Marne (94) & 94300 & Vincennes & 48.847 & 2.439 & Terry & Molars & - \\
\hline MNHN-ZM-MO-1954-294 & - & 1954.02. & Val-d'Oise (95) & 95560 & $\begin{array}{l}\text { Montsoult, Ferme du } \\
\text { Grand Fournay }\end{array}$ & 49.066 & 2.316 & Caillé Pierre & Molars & - \\
\hline MNHN-ZM-2017-3031 & YA0226 & 2013.09 .24 & Val-d'Oise (95) & 95491 & Plessis-Bouchard & 49.003 & 2.234 & Dormion Jérôme & Molars, DNA & KU189527 \\
\hline MNHN-ZM-2017-3032 & YA0227 & 2013.09.24 & Val-d'Oise (95) & 95491 & Plessis-Bouchard & 49.003 & 2.234 & Dormion Jérôme & Molars, DNA & KU189528 \\
\hline MNHN-ZM-2017-3033 & YA0228 & 2013.09.24 & Val-d'Oise (95) & 95491 & Plessis-Bouchard & 49.003 & 2.234 & Dormion Jérôme & Molars, DNA & KU189529 \\
\hline MNHN-ZM-2017-3034 & YA0229 & 2013.09.24 & Val-d'Oise (95) & 95491 & Plessis-Bouchard & 49.003 & 2.234 & Dormion Jérôme & Molars & - \\
\hline MNHN-ZM-2021-1411 & VN1869 & - & $\operatorname{Var}(83)$ & 83610 & Collobrières & 43.238 & 6.309 & - & Eyes & - \\
\hline MNHN SPOT11165 & - & - & Yonne (89) & 89320 & Cerisiers & 48.134 & 3.485 & _- & DNA & KF801513 \\
\hline MNHN SPOT6868 & _- & - & Yonne (89) & 89500 & Dixmont & 48.080 & 3.410 & _- & DNA & KF801512 \\
\hline MNHN-ZM-MO-1993-4223 & - & 1993.07.19 & Yonne (89) & 89350 & Louesme & 47.766 & 3.133 & Komerovsky Isabelle & Eyes, DNA & KU189435 \\
\hline MNHN-ZM-MO-1992-1406 & - & - & Yonne (89) & 89240 & Semilly-Escamps & 47.730 & 3.474 & Komerovsky Isabelle & Eyes, DNA & KU189429 \\
\hline MNHN-ZM-2013-156 & YA0012 & 2012.06. & Yvelines (78) & 78170 & La Celle-Saint-Cloud & 48.849 & 2.132 & Dormion Jérôme & Eyes & - \\
\hline MNHN-ZM-2017-3035 & YA0198 & 2013.08.07 & Yvelines (78) & 78113 & La Hauteville & 48.704 & 1.625 & Dormion Jérôme & Molars, DNA & KU189512 \\
\hline MNHN-ZM-2017-3036 & YA0199 & 2013.08.07 & Yvelines (78) & 78113 & La Hauteville & 48.704 & 1.625 & Dormion Jérôme & Molars, DNA & KU189513 \\
\hline MNHN-ZM-2017-3037 & YA0200 & 2013.08.07 & Yvelines (78) & 78113 & La Hauteville & 48.704 & 1.625 & Dormion Jérôme & Molars & - \\
\hline MNHN-ZM-2017-3038 & YA0201 & 2013.08.07 & Yvelines (78) & 78113 & La Hauteville & 48.704 & 1.625 & Dormion Jérôme & Molars & - \\
\hline MNHN-ZM-2017-3039 & YA0202 & 2013.08.07 & Yvelines (78) & 78113 & La Hauteville & 48.704 & 1.625 & Dormion Jérôme & Molars, DNA & KU189514 \\
\hline MNHN-ZM-2017-3040 & YA0203 & 2013.08.07 & Yvelines (78) & 78113 & La Hauteville & 48.704 & 1.625 & Dormion Jérôme & Molars, DNA & KU189515 \\
\hline MNHN-ZM-2017-3041 & YA0205 & 2013.08.07 & Yvelines (78) & 78610 & Les Bréviaires & 48.707 & 1.814 & Dormion Jérôme & Molars, DNA & KU189517 \\
\hline MNHN-ZM-2017-3042 & YA0195 & 2013.08.07 & Yvelines (78) & 78372 & Marly-le-Roy & 48.868 & 2.097 & Dormion Jérôme & Molars, DNA & KU189509 \\
\hline MNHN-ZM-2017-3043 & YA0230 & 2013.09.24 & Yvelines (78) & 78372 & Marly-le-Roy & 48.868 & 2.097 & Dormion Jérôme & Molars, DNA & KU189530 \\
\hline MNHN-ZM-2017-3044 & YA0231 & 2013.09.24 & Yvelines (78) & 78372 & Marly-le-Roy & 48.868 & 2.097 & Dormion Jérôme & Molars, DNA & KU189531 \\
\hline MNHN-ZM-2017-3045 & YA0232 & 2013.09.24 & Yvelines (78) & 78372 & Marly-le-Roy & 48.868 & 2.097 & Dormion Jérôme & Molars & - \\
\hline MNHN-ZM-2017-3046 & YA0204 & 2013.08.07 & Yvelines (78) & 78490 & Montfort L'Amaury & 48.772 & 1.815 & Dormion Jérôme & Molars, DNA & KU189516 \\
\hline MNHN-ZM-MO-1960-3764 & - & 1951.05. & Yvelines (78) & 78490 & Montfort l'Amaury & 48.783 & 1.816 & - & Molars & - \\
\hline MNHN-ZM-MO-1959-1773 & _- & 1959.10 .26 & Yvelines (78) & 78120 & Rambouillet & 48.650 & 1.833 & _- & Molars & - \\
\hline - & YA0432 & 2014.01 .28 & Yvelines (78) & 78730 & Saint-Arnoult-en-Yvelines & 48.572 & 1.941 & Dormion Jérôme & DNA & KU189577 \\
\hline _- & YA0433 & 2014.01 .28 & Yvelines (78) & 78730 & Saint-Arnoult-en-Yvelines & 48.572 & 1.941 & Dormion Jérôme & DNA & KU189578 \\
\hline - & YA0056 & 2012.10 .18 & Yvelines (78) & 78470 & Saint-Rémy-lès-Chevreuse & 48.702 & 2.069 & Dormion Jérôme & DNA & KU189460 \\
\hline- & YA0196 & 2013.08.07 & Yvelines (78) & 78646 & Versailles & 48.804 & 2.121 & Dormion Jérôme & Molars, DNA & KU189510 \\
\hline MNHN-ZM-2017-3047 & YA0197 & 2013.08 .07 & Yvelines (78) & 78646 & Versailles & 48.804 & 2.121 & Dormion Jérôme & Molars, DNA & KU189511 \\
\hline MNHN-ZM-2017-3167 & - & 2017.08.21 & Ain (01) & 01290 & Grièges & 46.255 & 4.851 & - & Eyes, DNA & - \\
\hline MNHN-ZM-2017-3166 & - & 2017.10.09 & Ain (01) & 01140 & Saint-Didier-sur-Charlonne & 46.178 & 4.817 & Hugot Jean-Pierre & Eyes, DNA & - \\
\hline NMNH 233828 & 19 & 1919.04.20 & Côtes d'or (21) & 21120 & Is-sur-Tille & 47.516 & 5.100 & Plummer A. B. & Molars & _- \\
\hline
\end{tabular}


APPENDIX 2. - Continuation.

\begin{tabular}{|c|c|c|c|c|c|c|c|c|c|c|}
\hline Museum Number & Field $\mathrm{Nb}$ & Date & Departement & Post. & Town & Lat. & Long. & \multirow{2}{*}{$\begin{array}{l}\text { Collector } \\
\text { Nicolas Violaine }\end{array}$} & \multicolumn{2}{|c|}{ Identification Genbank } \\
\hline MNHN-ZM-2017-3173 & - & 2017.02 .01 & Eure (27) & 27130 & $\begin{array}{l}\text { Verneuil-sur-Avre, Les } \\
\text { Barils (golf du Center } \\
\text { Park) }\end{array}$ & 48.728 & 0.840 & & Eyes, DNA & - \\
\hline MNHN-ZM-2017-3170 & - & 2017.09.01 & Hautes-Alpes (05) & 05320 & La Grave & 45.046 & 6.306 & - & Eyes, DNA & - \\
\hline MNHN-ZM-2017-3171 & - & 2017.09.01 & Hautes-Alpes (05) & 05320 & $\begin{array}{l}\text { La Grave, les Rivets, } \\
\text { Chazelet }\end{array}$ & 45.046 & 6.306 & - & Eyes, DNA & - \\
\hline MNHN-ZM-2017-3169 & - & 2017.09 .01 & Hautes-Alpes (05) & 05480 & Villar d'Arène & 45.043 & 6.337 & - & Eyes, DNA & - \\
\hline NMNH 233832 & 3 & 1919.03.18 & Loire-Atlantique (44 & 44550 & $\begin{array}{l}\text { Montoir, } 6 \mathrm{Mi} \text { NE of Saint } \\
\text { Nazaire (rive nord de } \\
\text { l'estuaire de la Loire) }\end{array}$ & 47.333 & -2.150 & Crick J. G. & Molars & - \\
\hline MNHN-ZM-2017-2283 & - & 2016.07.17 & Loiret (45) & 45220 & $\begin{array}{l}\text { Château-Renard, Les } \\
\text { Marchaisons }\end{array}$ & 47.915 & 2.903 & Pons Jean-Marc & Eyes, DNA & - \\
\hline MNHN-ZM-2017-3168 & - & 2017.08.22 & Rhône (69) & 69380 & Châtillon-d'Azergues & 45.878 & 4.646 & - & Eyes, DNA & - \\
\hline MNHN SPOT15269 & - & 2020.09.29 & Val-d’Oise (95) & 95550 & $\begin{array}{l}\text { Bessancourt (162 Grande } \\
\text { Rue) }\end{array}$ & 49.039 & 2.220 & de Jong Justine & DNA & - \\
\hline
\end{tabular}

